\title{
Total Synthesis and Biological Evaluation of
}

\section{Halipeptins A and D and Analogues}

K. C. Nicolaou,* Dimitrios E. Lizos, David W. Kim, Daniel Schlawe, Rita G. de Noronha, Deborah A. Longbottom, Manuela Rodriquez, ${ }^{\dagger}$ Mariarosaria Bucci, ${ }^{\ddagger}$ Giuseppe Cirino $^{\ddagger}$

Contribution from the Department of Chemistry and The Skaggs Institute for Chemical Biology, The Scripps Research Institute, 10550 North Torrey Pines Road, La Jolla, California 92037, and Department of Chemistry and Biochemistry, University of California, San Diego, 9500 Gilman Drive, La Jolla, California 92093.

Corresponding author e-mail: kcn@scripps.edu

\section{Supporting Information}

\section{Experimental Data for Compounds}

General Procedures. All reactions were carried out under an argon atmosphere with dry solvents under anhydrous conditions. Dry tetrahydrofuran (THF), toluene, diethyl ether $\left(\mathrm{Et}_{2} \mathrm{O}\right)$ and methylene chloride $\left(\mathrm{CH}_{2} \mathrm{Cl}_{2}\right)$ were obtained by passing commercially available pre-dried, oxygen-free formulations through activated alumina columns. Reagents and dry $N, N$-dimethylformamide (DMF), dimethylsulfoxide (DMSO) and 1,2-dichloroethane were purchased at the highest commercial quality and used without further purification. Yields refer to chromatographically and spectroscopically $\left({ }^{1} \mathrm{H}\right.$ NMR) homogeneous materials, unless otherwise stated. Reactions were monitored by thin-layer chromatography (TLC) carried out on $0.25 \mathrm{~mm}$ E. Merck silica gel plates (60F-254) using UV light as

\footnotetext{
Dipartimento di Scienze Farmaceutiche, University degli Studi di Salerno, Italy

${ }^{\ddagger}$ Dipartimento di Farmacologia Sperimentale, University degli Studi di Napoli, Italy
} 
visualizing agent and an aqueous (aq) solution of cerium ammonium nitrate, ammonium molybdate and sulfuric acid, and heat as developing agents. E. Merck silica gel (60, particle size 0.040-0.063 mm) was used for flash column chromatography. NMR spectra were recorded on Bruker DRX-600, DRX-500 and AMX-400 or Varian Inova-400 and Mercury-300 instruments and calibrated using residual undeuterated solvent as an internal reference. The following abbreviations were used to designate the multiplicities: $\mathrm{s}=$ singlet, $\mathrm{d}=$ doublet, $\mathrm{t}=$ triplet, $\mathrm{q}=$ quartet, $\mathrm{m}=$ multiplet, $\mathrm{br}=$ broad IR spectra were recorded on a Perkin-Elmer 1600 series FT-IR spectrometer. Electrospray ionization (ESI) mass spectrometry (MS) experiments were performed on an API 100 Perkin Elmer SCIEX single quadrupole mass spectrometer at $4000 \mathrm{~V}$ emitter voltage. High resolution mass spectra (HRMS) were recorded on a VG ZAB-ZSE mass spectrometer using MALDI (matrix-assisted laser-desorption ionization) or an Agilent ESI TOF (time of flight) mass spectrometer at $4000 \mathrm{~V}$ emitter voltage.

\section{Bromo TBS-ether 18 (Scheme 1):}

A suspension of $\mathrm{CuI}(69.34 \mathrm{mg}, 0.364 \mathrm{mmol})$ in $\mathrm{THF}(1 \mathrm{~mL})$ was cooled to $0{ }^{\circ} \mathrm{C}$ and a solution of ethylmagnesium bromide (1 M in THF, $728 \mathrm{~mL}, 0.728 \mathrm{mmol})$ was added dropwise. After $10 \mathrm{~min},(R)-4-$ Otirred for $10 \mathrm{~min}$ at $0{ }^{\circ} \mathrm{C}$. A sat aq $\mathrm{NH}_{4} \mathrm{Cl}$ solution $(1 \mathrm{~mL})$ was added to the reaction mixture until the aqueous phase became blue. The aqueous layer was washed with EtOAc $(3 \times 1 \mathrm{~mL})$ and the combined organic layers were dried $\left(\mathrm{MgSO}_{4}\right)$ and evaporated to give the desired bromo alcohol (59 mg, 99\%) as a pale yellow oil which was used without any further purification. $R_{\mathrm{f}}=0.38$ (silica gel, hexanes:EtOAc 4:1); IR (neat) $v_{\max } 3350,3060,3042,2937,2887 \mathrm{~cm}^{-1} ;{ }^{1} \mathrm{H} \mathrm{NMR}\left(600 \mathrm{MHz}, \mathrm{CDCl}_{3}\right) \delta$ $=3.79-3.81(\mathrm{~m}, 1 \mathrm{H}), 3.50-3.55(\mathrm{~m}, 2 \mathrm{H}), 1.89-1.97(\mathrm{~m}, 2 \mathrm{H}), 1.33-1.46(\mathrm{~m}, 4 \mathrm{H}), 0.9(\mathrm{t}, J=7.2 \mathrm{~Hz}, 3$

H) ppm; ${ }^{13} \mathrm{C}$ NMR $\left(150 \mathrm{MHz}, \mathrm{CDCl}_{3}\right) \delta=70.4,40.8,40.4,31.5,19.6,14.9$ ppm; GC-MS calcd for $\mathrm{C}_{6} \mathrm{H}_{13} \mathrm{BrO}[\mathrm{M}]^{+}: 180$; found $[\mathrm{M}]^{+}: 180$.

A solution of the bromo alcohol obtained as described above $(59.21 \mathrm{mg}, 0.327 \mathrm{mmol})$ in $\mathrm{CH}_{2} \mathrm{Cl}_{2}(1 \mathrm{~mL})$ and 2,6-lutidine $(76.18 \mathrm{~mL}, 0.654 \mathrm{mmol})$ was cooled to $0^{\circ} \mathrm{C}$ and TBSOTf $(114 \mathrm{~mL}, 0.497 \mathrm{mmol})$ was added dropwise. After 10 min the reaction mixture was washed with aq $\mathrm{HCl}(1 \mathrm{~N}, 2 \mathrm{~mL})$ and brine $(2$ $\mathrm{mL})$ and the aqueous phase was re-extracted with $\mathrm{CH}_{2} \mathrm{Cl}_{2}(5 \mathrm{~mL})$. The combined organic layers were 
dried $\left(\mathrm{MgSO}_{4}\right)$ and concentrated under vacuo. The crude product was purified by flash column chromatography (silica gel, hexanes) to afford bromo TBS-ether 18 (95 mg, 99\%) as a pale yellow oil. 18: $R_{\mathrm{f}}=0.73$ (silica gel, hexanes:EtOAc 4:1); $[\alpha]_{\mathrm{D}}{ }^{32}=+24\left(c=1.0, \mathrm{CHCl}_{3}\right)$; IR (neat) $v_{\max } 2958,2925$, 1468, 1264, $1034 \mathrm{~cm}^{-1} ;{ }^{1} \mathrm{H}$ NMR (125 MHz, $\left.\mathrm{CDCl}_{3}\right) \delta=3.81-3.85(\mathrm{~m}, 1 \mathrm{H}), 3.46(\mathrm{t}, J=6.5 \mathrm{~Hz}, 2 \mathrm{H})$, 1.91-1.98 (m, 2 H), 1.42-1.46 (m, $2 \mathrm{H}), 1.30-1.35$ (m, $2 \mathrm{H}), 0.88-0.92(\mathrm{~m}, 12 \mathrm{H}) 0.7$ (s, $6 \mathrm{H}) \mathrm{ppm} ;{ }^{13} \mathrm{C}$ NMR $\left(150 \mathrm{MHz}, \mathrm{CDCl}_{3}\right) \delta=70.1,40.0,39.4,30.7,25.8,18.1,18.0,14.2,-4.4,-4.5$ ppm; GC-MS calcd for $\mathrm{C}_{12} \mathrm{H}_{27} \mathrm{BrOSi}[\mathrm{M}]^{+}:$294; found $[\mathrm{M}+\mathrm{H}]^{+}: 295$.

\section{Iodide TBS-ether 19 (Scheme 1):}

$\mathrm{NaI}(96.55 \mathrm{mg}, 0.648 \mathrm{mmol})$ was added at $0{ }^{\circ} \mathrm{C}$ to a solution of bromo TBS-ether 18 (110 mg, 0.320 mmol) in acetone $(2 \mathrm{~mL})$. The resulting suspension was kept in the dark and the temperature was OTlowed to reach ambient temperature. The reaction mixture was stirred for $12 \mathrm{~h}$ and then the acetone was evaporated. The residue was dissolved in water $(2 \mathrm{~mL})$ and the aqueous phase was extracted $\mathrm{Et}_{2} \mathrm{O}(3 \times 4 \mathrm{~mL})$. The combined organic layers were dried $\left(\mathrm{MgSO}_{4}\right)$ and evaporated to dryness. The residue was purified by flash column chromatography (silica gel, hexanes) to afford iodide TBS-ether 19 (110 mg, 99\%) as a light orange oil. 19: $R_{\mathrm{f}}=0.86$ (silica gel, hexanes:EtOAc 4:1); $[\alpha]_{\mathrm{D}}^{32}=+45\left(c=1.1, \mathrm{CHCl}_{3}\right)$; IR (neat) $v_{\max } 2958,2861,1461,1252,1070,835,776 \mathrm{~cm}^{-1} ;{ }^{1} \mathrm{H}$ NMR $\left(500 \mathrm{MHz}, \mathrm{CDCl}_{3}\right) \delta=3.70-3.75(\mathrm{~m}, 1 \mathrm{H}), 3.17-3.26(\mathrm{t}, J=6.5 \mathrm{~Hz}, 2 \mathrm{H}), 1.92-1.98(\mathrm{~m}, 2 \mathrm{H})$, 1.41-1.46 (m, $2 \mathrm{H}), 1.28-1.35$ (m, $2 \mathrm{H}), 0.86-0.92$ (m, $12 \mathrm{H}) 0.72$ (s, $6 \mathrm{H}) \mathrm{ppm} ;{ }^{13} \mathrm{C} \mathrm{NMR}(125 \mathrm{MHz}$, $\left.\mathrm{CDCl}_{3}\right) \delta=71.9,40.1,39.1,25.7,18.1,18.0,14.2,3.7,-4.3,-4.4$ ppm; GC-MS calcd for $\mathrm{C}_{12} \mathrm{H}_{27} \mathrm{BIOSi}$ $[\mathrm{M}]^{+}: 342$; found $[\mathrm{M}+\mathrm{H}]^{+}: 343$.

\section{Hydroxy amide 20 (Scheme 1):}

A solution of $n$-BuLi $(2.5 \mathrm{M}$ in hexanes, $512.0 \mu \mathrm{L}, 1.280 \mathrm{mmol})$ was added dropwise to a suspension of freshly dried $\mathrm{LiCl}(172.3 \mathrm{mg}, 4.064 \mathrm{mmol})$ and diisopropylamine (193.4 $\mu \mathrm{L}, 1.379 \mathrm{mmol})$ in $\mathrm{THF}(1$

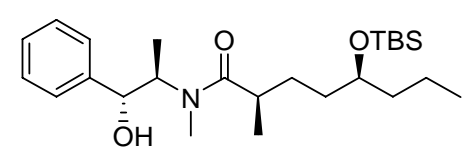

$\mathrm{mL}$ ) cooled to $-78^{\circ} \mathrm{C}$. The resulting mixture was warmed to $0{ }^{\circ} \mathrm{C}$, kept at that temperature for $5 \mathrm{~min}$, and then cooled to $-78^{\circ} \mathrm{C}$. A solution of $(S, S)$ $N$-(2-hydroxy-1-methyl-2-phenylethyl)- $N$-methylpropionamide 
$\mathrm{mg}, 0.672 \mathrm{mmol})$ in $\mathrm{THF}(0.5 \mathrm{~mL})$ was cooled to $-78{ }^{\circ} \mathrm{C}$ and then added dropwise to the reaction mixture. The resulting solution was stirred at $-78^{\circ} \mathrm{C}$ for $1 \mathrm{~h}$, at $0{ }^{\circ} \mathrm{C}$ for $15 \mathrm{~min}$, and at $25^{\circ} \mathrm{C}$ for $5 \mathrm{~min}$. The resulting suspension was then cooled to $0^{\circ} \mathrm{C}$ and a solution of iodide TBS-ether 19 (110 mg, 0.320 mmol) in THF ( $1 \mathrm{~mL})$ was added dropwise. After $19 \mathrm{~h}$ of stirring at $25{ }^{\circ} \mathrm{C}$ the mixture was treated with sat aq $\mathrm{NH}_{4} \mathrm{Cl}$ solution $(1 \mathrm{~mL})$, and the resulting mixture was extracted with EtOAc $(3 \times 2 \mathrm{~mL})$. The combined organic extracts were dried $\left(\mathrm{MgSO}_{4}\right)$ and evaporated to dryness. The crude product was purified by flash column chromatography (silica gel, hexanes:EtOAc 3:1) to afford hydroxy amide 20 (92 mg, 66\%, 99\% de by ${ }^{1} \mathrm{H}$ NMR spectroscopic analysis) as a pale yellow oil. 20: $R_{\mathrm{f}}=0.26$ ( silica gel, hexanes:EtOAc 3:1); $[\alpha]_{\mathrm{D}}^{32}=+42.2\left(c=1.1, \mathrm{CHCl}_{3}\right)$; IR (neat) $v_{\max } 3362,2925,2843,1616,1464$, 1248, 1070, 837, $772 \mathrm{~cm}^{-1} ;{ }^{1} \mathrm{H}$ NMR $\left(600 \mathrm{MHz} \mathrm{CDCl}_{3}\right.$, ca 9:1 ratio of rotamers, only signals for the major isomer are noted) $\delta=7.26-7.30(\mathrm{~m}, 5 \mathrm{H}), 4.58(\mathrm{~d}, J=7.5 \mathrm{~Hz}, 1 \mathrm{H}) 4.50(\mathrm{br} \mathrm{s}, 1 \mathrm{H}), 3.6(\mathrm{~d}, J=$ $9.5 \mathrm{~Hz}, 1 \mathrm{H}), 2.89(\mathrm{~s}, 3 \mathrm{H}), 2.58-2.61(\mathrm{~m}, 1 \mathrm{H}), 2.60-2.64(\mathrm{~m}, 1 \mathrm{H}), 1.25-2.41(\mathrm{~m}, 8 \mathrm{H}), 1.01-1.10$ (m, $6 \mathrm{H}) \quad 0.89-0.92(\mathrm{~m}, 12 \mathrm{H}) \quad 0.05-0.08(\mathrm{~s}, 6 \mathrm{H}) \mathrm{ppm} ;{ }^{13} \mathrm{C} \mathrm{NMR}\left(150 \mathrm{MHz}, \mathrm{CDCl}_{3}\right.$, ca 9:1 ratio of rotamers, only signals for the major isomer are noted) $\delta=179.9,143.4,129.56,129.2,128.4,127.8$, 127.2, 72.7, 40.0, 37.7, 35.6, 30.1, 26.8, 26.7, 19.4, 19.0, 18.1, 15.4, 15.2, -3.5 ppm; HRMS (ESI-TOF): calcd for $\mathrm{C}_{25} \mathrm{H}_{45} \mathrm{NO}_{3} \mathrm{Si}[\mathrm{M}+\mathrm{H}]^{+}: 436.3241$, found: 436.3251 .

\section{Dihydroxy amide 21 (Scheme 1):}

Hydroxy amide 20 (92 mg, $0.211 \mathrm{mmol})$ was dissolved in THF (1.5 mL) and TBAF (1 M in THF, 927.5 $\mu \mathrm{L}, 0.848 \mathrm{mmol}$ ) was added at ambient temperature. The reaction mixture was stirred for $16 \mathrm{~h}$ at that

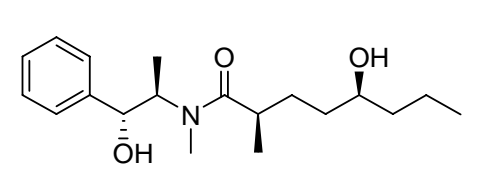
temperature. Water $(1 \mathrm{~mL})$ was then added and the aqueous phase was washed with EtOAc $(3 \times 1 \mathrm{~mL})$. The combined organic extracts were dried $\left(\mathrm{MgSO}_{4}\right)$ and evaporated under vacuo. The product was purified by flash column chromatography ( silica gel, hexanes:EtOAc 1:1) to give dihydroxy amide 21 (68 mg, 99\%) as a colorless oil. 21: $R_{\mathrm{f}}=0.16$ (silica gel, hexanes:EtOAc 1:1); $[\alpha]_{\mathrm{D}}^{32}=+39.2\left(c=1.0, \mathrm{CHCl}_{3}\right)$; IR (neat) $v_{\max } 3350,2930,2850,1607,1441,1296,1109,1050 \mathrm{~cm}^{-1} ;{ }^{1} \mathrm{H} \mathrm{NMR}\left(400 \mathrm{MHz}, \mathrm{CDCl}_{3}\right.$, ca 8:1 ratio of rotamers, only signals for the major isomer are noted) $\delta=7.34-7.36(\mathrm{~m}, 5 \mathrm{H}), 4.64(\mathrm{~d}, J=7.6$ Hz, 1 H) 4.46 (br s, 1 H), 3.50-3.56 (m, $1 \mathrm{H}), 2.86(\mathrm{~s}, 3 \mathrm{H}), 2.84$ (br s, $1 \mathrm{H}), 2.59-2.64(\mathrm{~m}, 1 \mathrm{H})$, 
$1.71-1.78(\mathrm{~m}, 2 \mathrm{H}), 1.32-1.52(\mathrm{~m}, 8 \mathrm{H}), 0.12-1.15(\mathrm{~m}, 6 \mathrm{H}) \mathrm{ppm} ;{ }^{13} \mathrm{C} \mathrm{NMR}\left(100 \mathrm{MHz}, \mathrm{CDCl}_{3}\right.$, ca $8: 1$ ratio of rotamers, only signals for the major isomer are noted) $\delta=179.8,128.7,127.5,126.3,100.0$, 71.5, 58.0, 39.5, 36.7, 34.9, 29.7, 18.9, 18.8, 18.6, 17.5, 14.4, 14.1 ppm; HRMS (ESI-TOF): calcd for $\mathrm{C}_{19} \mathrm{H}_{31} \mathrm{NO}_{3}[\mathrm{M}+\mathrm{H}]^{+}: 321.2304$, found: 321.2308 .

\section{Hydroxy methyl ether 22 (Scheme 1):}

To a suspension of $\mathrm{NaH}(60 \%$ suspension in mineral oil, $180 \mathrm{mg}, 7.50 \mathrm{mmol})$ in THF $(50 \mathrm{~mL})$ at $0{ }^{\circ} \mathrm{C}$ was added dropwise a solution of dihydroxy amide $21(1.2 \mathrm{~g}, 3.75 \mathrm{mmol})$ in THF $(10 \mathrm{~mL})$ at $0{ }^{\circ} \mathrm{C}$. The

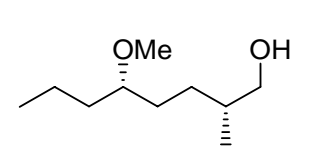
reaction mixture was stirred at that temperature for $10 \mathrm{~min}$ and then $\mathrm{MeI}(0.7 \mathrm{~mL}$, $11.25 \mathrm{mmol}$ ) was added. The resulting mixture was stirred at $0{ }^{\circ} \mathrm{C}$ for $45 \mathrm{~min}$ then let to stir for $16 \mathrm{~h}$ at room temperature and then quenched slowly with sat aq $\mathrm{NH}_{4} \mathrm{Cl}$ solution $(10 \mathrm{~mL})$. The reaction mixture was extracted with $\mathrm{Et}_{2} \mathrm{O}(3 \times 30 \mathrm{~mL})$ and the combined organic layers were then washed with brine $(30 \mathrm{~mL})$, dried with $\mathrm{MgSO}_{4}$, filtered and evaporated to dryness. The resulting residue was purified by flash column chromatography (silica gel, hexanes:EtOAc 2:1) to yield the desired amide $(1.24 \mathrm{~g}, 95 \%)$ as a colorless oil. $R_{\mathrm{f}}=0.26$ (silica gel, hexanes:EtOAc $\left.1: 1\right) ;[\alpha]_{\mathrm{D}}{ }^{32}=$ $+37.9\left(c=0.9, \mathrm{CHCl}_{3}\right)$; IR (neat) $v_{\max } 3024,2935,2846,1610,1441,1289,1110,1040 \mathrm{~cm}^{-1} ;{ }^{1} \mathrm{H} \mathrm{NMR}$ (600 MHz, $\mathrm{CDCl}_{3}$, ca 3:1 ratio of rotamers, only signals for the major isomer are noted) $\delta=7.41$ (d, $J=$ $8.4 \mathrm{~Hz}, 1 \mathrm{H}), 7.23-7.34(\mathrm{~m}, 4 \mathrm{H}), 4.13-4.19(\mathrm{~m}, 1 \mathrm{H}), 3.87(\mathrm{~d}, J=10.2 \mathrm{~Hz}, 1 \mathrm{H}), 3.42(\mathrm{~s}, 3 \mathrm{H})$, 3.31-3.36 (m, $1 \mathrm{H}), 3.15$ (s, $3 \mathrm{H}), 3.07$ (s, $3 \mathrm{H}), 2.91-2.95$ (m, $1 \mathrm{H}), 1.71-1.78(\mathrm{~m}, 2 \mathrm{H}), 1.50-1.78(\mathrm{~m}$, $6 \mathrm{H}), 1.32(\mathrm{~d}, J=8.4 \mathrm{~Hz}, 3 \mathrm{H}), 1.05(\mathrm{~m}, 3 \mathrm{H}), 0.88(\mathrm{~d}, J=8.2 \mathrm{~Hz}, 3 \mathrm{H}) \mathrm{ppm} ;{ }^{13} \mathrm{C}$ NMR $(150 \mathrm{MHz}$, $\mathrm{CDCl}_{3}$, ca 3:1 ratio of rotamers, only signals for the major isomer are noted) $\delta=179.1,128.3,127.1$, $126.0,85.6,81.1,59.5,56.2,36.7,36.4,31.8,30.2,27.3,19.1,18.8,18.2,15.6,14.8,14.7$; HRMS (ESITOF): calcd for $\mathrm{C}_{21} \mathrm{H}_{36} \mathrm{NO}_{3}[\mathrm{M}+\mathrm{H}]^{+}: 349.2617$, found: 349.2625 .

To a solution of diisopropyl amine $(0.45 \mathrm{~mL}, 3.2 \mathrm{mmol})$ in THF $(2 \mathrm{~mL})$ at $-78^{\circ} \mathrm{C}$ was added $n$-BuLi ( $2.5 \mathrm{M}$ in hexanes, $1.28 \mathrm{~mL}, 3.2 \mathrm{mmol})$. After $10 \mathrm{~min}$, the solution was warmed to $0{ }^{\circ} \mathrm{C}$ and after a further $15 \mathrm{~min}, \mathrm{BH}_{3} \cdot \mathrm{NH}_{3}(110 \mathrm{mg}, 3.2 \mathrm{mmol})$ was added in one portion. The mixture was allowed to stir for $15 \mathrm{~min}$ at $0{ }^{\circ} \mathrm{C}$ and then was warmed up to room temperature and stirred for a further $15 \mathrm{~min}$. It was then recooled back to $0{ }^{\circ} \mathrm{C}$ and a solution of the above amide $(270 \mathrm{mg}, 0.77 \mathrm{mmol})$ in THF $(2.5$ 
$\mathrm{mL}$ ) was then added dropwise via syringe. After $2 \mathrm{~h}$ of stirring, the reaction was warmed up to ambient temperature and stirred for $10 \mathrm{~h}$ before it was quenched with sat aq $\mathrm{NH}_{4} \mathrm{Cl}$ solution $(10 \mathrm{~mL})$. After stirring for a further $20 \mathrm{~min}$, two heterogeneous layers were formed. The mixture was extracted with $\mathrm{Et}_{2} \mathrm{O}(3 \times 10 \mathrm{~mL})$ and the dried $\left(\mathrm{MgSO}_{4}\right)$ combined organic phase was concentrated under vacuo and purified by flash column chromatography (silica gel, hexane:EtOAc 4:1) to give hydroxy methyl ether $22(108 \mathrm{mg}, 82 \%)$ as a colorless oil. 22: $R_{\mathrm{f}}=0.21$ (silica gel, hexanes:EtOAc $\left.4: 1\right) ;[\alpha]_{\mathrm{D}}{ }^{25}=+19.8(c=$ 1.9, $\mathrm{CHCl}_{3}$ ); IR (neat) $v_{\max } 3412,2932,1424,1186,1094 \mathrm{~cm}^{-1} ;{ }^{1} \mathrm{H} \mathrm{NMR}\left(400 \mathrm{MHz}, \mathrm{CDCl}_{3}\right) \delta=$ 5.64-5.72 (m, $1 \mathrm{H}), 4.99-5.02(\mathrm{~m}, 2 \mathrm{H}), 3.33-3.40$ (m, $2 \mathrm{H}), 3.31$ (s, $3 \mathrm{H}), 3.13-3.19$ (m, $1 \mathrm{H}), 2.34$ (s, $1 \mathrm{H}), 2.18^{-2.22}(\mathrm{~m}, 2 \mathrm{H}), 1.36-1.55(\mathrm{~m}, 4 \mathrm{H}), 1.16^{-1.22}(\mathrm{~m}, 1 \mathrm{H}), 0.85(\mathrm{~d}, J=6.6 \mathrm{~Hz}, 3 \mathrm{H}) ;{ }^{13} \mathrm{C}$ NMR $\left(100 \mathrm{MHz} \mathrm{CDCl}_{3}\right) \delta=134.4,116.9,80.8,67.8,56.0,37.6,35.7,30.2,28.1,16.9$; HRMS (ESI-TOF): calcd. for $\mathrm{C}_{10} \mathrm{H}_{20} \mathrm{O}_{2}[\mathrm{M}]^{+}$requires 172.1463, found 172.1464 .

\section{Hydroxy ester 23 (Scheme 1):}

To a stirred solution of $(\mathrm{COCl})_{2}(0.8 \mathrm{~mL}, 9.3 \mathrm{mmol})$ in $\mathrm{CH}_{2} \mathrm{Cl}_{2}(30 \mathrm{~mL})$ at $-78{ }^{\circ} \mathrm{C}$ was added dropwise a solution of DMSO $(0.99 \mathrm{~mL}, 13.9 \mathrm{mmol})$ in $\mathrm{CH}_{2} \mathrm{Cl}_{2}(5 \mathrm{~mL})$. After $20 \mathrm{~min}$, a solution of hydroxy methyl

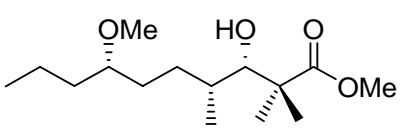
ether $22(0.8 \mathrm{~g}, 4.6 \mathrm{mmol})$ in $\mathrm{CH}_{2} \mathrm{Cl}_{2}(5 \mathrm{~mL})$ was added dropwise. The mixture was stirred for $30 \mathrm{~min}$ at $-78{ }^{\circ} \mathrm{C}$, and then $\mathrm{Et}_{3} \mathrm{~N}(5.5 \mathrm{~mL}, 23.2$ mmol) was added. After being stirred at $-78{ }^{\circ} \mathrm{C}$ for $15 \mathrm{~min}$ the reaction

mixture was let to stir at room temperature before it was quenched with sat aq $\mathrm{NH}_{4} \mathrm{Cl}$ solution (100 $\mathrm{mL})$. The resulting mixture was extracted with $\mathrm{CH}_{2} \mathrm{Cl}_{2}(2 \times 100 \mathrm{~mL})$, washed with brine $(100 \mathrm{~mL})$, and dried over $\mathrm{Na}_{2} \mathrm{SO}_{4}$. The crude aldehyde obtained upon evaporation was used in the next step without further purification.

To a stirred solution of $N$-Ts- $(R)$-Val $(1.29 \mathrm{~g}, 4.6 \mathrm{mmol})$ in $\mathrm{CH}_{2} \mathrm{Cl}_{2}(70 \mathrm{~mL})$ at room temperature was added dropwise $\mathrm{BH}_{3} \bullet$ THF (1 M solution in THF, $4.6 \mathrm{~mL}, 4.6 \mathrm{mmol}$ ). After $30 \mathrm{~min}$, to the resulting mixture were successively added a solution of the aldehyde obtained above (0.8 g, $4.6 \mathrm{mmol})$ in $\mathrm{CH}_{2} \mathrm{Cl}_{2}$ (5 mL) and 1-(trimethylsiloxy)-1-methoxy-2-methyl-1-propene (1.12 mL, $5.52 \mathrm{mmol})$ in $\mathrm{CH}_{2} \mathrm{Cl}_{2}(5 \mathrm{~mL})$ at $-78^{\circ} \mathrm{C}$. After being stirred at the same temperature for $3 \mathrm{~h}$, the reaction mixture was quenched with pH 7 phosphate buffer $(80 \mathrm{~mL})$, extracted with $\mathrm{CH}_{2} \mathrm{Cl}_{2}(2 \times 80 \mathrm{~mL})$, washed with brine $(100 \mathrm{~mL})$, and 
dried over $\mathrm{Na}_{2} \mathrm{SO}_{4}$. Concentration and flash column chromatography (silica gel, hexanes:EtOAc 4:1) afforded hydroxy ester $23(1.2 \mathrm{~g}, 89 \%)$ as a colorless viscous oil. 23: $R_{\mathrm{f}}=0.44$ (silica gel, hexanes:EtOAc 4:1); $[\alpha]_{\mathrm{D}}{ }^{25}=-9.8\left(c=2.3, \mathrm{CHCl}_{3}\right)$; IR (neat) $v_{\max }=3476,2933,2877,1730,1458$, 1266, 1192, 1141, 1096, $988 \mathrm{~cm}^{-1}$; ${ }^{1} \mathrm{H}$ NMR $\left(600 \mathrm{MHz}, \mathrm{CDCl}_{3}\right) \delta=3.64(\mathrm{~s}, 3 \mathrm{H}), 3.42$ (br s, $\left.1 \mathrm{H}\right), 3.26$ (s, 3 H), 3.06 (m, 1 H), 2.92 (br s, 1 H), 1.59 (m, 1 H), 1.22-1.56 (m, 8 H), 1.24 (s, 3 H), 1.12 (s, 3 H), $0.86(\mathrm{t}, J=7.1 \mathrm{~Hz}, 3 \mathrm{H}), 0.71(\mathrm{~d}, J=6.8 \mathrm{~Hz}, 3 \mathrm{H}) \mathrm{ppm} ;{ }^{13} \mathrm{C} \mathrm{NMR}\left(150 \mathrm{MHz}, \mathrm{CDCl}_{3}\right) \delta=178.6,80.8$, 79.9, 56.4, 51.9, 45.7, 35.6, 34.6, 31.4, 31.2, 24.6, 21.9, 18.4, 14.2, 13.2 ppm; HRMS (ESI-TOF): calcd for $\mathrm{C}_{15} \mathrm{H}_{30} \mathrm{O}_{4} \mathrm{Na}[\mathrm{M}+\mathrm{Na}]^{+}:$297.2036, found: 297.2036.

\section{Hydroxy decanoic acid 15 (Scheme 1):}

To a solution of hydroxy ester $23(200 \mathrm{mg}, 0.730 \mathrm{mmol})$ in $\mathrm{MeOH}: \mathrm{H}_{2} \mathrm{O}(4: 1,7 \mathrm{~mL})$ was added $\mathrm{LiOH} \cdot \mathrm{H}_{2} \mathrm{O}(184 \mathrm{mg}, 4.38 \mathrm{mmol})$ at ambient temperature. The reaction mixture was stirred for $24 \mathrm{~h}$ at that temperature and then partitioned between EtOAc $(50 \mathrm{~mL})$ and aq $\mathrm{HCl}(1$ were re-extracted with EtOAc $(2 \times 50 \mathrm{~mL})$, and the combined organic layers were dried $\left(\mathrm{Na}_{2} \mathrm{SO}_{4}\right)$, filtered, and evaporated to dryness. The residue was purified by flash column chromatography (silica gel, hexanes:EtOAc:AcOH 74:25:1) to afford hydroxy decanoic acid 15 (187.3 mg, 99\%) as a colorless

viscous oil. 15: $R_{\mathrm{f}}=0.23$ (silica gel, hexanes:EtOAc: $\left.\mathrm{AcOH} 74: 25: 1\right) ;[\alpha]_{\mathrm{D}}^{25}=-28.9\left(c=1.1, \mathrm{CHCl}_{3}\right)$; IR (neat) $v_{\max } 3426,2927,2871,1698,1460,1255,1150,1088,977 \mathrm{~cm}^{-1} ;{ }^{1} \mathrm{H} \mathrm{NMR}\left(400 \mathrm{MHz}, \mathrm{CDCl}_{3}\right)$ $\delta=3.50(\mathrm{~d}, J=2.3 \mathrm{~Hz}, 1 \mathrm{H}), 3.29(\mathrm{~s}, 3 \mathrm{H}), 3.13(\mathrm{~m}, 1 \mathrm{H}), 1.67(\mathrm{~m}, 1 \mathrm{H}), 1.22-1.49(\mathrm{~m}, 8 \mathrm{H}), 1.33(\mathrm{~s}, 3$ $\mathrm{H}), 1.13(\mathrm{~s}, 3 \mathrm{H}), 0.87$ (t, $J=7.2 \mathrm{~Hz}, 3 \mathrm{H}), 0.80(\mathrm{~d}, J=6.9 \mathrm{~Hz}, 3 \mathrm{H}) \mathrm{ppm} ;{ }^{13} \mathrm{C} \mathrm{NMR}\left(100 \mathrm{MHz}, \mathrm{CDCl}_{3}\right)$ $\delta=181.9,81.1,79.8,56.3,45.1,35.4,34.6,30.9,30.8,25.5,21.6,18.4,14.2,12.9$ ppm; HRMS (ESITOF): calcd for $\mathrm{C}_{14} \mathrm{H}_{28} \mathrm{O}_{4} \mathrm{Na}[\mathrm{M}+\mathrm{Na}]^{+}: 283.1880$, found: 283.1880 .

\section{TBDPS-ether 27 (Scheme 2):}

To a cooled solution of 3-butyn-1-ol $(26.5 \mathrm{~mL}, 0.35 \mathrm{~mol})$, imidazole $(52.3 \mathrm{~g}, 0.77 \mathrm{~mol})$ and 4-DMAP (4.3 g, $35 \mathrm{mmol})$ in $\mathrm{CH}_{2} \mathrm{Cl}_{2}(700 \mathrm{~mL})$ was slowly added TBDPSCl $(100 \mathrm{~mL}, 0.38 \mathrm{~mol})$ at $0{ }^{\circ} \mathrm{C}$. The OTBDPS resulting solution was warmed to room temperature and was stirred for $16 \mathrm{~h}$, the 
reaction mixture was quenched with aq $\mathrm{HCl}(1 \mathrm{~N}, 500 \mathrm{~mL})$ and the layers separated. The organic phase was washed with brine $(500 \mathrm{~mL})$, dried over $\mathrm{MgSO}_{4}$, filtered and concentrated to afford TBDPS-ether $27\left(107 \mathrm{~g}, 99 \%\right.$ ) as a colorless oil. 27: $R_{\mathrm{f}}=0.75$ (silica gel, hexanes: $\mathrm{Et}_{2} \mathrm{O} 2: 1$ ); IR (neat) $v_{\max } 3568$, 2971, 2934, 1659, 1454, 1377, 1177, 1092, 998, $918 \mathrm{~cm}^{-1} ;{ }^{1} \mathrm{H}$ NMR $\left(500 \mathrm{MHz}, \mathrm{CDCl}_{3}\right) \delta=7.79(\mathrm{~m}, 4$ H), 7.34-7.44 (m, $6 \mathrm{H}), 3.80(\mathrm{t}, J=7.0 \mathrm{~Hz}, 2 \mathrm{H}), 2.46(\mathrm{dt}, J=2.7,7.1 \mathrm{~Hz}, 2 \mathrm{H}), 1.95(\mathrm{t}, J=2.7 \mathrm{~Hz}, 1$ H), 1.07 (s, $9 \mathrm{H}) \mathrm{ppm} ;{ }^{13} \mathrm{C} \mathrm{NMR}\left(125 \mathrm{MHz}, \mathrm{CDCl}_{3}\right) \delta=135.5,133.6,129.7,127.7,69.3,62.3,26.8$, 22.6, 19.2 ppm; GC-MS calcd for $\mathrm{C}_{20} \mathrm{H}_{24} \mathrm{OSi}[\mathrm{M}]^{+}: 308$; found $[\mathrm{M}-t \mathrm{Bu}]^{+}: 251$.

\section{Hydroxy acetylene 28 (Scheme 2):}

To a cooled solution of TBDPS-ether 27 (107 g, $0.35 \mathrm{~mol})$ in $\mathrm{Et}_{2} \mathrm{O}(580 \mathrm{~mL})$ was slowly added $n$-BuLi $(2.5 \mathrm{M}$ in hexanes, $154 \mathrm{~mL}, 0.38 \mathrm{~mol})$ at $-78^{\circ} \mathrm{C}$. After stirring the mixture at that temperature for $1 \mathrm{~h}$, OотBDPS paraformaldehyde $(16.8 \mathrm{~g}, 0.56 \mathrm{~mol})$ was added and the resulting reaction mixture was slowly warmed to room temperature. After stirring for $18 \mathrm{~h}$ the reaction was quenched with sat aq $\mathrm{NH}_{4} \mathrm{Cl}$ solution $(300 \mathrm{~mL})$, the two layers were separated and the aqueous phase was extracted with $\mathrm{Et}_{2} \mathrm{O}(2 \times 200 \mathrm{~mL})$. The combined organic extracts were washed with brine $(400 \mathrm{~mL})$, dried over $\mathrm{MgSO}_{4}$, filtered and concentrated under vacuo. The resulting residue was purified by flash column chromatography (siliga gel, hexanes: $\mathrm{Et}_{2} \mathrm{O} 3: 1$ ) to afford hydroxy acetylene 28 $\left(99.3 \mathrm{~g}, 72 \%\right.$ ) as a colorless oil. 28: $R_{\mathrm{f}}=0.48$ (silica gel, hexanes:Et ${ }_{2} \mathrm{O} 1: 1$ ); IR (neat) $v_{\max } 3354,3070$, 3048.8, 2931, 2857, 1589, 1472, 1428, 1112, 1010, 822, 738, 702, $614 \mathrm{~cm}^{-1}$; ${ }^{1} \mathrm{H}$ NMR (600 MHz, $\left.\mathrm{CDCl}_{3}\right) \delta=7.73(\mathrm{~m}, 4 \mathrm{H}), 7.40-7.48(\mathrm{~m}, 6 \mathrm{H}), 4.21(\mathrm{t}, J=2.2 \mathrm{~Hz}, 2 \mathrm{H}), 3.82(\mathrm{t}, J=7.0 \mathrm{~Hz}, 2 \mathrm{H}), 2.52$ (tt, $J=2.1,7.0 \mathrm{~Hz}, 2 \mathrm{H}), 1.97$ (br s, $1 \mathrm{H}), 1.11$ (s, $9 \mathrm{H}) \mathrm{ppm} ;{ }^{13} \mathrm{C} \mathrm{NMR}\left(150 \mathrm{MHz}, \mathrm{CDCl}_{3}\right) \delta=135.5$, 133.5, 129.6, 127.6, 83.2, 79.5, 62.4, 51.1, 26.7, 22.8, 19.1 ppm; HRMS (ESI-TOF): calcd for $\mathrm{C}_{21} \mathrm{H}_{26} \mathrm{O}_{2} \mathrm{Si}[\mathrm{M}+\mathrm{Na}]^{+}: 361.1594$, found: 361.1595 .

\section{Allylic alcohol 29 (Scheme 2):}

A thoroughly de-airated and argon-purged solution of hydroxy acetylene 28 (98.25 g, 0.29 mol), quinoline ( $9 \mathrm{~mL}, 10 \%$ by weight) and $5 \% \mathrm{Pd} / \mathrm{BaSO}_{4}(9.8 \mathrm{~g}, 10 \% \mathrm{w} / \mathrm{w})$ in $\mathrm{MeOH}(950 \mathrm{~mL})$ was refilled HOOTBDPS with hydrogen ( $1 \mathrm{~atm}$, balloon). After stirring for $40 \mathrm{~min}$ at ambient temperature, 
the reaction mixture was filtered through a pad of celite, and the pad was further washed with $\mathrm{MeOH}$. The filtrate was concentrated and the residue was purified by flash column chromatography (silica gel, hexanes: $\mathrm{Et}_{2} \mathrm{O}$ 1:1) to afford allylic alcohol $29(97.6 \mathrm{~g}, 98 \%)$ as a colorless oil. 29: $R_{\mathrm{f}}=0.42$ ( silica gel, hexanes: $\mathrm{Et}_{2} \mathrm{O} 1: 1$ ); IR (neat) $v_{\max } 3333,3070,3010,2930,2857,1589,1472,1428,1111,1035,998$, 935, 823, 738, 702, $614 \mathrm{~cm}^{-1} ;{ }^{1} \mathrm{H}$ NMR (400 MHz, $\left.\mathrm{CDCl}_{3}\right) \delta=7.63(\mathrm{~m}, 4 \mathrm{H}), 7.38-7.45$ (m, $\left.6 \mathrm{H}\right), 5.77$ (m, $1 \mathrm{H}), 5.60(\mathrm{~m}, 1 \mathrm{H}), 4.15(\mathrm{~d}, J=6.7 \mathrm{~Hz}, 2 \mathrm{H}), 3.68(\mathrm{t}, J=6.4 \mathrm{~Hz}, 2 \mathrm{H}), 2.37(\mathrm{q}, J=6.7 \mathrm{~Hz}, 2 \mathrm{H})$, $1.72(\mathrm{~s}, 1 \mathrm{H}), 1.07$ (s, $9 \mathrm{H}) \mathrm{ppm} ;{ }^{13} \mathrm{C} \mathrm{NMR}\left(100 \mathrm{MHz}, \mathrm{CDCl}_{3}\right) \delta=135.6,133.5,130.6,129.6,129.4$, 127.6, 63.2, 58.4, 30.8, 26.8, 19.1 ppm; HRMS (ESI-TOF): calcd for $\mathrm{C}_{21} \mathrm{H}_{28} \mathrm{O}_{2} \mathrm{Si}[\mathrm{M}+\mathrm{Na}]^{+}$: 363.1751, found: 363.1745 .

\section{Hydroxy epoxide 30 (Scheme 2):}

To a suspension of thoroughly dried molecular sieves $4 \AA$ ( $3 \mathrm{~g})$ in dry $\mathrm{CH}_{2} \mathrm{Cl}_{2}(60 \mathrm{~mL})$ was added $\mathrm{Ti}(\mathrm{OiPr})_{4}(1.58 \mathrm{~mL}, 5.3 \mathrm{mmol})$ followed by slow addition of $(+)-\mathrm{DET}(1.3 \mathrm{~mL}, 6.2 \mathrm{mmol})$ at $-20{ }^{\circ} \mathrm{C}$. After stirring for $30 \mathrm{~min}$ TBHP (5 $\mathrm{M}$ in decanes, $7.1 \mathrm{~mL}, 35.4 \mathrm{mmol}$ ) was slowly added and the resulting solution was stirred at $-20{ }^{\circ} \mathrm{C}$ for a further $30 \mathrm{~min}$. Allylic alcohol 29 (6.35 g, 19 HOTBDPS mmol) in $\mathrm{CH}_{2} \mathrm{Cl}_{2}(320 \mathrm{~mL})$ was then added and the reaction mixture was stirred at $-20{ }^{\circ} \mathrm{C}$ for $24 \mathrm{~h}$, then warmed up to $0{ }^{\circ} \mathrm{C}$ and quenched with an aq basic solution (3 $\mathrm{M} \mathrm{NaOH}$ :brine 3:7, $100 \mathrm{~mL}$ ). After stirring for $1 \mathrm{~h}$, the reaction mixture was filtered through a pad of celite and the pad was further washed with $\mathrm{CH}_{2} \mathrm{Cl}_{2}$. The filtrate was concentrated and purified by flash column chromatography (silica gel, hexanes: $\mathrm{Et}_{2} \mathrm{O}$ 1:1) to afford hydroxy epoxide 30 (4.93 g, 99\%) as a colorless oil. 30: $R_{\mathrm{f}}=0.36$ (silica gel, hexanes: $\left.\mathrm{Et}_{2} \mathrm{O} 1: 1\right) ;[\alpha]_{\mathrm{D}}{ }^{32}=+2.19\left(c=0.81, \mathrm{CHCl}_{3}\right)$; IR (neat) $v_{\max } 3424,3070,2958,2950,2857,1742,1472,1428,1111,1041,823,740,702,614 \mathrm{~cm}^{-1}$; ${ }^{1} \mathrm{H}$ NMR $\left(600 \mathrm{MHz}, \mathrm{CDCl}_{3}\right) \delta=7.67(\mathrm{~m}, 4 \mathrm{H}), 7.38-7.45(\mathrm{~m}, 6 \mathrm{H}), 3.81(\mathrm{~m}, 2 \mathrm{H}), 3.74(\mathrm{~d}, J=5.6 \mathrm{~Hz}$, $2 \mathrm{H}), 3.21(\mathrm{~m}, 1 \mathrm{H}), 3.17(\mathrm{~m}, 1 \mathrm{H}), 2.24$ (br s, $1 \mathrm{H}), 1.89(\mathrm{~m}, 1 \mathrm{H}), 1.81(\mathrm{~m}, 1 \mathrm{H}), 1.07(\mathrm{~s}, 9 \mathrm{H}) \mathrm{ppm} ;{ }^{13} \mathrm{C}$ NMR $\left(150 \mathrm{MHz}, \mathrm{CDCl}_{3}\right) \delta=135.5,133.1,129.8,127.8,61.3,60.8,56.2,54.9,30.8,26.8,26.8,19.1$ ppm; HRMS (ESI-TOF): calcd for $\mathrm{C}_{21} \mathrm{H}_{28} \mathrm{O}_{3} \mathrm{Si}[\mathrm{M}+\mathrm{Na}]^{+}: 379.1700$, found: 379.1710 .

\section{Carboxylic acid epoxide 31 (Scheme 2):}


To a solution of hydroxy epoxide 30 (4.9 $\mathrm{g}, 13.7 \mathrm{mmol})$ and $\mathrm{NaIO}_{4}(12 \mathrm{~g}, 54.4 \mathrm{mmol})$ in $\mathrm{CCl}_{4} /$ acetonitrile $/ \mathrm{H}_{2} \mathrm{O}(1: 1: 1.5,80 \mathrm{~mL})$ was added $\mathrm{RuCl}_{3}{ }^{\cdot} \mathrm{H}_{2} \mathrm{O}(63 \mathrm{mg}, 0.3 \mathrm{mmol}, 2.2 \%$ by weight $)$ under

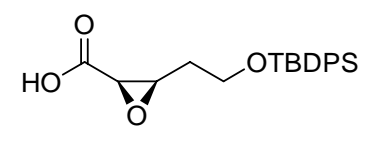
vigorous stirring, at ambient temperature. After stirring for $4 \mathrm{~h}$, the reaction mixture was partitioned between water $(100 \mathrm{~mL})$ and $\mathrm{CH}_{2} \mathrm{Cl}_{2}(200 \mathrm{~mL})$ and the layers were separated. The aqueous phase was extracted with $\mathrm{CH}_{2} \mathrm{Cl}_{2}(4 \times 100$ $\mathrm{mL}$ ), the combined organic extracts were dried over $\mathrm{MgSO}_{4}$, filtered, concentrated and purified by flash column chromatography (silica gel, hexanes:EtOAc:AcOH 6:4:0.1) to afford carboxylic acid epoxide 31 (4.05 g, 80\%) as a pale yellow oil. 31: $R_{\mathrm{f}}=0.17$ (silica gel, hexanes:EtOAc:AcOH 6:4:0.1); IR (neat) $v_{\max } 3600,3400,3071,2931,2857,1729,1472,1428,1236,1112,939,823,741,702,614 \mathrm{~cm}^{-1} ;{ }^{1} \mathrm{H}$ $\operatorname{NMR}\left(600 \mathrm{MHz}, \mathrm{CDCl}_{3}\right) \delta=7.66(\mathrm{~m}, 4 \mathrm{H}), 7.38-7.44(\mathrm{~m}, 6 \mathrm{H}), 3.84(\mathrm{~m}, 2 \mathrm{H}), 3.60(\mathrm{~d}, J=4.7 \mathrm{~Hz}, 1$ $\mathrm{H}), 3.50(\mathrm{~m}, 1 \mathrm{H}), 1.92(\mathrm{~m}, 2 \mathrm{H}), 1.05(\mathrm{~s}, 9 \mathrm{H}) \mathrm{ppm} ;{ }^{13} \mathrm{C} \mathrm{NMR}\left(150 \mathrm{MHz}, \mathrm{CDCl}_{3}\right) \delta=173.7,135.5$, 133.3, 129.7, 127.7, 60.8, 56.2, 52.3, 30.4, 26.8, 25.6, 19.1 ppm; HRMS (ESI-TOF): calcd for $\mathrm{C}_{21} \mathrm{H}_{26} \mathrm{O}_{4} \mathrm{Si}[\mathrm{M}+\mathrm{Na}]^{+}:$393.1492, found: 393.1501.

\section{Hydroxy acid 32 (Scheme 2):}

To a cold $\left(0^{\circ} \mathrm{C}\right)$ stirred solution of carboxylic acid epoxide 31 (1.54 g, $\left.4.1 \mathrm{mmol}\right)$ in dry hexanes $(20.5$ $\mathrm{mL})$ was slowly added $\mathrm{AlMe}_{3}(2.0 \mathrm{M}$ in hexanes, $6.25 \mathrm{~mL}, 12.5 \mathrm{mmol})$. The reaction mixture was OTBDPS

warmed to room temperature and stirred for $40 \mathrm{~h}$. The reaction was quenched at

$0{ }^{\circ} \mathrm{C}$ by slow addition of aq $\mathrm{HCl}(1 \mathrm{M})$ until complete hydrolysis of the excess $\mathrm{AlMe}_{3}$ and complete dissolution of all solids. The aqueous mixture was stirred at $0{ }^{\circ} \mathrm{C}$ for $1 \mathrm{~h}$ and then extracted with EtOAc $(6 \times 100 \mathrm{~mL})$. The combined organic layer was dried over $\mathrm{MgSO}_{4}$, filtered, concentrated and purified by flash column chromatography (hexanes:EtOAc:AcOH 6:4:0.1) to afford hydroxy acid $32(1.27 \mathrm{~g}, 80 \%)$ as a pale yellow oil. $32: R_{\mathrm{f}}=0.22$ (silica gel, hexanes/EtOAc/AcOH 6:4:0.1); $[\alpha]_{\mathrm{D}}^{32}=-2.28\left(c=0.80, \mathrm{CHCl}_{3}\right)$; IR (neat) $v_{\max } 3426,3070,2959$, 2931, 2857, 1726, 1472, 1428, 1389,1258, 1112, 822, 738, 702, $614 \mathrm{~cm}^{-1} ;{ }^{1} \mathrm{H}$ NMR (400 MHz, $\left.\mathrm{CDCl}_{3}\right)$ $\delta=7.68(\mathrm{~m}, 4 \mathrm{H}), 7.38-7.47(\mathrm{~m}, 6 \mathrm{H}), 4.35(\mathrm{~d}, J=2.7 \mathrm{~Hz}, 1 \mathrm{H}), 3.76(\mathrm{~m}, 2 \mathrm{H}), 2.36(\mathrm{~m}, 1 \mathrm{H}), 1.72(\mathrm{~m}$, $2 \mathrm{H}), 1.07(\mathrm{~s}, 9 \mathrm{H}), 0.91(\mathrm{~d}, J=7.0 \mathrm{~Hz}, 3 \mathrm{H}) \mathrm{ppm} ;{ }^{13} \mathrm{C} \mathrm{NMR}\left(100 \mathrm{MHz}, \mathrm{CDCl}_{3}\right) \delta=177.4,135.5,133.1$, 
129.8, 127.8, 73.2, 61.6, 35.7, 33.9, 26.8, 19.1, 13.1 ppm; HRMS (ESI-TOF): calcd for $\mathrm{C}_{22} \mathrm{H}_{30} \mathrm{O}_{4} \mathrm{Si}[\mathrm{M}$ $+\mathrm{Na}]^{+}: 409.1805$, found: 409.1811 .

\section{Hydroxy methyl ester 33 (Scheme 2):}

A solution of hydroxy acid $32(3.42 \mathrm{~g}, 8.8 \mathrm{mmol}), \mathrm{K}_{2} \mathrm{CO}_{3}(3.4 \mathrm{~g}, 8.8 \mathrm{mmol})$ and $\mathrm{MeI}(0.72 \mathrm{~mL}, 11.5$ $\mathrm{mmol})$ in dry acetone $(44 \mathrm{~mL})$ was stirred at room temperature for $18 \mathrm{~h}$, then it was filtered through a

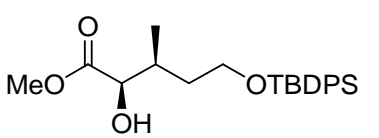
pad of celite and the pad was subsequently washed with acetone. The filtrate was concentrated and the residue was purified by flash column chromatography (silica gel, hexanes: EtOAc 4:1) to afford hydroxy methyl ester $33(3.3 \mathrm{~g}, 90 \%)$ as a colorless oil. 33: $R_{\mathrm{f}}=0.30\left(\right.$ silica gel, hexanes: $\left.\mathrm{Et}_{2} \mathrm{O} 2: 1\right) ;[\alpha]_{\mathrm{D}}^{32}=-17.2(c=$ 0.705, $\mathrm{CHCl}_{3}$ ); IR (neat) $v_{\max } 3522,3070,2957,2991,2857,1737,1589,1472,1428,1388,1257,1221$, 1112, 823, 738, 703, $614 \mathrm{~cm}^{-1} ;{ }^{1} \mathrm{H}$ NMR $\left(500 \mathrm{MHz}, \mathrm{CDCl}_{3}\right) \delta=7.69(\mathrm{~m}, 4 \mathrm{H}), 7.38-7.46(\mathrm{~m}, 6 \mathrm{H})$, $4.24(\mathrm{~d}, J=2.8 \mathrm{~Hz}, 1 \mathrm{H}), 3.81(\mathrm{~s}, 3 \mathrm{H}), 3.75(\mathrm{~m}, 2 \mathrm{H}), 2.88($ br s, $1 \mathrm{H}), 2.27$ (d sext, $J=2.8,7.0 \mathrm{~Hz}, 1$ H), $1.79(\mathrm{dtd}, J=5.7,6.8,12.4 \mathrm{~Hz}, 1 \mathrm{H}), 1.57(\mathrm{dtd}, J=5.6,6.9,12.6 \mathrm{~Hz}, 1 \mathrm{H}), 1.08(\mathrm{~s}, 9 \mathrm{H}), 0.82(\mathrm{~d}, J$ $=7.0 \mathrm{~Hz}, 3 \mathrm{H}) \mathrm{ppm} ;{ }^{13} \mathrm{C} \mathrm{NMR}\left(125 \mathrm{MHz}, \mathrm{CDCl}_{3}\right) \delta=175.4,135.5,133.7,129.6,127.6,73.2,61.7$, 52.4, 35.7, 33.5, 26.8, 26.8, 19.6, 13.4 ppm; HRMS (ESI-TOF): calcd for $\mathrm{C}_{23} \mathrm{H}_{32} \mathrm{O}_{4} \mathrm{Si}[\mathrm{M}+\mathrm{Na}]^{+}$: 423.1962, found: 423.1968 .

\section{Triflate 34 (Scheme 2):}

To a cooled $\left(0^{\circ} \mathrm{C}\right)$ stirred solution of hydroxy methyl ester $33(0.90 \mathrm{~g}, 2.25 \mathrm{mmol})$ and pyridine $(1.83$ $\mathrm{mL}, 22.5 \mathrm{mmol})$ in $\mathrm{CH}_{2} \mathrm{Cl}_{2}(22 \mathrm{~mL})$ was added $\mathrm{Tf}_{2} \mathrm{O}(0.57 \mathrm{~mL}, 3.38 \mathrm{mmol})$. The reaction mixture was

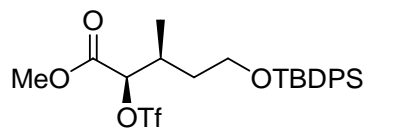
stirred for $25 \mathrm{~min}$ at $0{ }^{\circ} \mathrm{C}$ and then quenched with cold water $(100 \mathrm{~mL})$. The layers were separated and the aqueous phase was extracted with $\mathrm{Et}_{2} \mathrm{O}(3 \times 100$ $\mathrm{mL})$. The combined organic layer was quickly washed with cold aq $\mathrm{HCl}(1 \mathrm{~N}$,

$100 \mathrm{~mL}$ ), dried over $\mathrm{MgSO}_{4}$, filtered and concentrated to afford crude triflate 34 (quantitative yield) as a yellow oil, which was used immediately and without further purification. 34: $R_{\mathrm{f}}=0.65$ (silica gel, hexanes:Et ${ }_{2} \mathrm{O}$ 2:1); IR (neat) $v_{\max } 3072,2957,2932,2858,1769,1590,1416,1213,1145,1112,1003$, 945, 823, 738, $703 \mathrm{~cm}^{-1} ;{ }^{1} \mathrm{H}$ NMR (400 MHz, $\left.\mathrm{CDCl}_{3}\right): \delta=7.66(\mathrm{~m}, 4 \mathrm{H}), 7.37-7.45(\mathrm{~m}, 6 \mathrm{H}), 5.13(\mathrm{~d}, J$ 
= $3.0 \mathrm{~Hz}, 1 \mathrm{H}), 3.86(\mathrm{~s}, 3 \mathrm{H}), 3.73(\mathrm{~m}, 2 \mathrm{H}), 2.62(\mathrm{~m}, 1 \mathrm{H}), 1.74(\mathrm{~m}, 1 \mathrm{H}), 1.49(\mathrm{~m}, 1 \mathrm{H}), 1.06(\mathrm{~s}, 9 \mathrm{H})$, $0.95(\mathrm{~d}, J=7.0 \mathrm{~Hz}, 3 \mathrm{H}) \mathrm{ppm} ;{ }^{13} \mathrm{C} \mathrm{NMR}\left(100 \mathrm{MHz}, \mathrm{CDCl}_{3}\right) \delta=167.4,135.5,133.4,129.8,127.7,87.0$, $60.5,53.1,34.9,32.4,26.8,19.2,13.6 \mathrm{ppm}$.

\section{Azide 35 (Scheme 2):}

To a cooled $\left(0^{\circ} \mathrm{C}\right)$ stirred solution of crude triflate $34($ ca $2.25 \mathrm{mmol})$ in DMF $(20 \mathrm{~mL})$ was added $\mathrm{NaN}_{3}$ (263 mg, $4.05 \mathrm{mmol}$ ). After stirring at ambient temperature for $40 \mathrm{~min}$, the reaction was quenched with<smiles>COC(=O)[C@H](N)C(C)CCO[PbH2]</smiles>
water $(100 \mathrm{~mL})$ and the product was extracted with $\mathrm{Et}_{2} \mathrm{O}(3 \times 100 \mathrm{~mL})$. The combined organic extracts were dried over $\mathrm{MgSO}_{4}$, filtered, concentrated and purified by flash column chromatography (silica gel, hexanes:Et $\mathrm{t}_{2} \mathrm{O}$ 4:1) to

afford azide $35\left(0.72 \mathrm{~g}, 75 \%\right.$ from 33) as a colorless oil. 35: $R_{\mathrm{f}}=0.65$ (silica gel, hexanes:Et $\left.\mathrm{O}_{2} \mathrm{O} 4: 1\right)$; $[\alpha]_{\mathrm{D}}^{32}=-16.0\left(c=0.505, \mathrm{CHCl}_{3}\right)$; IR (neat) $v_{\max } 3071,2957,2931,2853,2108,1746,1589,1472$, $1428,1389,1264,1203,1111,998,823,738,702,614 \mathrm{~cm}^{-1} ;{ }^{1} \mathrm{H} \mathrm{NMR}\left(500 \mathrm{MHz}, \mathrm{CDCl}_{3}\right) \delta=7.66(\mathrm{~m}$, $4 \mathrm{H}), 7.37-7.44(\mathrm{~m}, 6 \mathrm{H}), 3.83(\mathrm{~d}, J=5.6 \mathrm{~Hz}, 1 \mathrm{H}), 3.77(\mathrm{~s}, 3 \mathrm{H}), 3.70(\mathrm{~m}, 2 \mathrm{H}), 2.34(\mathrm{~m}, 1 \mathrm{H}), 1.77(\mathrm{~m}$, $1 \mathrm{H}), 1.41(\mathrm{~m}, 1 \mathrm{H}), 1.06(\mathrm{~s}, 9 \mathrm{H}), 0.95(\mathrm{~d}, J=6.8 \mathrm{~Hz}, 3 \mathrm{H}) \mathrm{ppm} ;{ }^{13} \mathrm{C} \mathrm{NMR}\left(125 \mathrm{MHz}, \mathrm{CDCl}_{3}\right) \delta=$ 170.4, 135.5, 133.7, 129.6, 127.6, 67.5, 61.1, 52.4, 34.7, 32.4, 26.8, 19.2, 16.2 ppm; HRMS (ESI-TOF): calcd for $\mathrm{C}_{23} \mathrm{H}_{31} \mathrm{~N}_{3} \mathrm{O}_{3} \mathrm{Si}[\mathrm{M}+\mathrm{Na}]^{+}: 448.2027$, found: 448.2020 .

\section{Amino ester 14a (Scheme 2):}

A thoroughly argon-purged solution of azide $35(673 \mathrm{mg}, 1.58 \mathrm{mmol})$ and 10\% $\mathrm{Pd} / \mathrm{C}(135 \mathrm{mg}, 20 \%$ $\mathrm{w} / \mathrm{w})$ in $\mathrm{MeOH}(16 \mathrm{~mL})$ was refilled with hydrogen (1 atm, balloon) and stirred at ambient temperature.

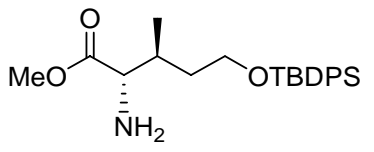

After $1 \mathrm{~h}$, the reaction mixture was filtered through a pad of celite, the pad was thoroughly washed with $\mathrm{MeOH}$ and the filtrate was concentrated under vacuo to afford crude amino ester 14a, which was used without further purification. 14a: $R_{\mathrm{f}}=0.19$ (silica gel, hexanes:EtOAc 7:3); IR (neat) $v_{\max } 3171,3070,3048,2957,2931,2856,1738$, $1589,1537,1472,1428,1389,1212,1170,1111,998,823,738,702,614 \mathrm{~cm}^{-1} ;{ }^{1} \mathrm{H}$ NMR $(500 \mathrm{MHz}$, $\left.\mathrm{CDCl}_{3}\right) \delta=7.66(\mathrm{~m}, 4 \mathrm{H}), 7.34-7.45(\mathrm{~m}, 6 \mathrm{H}), 3.77-3.65(\mathrm{~m}, 2 \mathrm{H}), 3.69(\mathrm{~s}, 3 \mathrm{H}), 3.43(\mathrm{~d}, J=4.5 \mathrm{~Hz}, 1$ H), $2.15(\mathrm{~m}, 1 \mathrm{H}), 1.70(\mathrm{~m}, 1 \mathrm{H}), 1.38(\mathrm{~m}, 1 \mathrm{H}), 1.05(\mathrm{~s}, 9 \mathrm{H}), 0.93(\mathrm{~d}, J=6.9 \mathrm{~Hz}, 3 \mathrm{H}) \mathrm{ppm} ;{ }^{13} \mathrm{C} \mathrm{NMR}$ 
$\left(125 \mathrm{MHz}, \mathrm{CDCl}_{3}\right) \delta=175.5,136.0,134.3,130.0,128.1,62.0,59.6,52.3,34.9,34.2,27.3,19.6,16.5$ ppm; HRMS (ESI-TOF): calcd for $\mathrm{C}_{23} \mathrm{H}_{33} \mathrm{NO}_{3} \mathrm{Si}[\mathrm{M}+\mathrm{H}]^{+}$: 400.2302, found: 400.2305 .

\section{Carboxylic acid 39d (Scheme 4):}

A solution of azido alcohol $38(327.1 \mathrm{mg}, 2.06 \mathrm{mmol})$ in $\mathrm{CH}_{2} \mathrm{Cl}_{2}(20 \mathrm{~mL})$ was cooled to $0{ }^{\circ} \mathrm{C}$ and 2,6 lutidine $(0.96 \mathrm{~mL}, 8.24 \mathrm{mmol})$ was added in one portion, followed by dropwise addition of TBSOTf $\mathrm{N}_{3} \stackrel{\mathrm{O}}{\mathrm{O}} \mathrm{OH}_{\mathrm{OTS}}^{\mathrm{OH}}$ $(0.94 \mathrm{~mL}, 4.09 \mathrm{mmol})$. The reaction mixture was stirred for $2 \mathrm{~h}$ at $0{ }^{\circ} \mathrm{C}$ and quenched with $\mathrm{MeOH}(5 \mathrm{~mL})$. The solvents were removed under vacuo and the obtained residue was purified by flash column chromatography (silica gel, hexanes:EtOAc 10:1) to afford the corresponding pure TBS-protected alcohol $\left(550.1 \mathrm{mg}, 98 \%\right.$ ) as a colorless oil. $R_{\mathrm{f}}=0.72$ (silica gel, hexane:EtOAc 10:1); $[\alpha]_{\mathrm{D}}{ }^{32}=+28.5\left(c=0.85, \mathrm{CHCl}_{3}\right)$; IR (film) $v_{\max } 2955,2931,2142,2104,1745$, $1462,1389,1362,1258,1106,840,779 \mathrm{~cm}^{-1} ;{ }^{1} \mathrm{H}$ NMR $\left(500 \mathrm{MHz}, \mathrm{CDCl}_{3}\right) \delta=3.95$ (d, $J=9.8 \mathrm{~Hz}, 1$ H), 3.79 (s, $3 \mathrm{H}), 3.75$ (d, J = 9.8 Hz, $1 \mathrm{H}), 1.31$ (s, $3 \mathrm{H}), 0.88$ (s, $9 \mathrm{H}), 0.07$ (s, $3 \mathrm{H}), 0.05$ (s, $3 \mathrm{H}) \mathrm{ppm}$; ${ }^{13} \mathrm{C}$ NMR $\left(125 \mathrm{MHz}, \mathrm{CDCl}_{3}\right) \delta=171.8,69.5,67.6,52.6,25.6,19.7,18.1,-5.7,-5.8 \mathrm{ppm}$; HRMS (ESITOF): calcd for $\mathrm{C}_{11} \mathrm{H}_{23} \mathrm{~N}_{3} \mathrm{O}_{3} \mathrm{Si}[\mathrm{M}+\mathrm{Na}]^{+}$: 296.1401, found: 296.1387 .

To a solution of the above TBS-protected alcohol $(416.6 \mathrm{mg}, 1.52 \mathrm{mmol})$ in $\mathrm{MeOH}: \mathrm{H}_{2} \mathrm{O}(4: 1,30 \mathrm{~mL})$ was added, at room temperature, $\mathrm{LiOH} \cdot \mathrm{H}_{2} \mathrm{O}(200 \mathrm{mg}, 4.77 \mathrm{mmol})$. The reaction mixture was stirred at ambient temperature for $3 \mathrm{~h}$ and then quenched with a cold $\left(0^{\circ} \mathrm{C}\right)$ solution of aq $\mathrm{HCl}(1 \mathrm{~N}$, added until the reaction mixture reached $\mathrm{pH} \sim 1-2)$. The resulting reaction mixture was diluted with water $(50 \mathrm{~mL})$ and extracted with $\mathrm{Et}_{2} \mathrm{O}(4 \times 20 \mathrm{~mL})$. The combined organic layer was washed with brine $(20 \mathrm{~mL})$, dried with $\mathrm{MgSO}_{4}$, filtered and concentrated. The product was purified by flash column chromatography (silica gel, EtOAc:MeOH 9:1) to yield carboxylic acid 39d (379.2 $\mathrm{mg}, 100 \%)$ as a colorless oil. 39d: $R_{\mathrm{f}}$ $=0.61$ (silica gel, EtOAc: $\mathrm{MeOH} 9: 1) ;[\alpha]_{\mathrm{D}}^{32}=+12.4\left(c=0.31, \mathrm{CHCl}_{3}\right)$; IR (film) $v_{\max } 3420,2925$, $2855,2104,1719,1460,1258,1108,834,778 \mathrm{~cm}^{-1} ;{ }^{1} \mathrm{H}$ NMR $\left(500 \mathrm{MHz}, \mathrm{CDCl}_{3}\right) \delta=3.97(\mathrm{~d}, J=10.5$ $\mathrm{Hz}, 1 \mathrm{H}), 3.80$ (d, J = 10.5 Hz, $1 \mathrm{H}), 1.39$ (s, $3 \mathrm{H}), 0.90$ (s, $9 \mathrm{H}), 0.10$ (s, $3 \mathrm{H}), 0.09$ (s, $3 \mathrm{H}) \mathrm{ppm} ;{ }^{13} \mathrm{C}$ NMR $\left(125 \mathrm{MHz}, \mathrm{CDCl}_{3}\right) \delta=175.8,69.1,67.1,25.6,19.6,18.1,-5.6,-5.8$ ppm; HRMS (ESI-TOF): calcd for $\mathrm{C}_{10} \mathrm{H}_{21} \mathrm{~N}_{3} \mathrm{O}_{3} \mathrm{Si}[\mathrm{M}-\mathrm{H}]^{+}: 258.1279$, found: 258.1269. 


\section{Azido dipeptide 40a (Scheme 4):}

To a mixture of carboxylic acid 39a (629 mg, $4.15 \mathrm{mmol})$, crude amino ester 14a $(1.82 \mathrm{~g}, 4.57 \mathrm{mmol})$ and HOAt $(677.3 \mathrm{mg}, 4.98 \mathrm{mmol})$ in $\mathrm{CH}_{2} \mathrm{Cl}_{2}(42 \mathrm{~mL})$ was added $\mathrm{EDC}(956.2 \mathrm{mg}, 4.98 \mathrm{mmol})$ and

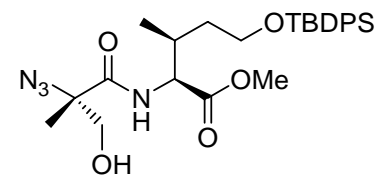

$i \operatorname{Pr}_{2} \mathrm{NEt}(2.1 \mathrm{~mL}, 12.4 \mathrm{mmol})$ at ambient temperature. The reaction mixture was stirred for $18 \mathrm{~h}$ and then the solvent was removed under reduced pressure. The remaining residue was partitioned between cold $\left(0{ }^{\circ} \mathrm{C}\right)$ aq $\mathrm{HCl}(1 \mathrm{~N}, 100 \mathrm{~mL})$ and $\mathrm{Et}_{2} \mathrm{O}(100 \mathrm{~mL})$, and the layers were separated. The aqueous phase was further extracted with $\mathrm{Et}_{2} \mathrm{O}$ $(2 \times 100 \mathrm{~mL})$ and the combined organic extracts were washed with brine $(150 \mathrm{~mL})$, dried over $\mathrm{MgSO}_{4}$, and concentrated, and the resulting residue was purified by flash column chromatography (silica gel, hexane:EtOAc $1: 1)$ to afford azido dipeptide $40 \mathrm{a}(1.46 \mathrm{~g}, 55 \%$ from 35$)$ as a colorless oil. $40 \mathrm{a}: R_{\mathrm{f}}=0.63$ (silica gel, hexanes:EtOAc 1:1); $[\alpha]_{\mathrm{D}}{ }^{32}=+12.8\left(c=0.585, \mathrm{CHCl}_{3}\right)$; IR (neat) $v_{\max } 3409,2932,2858$, 2110, 1743, 1664, 1518, 1428, 1111, 738, $703 \mathrm{~cm}^{-1} ;{ }^{1} \mathrm{H}$ NMR $\left(500 \mathrm{MHz}, \mathrm{CDCl}_{3}\right) \delta=7.65(\mathrm{~m}, 4 \mathrm{H})$, 7.38-7.43 ( m, $6 \mathrm{H}), 7.04$ (d, $J=8.8 \mathrm{~Hz}, 1 \mathrm{H}), 4.57(\mathrm{dd}, J=4.6,9.5 \mathrm{~Hz}, 1 \mathrm{H}), 3.80(\mathrm{ABq}, J=11.4$, 42.4 Hz, 2 H), 3.73 (s, 3 H), 3.65-3.75 (m, 2 H), 2.33 (m, 1 H), 1.69 (m, 1 H), 1.52 (s, 3 H), 1.32 (m, 1 H), $1.05(\mathrm{~s}, 9 \mathrm{H}), 0.89(\mathrm{~d}, J=6.9 \mathrm{~Hz}, 3 \mathrm{H}) \mathrm{ppm} ;{ }^{13} \mathrm{C} \mathrm{NMR}\left(125 \mathrm{MHz}, \mathrm{CDCl}_{3}\right) \delta=171.7,171.2,135.5$, 133.6, 129.6, 127.6, 67.5, 67.3, 61.1, 56.9, 52.3, 34.7, 32.6, 26.8, 19.1, 16.0 ppm; HRMS (ESI-TOF): calcd for $\mathrm{C}_{27} \mathrm{H}_{38} \mathrm{~N}_{4} \mathrm{O}_{5} \mathrm{Si}[\mathrm{M}+\mathrm{Na}]^{+}:$549.2504, found: 549.2504 .

\section{Azido dipeptide TES-ether 41a (Scheme 4):}

To a cold $\left(0{ }^{\circ} \mathrm{C}\right)$ stirred solution of azido dipeptide 40a $(2.28 \mathrm{~g}, 4.32 \mathrm{mmol})$ in $\mathrm{CH}_{2} \mathrm{Cl}_{2}(43 \mathrm{~mL})$ was added 2,6-lutidine $(1 \mathrm{~mL}, 8.66 \mathrm{mmol})$ followed by slow addition of TESOTf $(1.27 \mathrm{~mL}, 5.63 \mathrm{mmol})$.

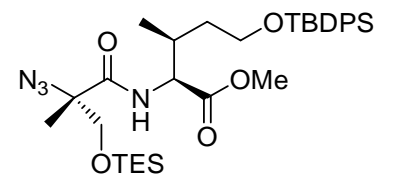

After stirring at $0{ }^{\circ} \mathrm{C}$ for $30 \mathrm{~min}$, the reaction mixture was quenched with $\mathrm{MeOH}(5 \mathrm{~mL})$, partitioned between $\mathrm{Et}_{2} \mathrm{O} / \mathrm{H}_{2} \mathrm{O}(1: 1,200 \mathrm{~mL})$ and basified with solid $\mathrm{NaHCO}_{3}$ until the $\mathrm{pH}$ was 8 . The layers were separated and the aqueous phase was further extracted with $\mathrm{Et}_{2} \mathrm{O}(2 \times 100 \mathrm{~mL})$. The combined organic phase was washed with brine $(150 \mathrm{~mL})$, dried over $\mathrm{MgSO}_{4}$, concentrated and purified by flash column chromatography (silica gel, hexanes:EtOAc 4:1) to afford azido dipeptide TES-ether $41 \mathrm{a}(2.7 \mathrm{~g}, 85 \%)$ as a colorless oil. 41a: $R_{\mathrm{f}}$ $=0.39$ (silica gel, hexanes:EtOAc 4:1); $[\alpha]_{\mathrm{D}}{ }^{32}=+23.0\left(c=0.775, \mathrm{CHCl}_{3}\right)$; IR (neat) $v_{\max } 3414,3070$, 
2956, 2876, 2111, 1744, 1686, 1512, 1459, 1428, 1387, 1267, 1207, 1111, 1007, 824, 738, $702 \mathrm{~cm}^{-1} ;{ }^{1} \mathrm{H}$ $\operatorname{NMR}\left(500 \mathrm{MHz}, \mathrm{CDCl}_{3}\right) \delta=7.75(\mathrm{~m}, 4 \mathrm{H}), 7.45-7.54(\mathrm{~m}, 6 \mathrm{H}), 7.21(\mathrm{~d}, J=8.8 \mathrm{~Hz}, 1 \mathrm{H}), 4.65(\mathrm{q}, J=$ 4.4, 8.8 Hz, $1 \mathrm{H}), 3.95$ ( q, J = 10.2 Hz, $2 \mathrm{H}), 3.80$ (s, $3 \mathrm{H}), 3.72-3.85$ (m, $2 \mathrm{H}), 2.40$ (m, $1 \mathrm{H}), 1.79$ (m, $1 \mathrm{H}), 1.61(\mathrm{~s}, 3 \mathrm{H}), 1.40(\mathrm{~m}, 1 \mathrm{H}), 1.15(\mathrm{~s}, 9 \mathrm{H}), 1.06$ (t, $J=7.9 \mathrm{~Hz}, 9 \mathrm{H}), 0.98(\mathrm{~d}, J=6.9 \mathrm{~Hz}, 3 \mathrm{H}), 0.72$ $(\mathrm{q}, J=7.9 \mathrm{~Hz}, 6 \mathrm{H}) \mathrm{ppm} ;{ }^{13} \mathrm{C} \mathrm{NMR}\left(125 \mathrm{MHz}, \mathrm{CDCl}_{3}\right) \delta=171.8,170.5,135.5,135.4,133.7,133.6$, 129.6, 127.6, 68.1 , 67.7, 61.2, 56.8, 52.1, 34.6, 32.6, 26.8, 19.1, 16.0, 6.6, 4.2 ppm; HRMS (ESI-TOF): calcd for $\mathrm{C}_{33} \mathrm{H}_{52} \mathrm{~N}_{4} \mathrm{O}_{5} \mathrm{Si}_{2}[\mathrm{M}+\mathrm{Na}]^{+}: 663.3368$, found: 663.3366 .

\section{Azido dipeptide 41d (Scheme 4):}

To a solution of carboxylic acid $39 \mathrm{~d}(422.4 \mathrm{mg}, 1.63 \mathrm{mmol})$ in $\mathrm{CH}_{2} \mathrm{Cl}_{2}(25 \mathrm{~mL})$ were added Ile-OMe 14d (385 mg, $2.12 \mathrm{mmol}), \operatorname{EDC}(343.4 \mathrm{mg}, 1.79 \mathrm{mmol})$, HOAt (244 mg, $1.79 \mathrm{mmol})$, and $\operatorname{Pr}_{2} \mathrm{NEt}$ (0.85

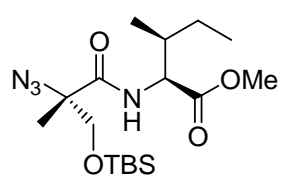
$\mathrm{mL}, 4.88 \mathrm{mmol}$ ) at room temperature. The reaction mixture was stirred at this temperature for $24 \mathrm{~h}$, and then concentrated, and the residue was subjected to flash column chromatography (silica gel, hexanes:EtOAc 4:1) to afford the azido dipeptide 41d (572.8 mg, 91\%) as a colorless oil. 41d: $R_{\mathrm{f}}=0.43$ (silica gel, hexanes:EtOAc 4:1); $[\alpha]_{\mathrm{D}}{ }^{32}=+38.6(c$ $\left.=0.86, \mathrm{CHCl}_{3}\right)$; IR (film) $v_{\max } 3416,2959,2932,2858,2119,1746,1688,1682,1514,1463,1384$, 1362, 1258, 1208, 1108, 1006, 840, $779 \mathrm{~cm}^{-1} ;{ }^{1} \mathrm{H}$ NMR $\left(500 \mathrm{MHz}, \mathrm{CDCl}_{3}\right) \delta=7.10(\mathrm{~d}, J=8.5 \mathrm{~Hz}, 1$ H), 4.51 (dd, $J=5.0,8.5 \mathrm{~Hz}, 1 \mathrm{H}), 3.87$ (d, $J=10.3 \mathrm{~Hz}, 1 \mathrm{H}), 3.82$ (d, J=10.3 Hz, $1 \mathrm{H}), 3.74$ (s, $3 \mathrm{H}$ ), 1.87-1.91 (m, 1 H), 1.50 (s, 3 H), 1.41-1.46 (m, 1 H), 1.15-1.21 (m, 1 H), 0.86-0.93 (m, 15 H), 0.09 (s, $3 \mathrm{H}), 0.08(\mathrm{~s}, 3 \mathrm{H}) \mathrm{ppm} ;{ }^{13} \mathrm{C} \mathrm{NMR}\left(125 \mathrm{MHz}, \mathrm{CDCl}_{3}\right) \delta=171.9,170.4,68.4,67.8,56.5,52.1,37.8$, 25.7, 25.1, 19.1, 18.2, 15.5, 11.5, -5.6, -5.7 ppm; HRMS (ESI-TOF): calcd for $\mathrm{C}_{17} \mathrm{H}_{34} \mathrm{~N}_{4} \mathrm{O}_{4} \mathrm{Si}[\mathrm{M}+\mathrm{H}]^{+}$: 387.2422, found: 387.2423 .

\section{Methylated azido dipeptide TES-ether 42a (Scheme 4):}

To a cold $\left(0^{\circ} \mathrm{C}\right)$ stirred solution of azido dipeptide TES-ether 41a (400 mg, $\left.0.62 \mathrm{mmol}\right)$ in dry THF (12 $\mathrm{mL}$ ) was added $\mathrm{NaH}$ (60\% suspension in mineral oil, $100 \mathrm{mg}, 2.50 \mathrm{mmol})$ followed by MeOTf (176 $\mu \mathrm{L}$,

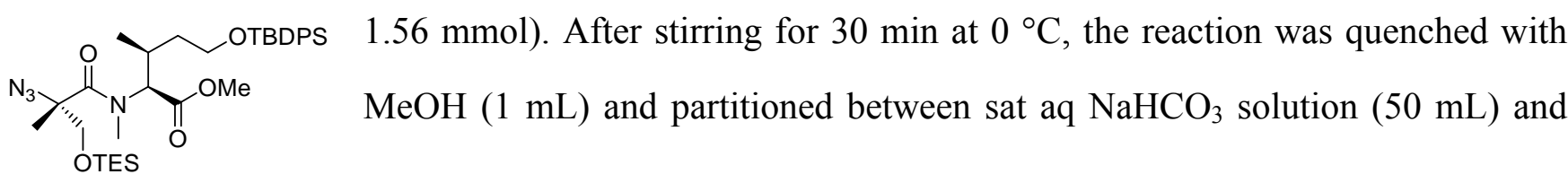


$\mathrm{Et}_{2} \mathrm{O}(50 \mathrm{~mL})$. The two layers were separated and the aqueous phase was further extracted with $\mathrm{Et}_{2} \mathrm{O}(2$ $\times 50 \mathrm{~mL})$. The combined organic phase was washed with brine $(100 \mathrm{~mL})$, dried over $\mathrm{MgSO}_{4}$, and concentrated, and the resulting residue was purified by flash column chromatography (silica gel, hexanes:EtOAc 5:1) to afford methylated azido dipeptide TES-ether 42a (2.7 g, 83\%) as a colorless oil. 42a: $R_{\mathrm{f}}=0.31$ (silica gel, hexanes:EtOAc 9:1); $[\alpha]_{\mathrm{D}}{ }^{32}=-35.4\left(c=0.60, \mathrm{CHCl}_{3}\right)$; IR (neat) $v_{\max } 3071$, 2954, 2876, 2111, 1742, 1644, 1470, 1428, 1392, 1256, 1111, 1007, 822, 739, $702 \mathrm{~cm}^{-1} ;{ }^{1} \mathrm{H}$ NMR (500 $\left.\mathrm{MHz}_{\mathrm{CDCl}}\right) \delta=7.06(\mathrm{~m}, 4 \mathrm{H}), 7.35-7.45(\mathrm{~m}, 6 \mathrm{H}), 4.80(\mathrm{~d}, J=10.6 \mathrm{~Hz}, 1 \mathrm{H}), 4.10(\mathrm{~d}, J=10.1 \mathrm{~Hz}, 1$ H), 3.86 (d, $J=10.1 \mathrm{~Hz}, 1 \mathrm{H}), 3.72$ (br s, $3 \mathrm{H}), 3.62-3.75$ (m, $2 \mathrm{H}), 3.29$ (br s, $3 \mathrm{H}), 2.39$ (m, $1 \mathrm{H}), 1.76$ $(\mathrm{m}, 1 \mathrm{H}), 1.51(\mathrm{br} \mathrm{s}, 3 \mathrm{H}), 1.26(\mathrm{~m}, 1 \mathrm{H}), 1.05(\mathrm{~s}, 9 \mathrm{H}), 0.97(\mathrm{t}, J=7.9 \mathrm{~Hz}, 9 \mathrm{H}), 0.91(\mathrm{~d}, J=6.5 \mathrm{~Hz}, 3$ $\mathrm{H}), 0.64(\mathrm{q}, J=7.9 \mathrm{~Hz}, 6 \mathrm{H}) \mathrm{ppm} ;{ }^{13} \mathrm{C} \mathrm{NMR}\left(125 \mathrm{MHz}, \mathrm{CDCl}_{3}\right) \delta=171.6,170.2,135.55,135.52$, $133.64,133.59,129.63,129.61,127.65,67.22,65.84,60.94,51.83,35.23,26.81,19.15,19.11,16.26$, 15.26, 6.65, 4.28, 4.18 ppm; HRMS (ESI-TOF): calcd for $\mathrm{C}_{34} \mathrm{H}_{54} \mathrm{~N}_{4} \mathrm{O}_{5} \mathrm{Si}_{2}[\mathrm{M}+\mathrm{Na}]^{+}: 677.3525$, found: 677.3531.

\section{Methylated azido dipeptide 42d (Scheme 4):}

A solution of azido dipeptide $41 \mathrm{~d}(572.8 \mathrm{mg}, 1.48 \mathrm{mmol})$ in DMF $(50 \mathrm{~mL})$ was cooled to $0{ }^{\circ} \mathrm{C}$. To this solution was sequentially added with stirring $\mathrm{NaH}$ (60\% suspension in mineral oil, $179 \mathrm{mg}, 4.48 \mathrm{mmol})$

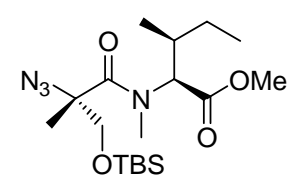
and $\mathrm{MeI}(0.37 \mathrm{~mL}, 5.93 \mathrm{mmol})$. The reaction mixture was stirred at $0{ }^{\circ} \mathrm{C}$ for $45 \mathrm{~min}$ and then quenched slowly with sat aq $\mathrm{NH}_{4} \mathrm{Cl}$ solution $(50 \mathrm{~mL})$. The resulting mixture was extracted with $\mathrm{Et}_{2} \mathrm{O}(3 \times 30 \mathrm{~mL})$ and the combined organic phase was washed with brine $(40 \mathrm{~mL})$, dried with $\mathrm{MgSO}_{4}$, filtered, and concentrated. The resulting residue was purified by flash column chromatography (silica gel, hexanes:EtOAc 4:1) to yield methylated azido dipeptide 42d (572.5 mg, 96\%) as a colorless oil. 42d: $R_{\mathrm{f}}=0.59$ (silica gel, hexanes:EtOAc 4:1); $[\alpha]_{\mathrm{D}}{ }^{32}$ $=-67.1\left(c=0.84, \mathrm{CHCl}_{3}\right)$; IR (film) $v_{\max } 2958,2932,2858,2112,1742,1650,1462,1393,1257,1200$, 1106, 1068, 1006, 838, $778 \mathrm{~cm}^{-1} ;{ }^{1} \mathrm{H}$ NMR $\left(600 \mathrm{MHz}, \mathrm{CDCl}_{3}\right) \delta=4.82(\mathrm{~d}, J=10.8 \mathrm{~Hz}, 1 \mathrm{H}), 4.10(\mathrm{bd}$, $J=9.6 \mathrm{~Hz}, 1 \mathrm{H}), 3.83(\mathrm{~d}, J=10.2 \mathrm{~Hz}, 1 \mathrm{H}), 3.72$ (bs, $3 \mathrm{H}), 3.26$ (bs, $3 \mathrm{H}), 2.04-2.05$ (m, $1 \mathrm{H}), 1.46$ (bm, $4 \mathrm{H}), 1.07-1.10(\mathrm{~m}, 1 \mathrm{H}), 0.97(\mathrm{~d}, J=6.6 \mathrm{~Hz}, 3 \mathrm{H}), 0.88-0.91(\mathrm{~m}, 12 \mathrm{H}), 0.10$ (s, $3 \mathrm{H}), 0.09$ (s, $3 \mathrm{H})$ ppm; ${ }^{13} \mathrm{C} \mathrm{NMR}\left(150 \mathrm{MHz}, \mathrm{CDCl}_{3}\right) \delta=172.0,171.2,69.5,67.3,61.9,51.8,32.7,31.9,30.3,25.7,25.1$, 
19.2, 18.2, 15.9, 10.6, -5.6, -5.7 ppm; HRMS (ESI-TOF): calcd for $\mathrm{C}_{18} \mathrm{H}_{36} \mathrm{~N}_{4} \mathrm{O}_{4} \mathrm{Si}[\mathrm{M}+\mathrm{H}]^{+}: 401.2578$, found: 401.2581 .

\section{Azido dipeptide 43a (Scheme 4):}

To a solution of methylated azido dipeptide TES-ether 42a (514.1 mg, $0.76 \mathrm{mmol})$ in THF (7.50 mL) was added aq $\mathrm{HCl}(1 \mathrm{~N}, 7.6 \mathrm{~mL}, 7.6 \mathrm{mmol})$ at ambient temperature. After stirring for $2 \mathrm{~h}$, the reaction

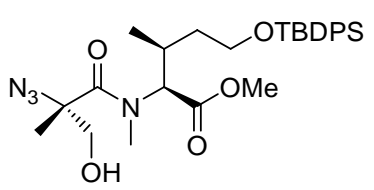

hexanes:EtOAc 2:1) to afford azido dipeptide 43a (332 mg, 100\%) as a colorless oil. 43a: $R_{\mathrm{f}}=0.17$ (silica gel, hexanes:EtOAc 4:1); $[\alpha]_{\mathrm{D}}^{32}=-28.2\left(c=1.09, \mathrm{CHCl}_{3}\right)$; IR (neat) $v_{\max } 3474,3071,2954$, 2858, 2114, 1741, 1634, 1472, 1428, 1391, 1253, 1112, 1086, 997, 823, 739, 703, $614 \mathrm{~cm}^{-1}$; ${ }^{1} \mathrm{H}$ NMR $\left(600 \mathrm{MHz}, \mathrm{CDCl}_{3}\right) \delta=7.65(\mathrm{~m}, 4 \mathrm{H}), 7.35-7.45(\mathrm{~m}, 6 \mathrm{H}), 4.78(\mathrm{~d}, J=10.8 \mathrm{~Hz}, 1 \mathrm{H}), 4.01(\mathrm{~d}, J=11.5$ Hz, $1 \mathrm{H}), 3.79(\mathrm{~d}, J=11.3 \mathrm{~Hz}, 1 \mathrm{H}), 3.73$ (br s, $3 \mathrm{H}), 3.63-3.82$ (m, $2 \mathrm{H}), 3.23$ (br s, $3 \mathrm{H}), 2.44$ (m, 1 H), $1.78(\mathrm{~m}, 1 \mathrm{H}), 1.36(\mathrm{br} \mathrm{s}, 3 \mathrm{H}), 1.17(\mathrm{~m}, 1 \mathrm{H}), 1.04(\mathrm{~s}, 9 \mathrm{H}), 0.95(\mathrm{~d}, J=6.2 \mathrm{~Hz}, 3 \mathrm{H}) \mathrm{ppm} ;{ }^{13} \mathrm{C} \mathrm{NMR}$ $\left(150 \mathrm{MHz}, \mathrm{CDCl}_{3}\right) \delta=172.5,171.4,135.5,133.6,133.5,129.6,127.7,70.3,67.0,62.5,60.8,51.9$, 32.0, 28.0, 26.8, 19.1, 19.0, 16.2 ppm; HRMS (ESI-TOF): calcd for $\mathrm{C}_{28} \mathrm{H}_{40} \mathrm{~N}_{4} \mathrm{O}_{5} \mathrm{Si}[\mathrm{M}+\mathrm{Na}]^{+}$: 563.2660, found: 563.2673 .

\section{Azido dipeptide 43d (Scheme 4):}

To a solution of methylated azido dipeptide 42d (900.6 mg, $2.248 \mathrm{mmol})$ in THF (30 mL) was added TBAF (1 M solution in THF, $6.74 \mathrm{~mL}, 6.74 \mathrm{mmol})$ at ambient temperature. The reaction mixture was

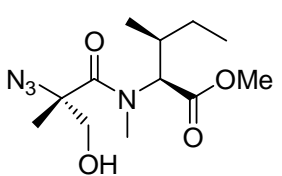
stirred at the same temperature for $1 \mathrm{~h}$ then quenched with sat aq $\mathrm{NH}_{4} \mathrm{Cl}$ solution $(15$ $\mathrm{mL})$ and extracted with EtOAc $(3 \times 20 \mathrm{~mL})$. The combined organic layers were washed with brine $(20 \mathrm{~mL})$, dried over $\mathrm{MgSO}_{4}$, filtered and concentrated. The resulting residue was purified by flash column chromatography (silica gel, hexanes:EtOAc 7:3) to yield azido dipeptide $43 \mathbf{d}(601.8 \mathrm{mg}, 98 \%)$ as a colorless oil. 43d: $R_{\mathrm{f}}=0.30$ (silica gel, hexanes:EtOAc 7:3); $[\alpha]_{\mathrm{D}}^{32}=-65.0\left(c=0.86, \mathrm{CHCl}_{3}\right)$; IR (film) $v_{\max } 3478,2967,2878,2113,1738,1644,1455,1395,1259$, 
1202, 1059, $1004 \mathrm{~cm}^{-1} ;{ }^{1} \mathrm{H}$ NMR $\left(600 \mathrm{MHz}, \mathrm{CDCl}_{3}\right) \delta=4.72(\mathrm{~d}, J=10.2 \mathrm{~Hz}, 1 \mathrm{H}), 3.95(\mathrm{dd}, J=5.4$, 11.4 Hz, 1 H), 3.69-3.72 (m, 1 H), 3.69 (s, 3 H), 3.24 (t, J = 7.0 Hz, 1 H), 3.20 (bs, 3 H), 2.08-2.10 (m, $1 \mathrm{H}), 1.46-1.50(\mathrm{~m}, 1 \mathrm{H}), 1.39(\mathrm{~s}, 3 \mathrm{H}), 1.11-1.15(\mathrm{~m}, 1 \mathrm{H}), 1.00(\mathrm{~d}, J=6.6 \mathrm{~Hz}, 3 \mathrm{H}), 0.91(\mathrm{t}, J=7.5$

$\mathrm{Hz}, 3 \mathrm{H}) \mathrm{ppm} ;{ }^{13} \mathrm{C} \mathrm{NMR}\left(75 \mathrm{MHz}, \mathrm{CDCl}_{3}\right) \delta=172.3,171.4,70.3,66.9,62.1,51.9,32.6,32.2,25.1$, 19.0, 15.9, 10.5 ppm; HRMS (ESI-TOF): calcd for $\mathrm{C}_{12} \mathrm{H}_{22} \mathrm{~N}_{4} \mathrm{O}_{4}[\mathrm{M}+\mathrm{H}]^{+}$: 287.1714, found: 287.1707.

\section{Azido ester 44a (Scheme 4):}

To a solution of Cbz-L-Ala-OH $(1.78 \mathrm{~g}, 8.0 \mathrm{mmol})$ in $\mathrm{CH}_{2} \mathrm{Cl}_{2}(40 \mathrm{~mL})$ was carefully added EDC (1.53 $\mathrm{g}, 8.0 \mathrm{mmol})$ at ambient temperature $\left(\mathrm{CO}_{2}\right.$ gas evolved). After stirring for $30 \mathrm{~min}$, a solution of azido

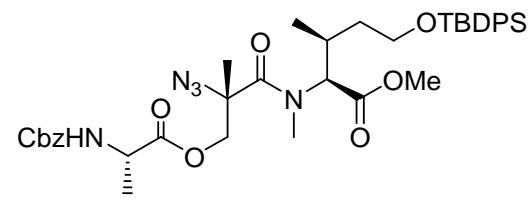
dipeptide 43a (445.6 mg, $0.8 \mathrm{mmol})$ in $\mathrm{CH}_{2} \mathrm{Cl}_{2}(40 \mathrm{~mL})$ was added and the reaction mixture was stirred at ambient temperature for $24 \mathrm{~h}$. The reaction mixture was concentrated and the so obtained residue was purified by flash column chromatography (silica gel, hexanes:EtOAc 1:1) to afford azido ester $44 a(527 \mathrm{mg}, 88 \%)$ as a colorless oil. $44 \mathrm{a}: \quad R_{\mathrm{f}}=0.62$ (silica gel, hexanes:EtOAc 1:1); $[\alpha]_{\mathrm{D}}^{32}=-31.8\left(c=0.915, \mathrm{CHCl}_{3}\right)$; IR (neat) $v_{\max } 3344,2953,2113,1735$, $1648,1508,1458,1428,1388,1252,1173,1111,1082,738,702 \mathrm{~cm}^{-1} ;{ }^{1} \mathrm{H} \mathrm{NMR}\left(500 \mathrm{MHz}, \mathrm{CDCl}_{3}\right) \delta=$ $7.67(\mathrm{~m}, 4 \mathrm{H}), 7.27-7.46(\mathrm{~m}, 11 \mathrm{H}), 5.39(\mathrm{~d}, J=6.9 \mathrm{~Hz}, 1 \mathrm{H}), 5.11(\mathrm{q}, J=12.2 \mathrm{~Hz}, 2 \mathrm{H}), 4.78(\mathrm{~d}, J=$ 10.7 Hz, 1 H), 4.66 (m, $1 \mathrm{H}), 4.44$ (m, $1 \mathrm{H}), 3.65-3.80$ (m, $2 \mathrm{H}), 3.73$ (br s, $3 \mathrm{H}), 3.30$ (br s, $3 \mathrm{H}), 2.42$ (m, $1 \mathrm{H}), 1.75(\mathrm{~m}, 1 \mathrm{H}), 1.50$ (br s, $3 \mathrm{H}), 1.44$ (d, J = $7.1 \mathrm{~Hz}, 3 \mathrm{H}), 1.17$ (m, $1 \mathrm{H}), 1.05$ (s, $9 \mathrm{H}), 0.93$ (d, $J=6.5 \mathrm{~Hz}, 3 \mathrm{H}) \mathrm{ppm} ;{ }^{13} \mathrm{C} \mathrm{NMR}\left(125 \mathrm{MHz}, \mathrm{CDCl}_{3}\right) \delta=172.1,169.8,155.4,136.2,135.5,135.4,133.5$, $133.4,129.6,128.4,128.1,128.0,127.6,69.6,66.8,65.8,60.8,51.8,49.6,35.2,29.6,26.8,19.1,18.4$, 16.2 ppm; HRMS (ESI-TOF): calcd for $\mathrm{C}_{39} \mathrm{H}_{51} \mathrm{~N}_{5} \mathrm{O}_{8} \mathrm{Si}[\mathrm{M}+\mathrm{Na}]^{+}:$768.3399, found: 768.3400 .

\section{Azido ester 44d (Scheme 4):}

To a solution of azido dipeptide 43d (142.5 mg, $0.498 \mathrm{mmol})$ in $\mathrm{CH}_{2} \mathrm{Cl}_{2}(10 \mathrm{~mL})$ were added Cbz-LAla-OH (166.5 mg, $0.750 \mathrm{mmol})$, EDC (191.0 mg, $0.996 \mathrm{mmol})$, HOAt (135.0 mg, $0.992 \mathrm{mmol})$, and

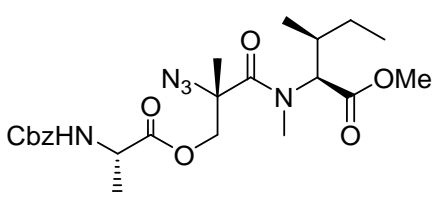
$i \operatorname{Pr}_{2} \mathrm{NEt}(0.260 \mathrm{~mL}, 1.493 \mathrm{mmol})$ at ambient temperature. The reaction mixture was stirred at the same temperature for $24 \mathrm{~h}$, and then concentrated 
to afford an oily residue which was subjected to flash column chromatography (silica gel, hexane:EtOAc 7:3) to give azido ester $44 d(235.3 \mathrm{mg}, 96 \%)$ as a colorless oil. 44d: $R_{\mathrm{f}}=0.26$ (silica gel, hexane:EtOAc 7:3); $[\alpha]_{\mathrm{D}}{ }^{32}=-47.9\left(c=1.12, \mathrm{CHCl}_{3}\right)$; IR (film) $v_{\max } 3346,2966,2878,2115,1734$, $1646,1524,1457,1398,1256,1203,1070,1001,742,698 \mathrm{~cm}^{-1} ;{ }^{1} \mathrm{H} \mathrm{NMR}\left(600 \mathrm{MHz}, \mathrm{CDCl}_{3}\right) \delta=$ 7.27-7.32 (m, $5 \mathrm{H}), 5.31(\mathrm{~d}, J=6.5 \mathrm{~Hz}, 1 \mathrm{H}), 5.05-5.11(\mathrm{~m}, 2 \mathrm{H}), 4.75(\mathrm{~d}, J=10.6 \mathrm{~Hz} .1 \mathrm{H}), 4.66$ (bd, $J$ $=8.8 \mathrm{~Hz}, 1 \mathrm{H}), 4.39-4.42(\mathrm{~m}, 1 \mathrm{H}), 4.34(\mathrm{bd}, J=8.8 \mathrm{~Hz}, 1 \mathrm{H}), 3.69$ (bs, $3 \mathrm{H}), 3.24$ (bs, $3 \mathrm{H}), 2.03$ (bm, $1 \mathrm{H}), 1.39-1.46(\mathrm{~m}, 7 \mathrm{H}), 1.08(\mathrm{bm}, 1 \mathrm{H}), 0.95(\mathrm{~d}, J=6.6 \mathrm{~Hz}, 3 \mathrm{H}), 0.86(\mathrm{bm}, 3 \mathrm{H}) \mathrm{ppm} ;{ }^{13} \mathrm{C}$ NMR $(150$ $\left.\mathrm{MHz}, \mathrm{CDCl}_{3}\right) \delta=172.2,169.6,155.5,136.2,128.5,128.1,128.1,128.1,69.8,66.9,62.1,51.9,49.6$, 49.5, 32.7, 32.1, 30.3, 25.2, 19.4, 18.5, 18.5, 15.6, 10.5 ppm; HRMS (ESI-TOF): calcd for $\mathrm{C}_{23} \mathrm{H}_{33} \mathrm{~N}_{5} \mathrm{O}_{7}$ $[\mathrm{M}+\mathrm{H}]^{+}:$492.2453, found: 492.2452 .

\section{Oxazoline 47a (Scheme 4):}

To a cold $\left(0^{\circ} \mathrm{C}\right)$ stirred solution of azido ester $44 \mathrm{a}(527 \mathrm{mg}, 0.71 \mathrm{mmol})$ in toluene $(2 \mathrm{~mL})$ was slowly added $\mathrm{PMe}_{3}(1 \mathrm{M}$ in toluene, $0.78 \mathrm{~mL}, 0.78 \mathrm{mmol})$. After stirring for $2 \mathrm{~min}$ at $0{ }^{\circ} \mathrm{C}$, the reaction mixture

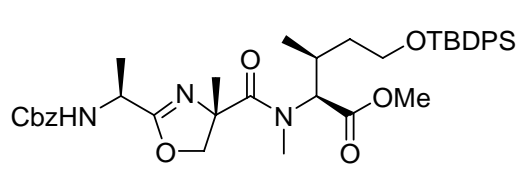
was directly purified by flash column chromatography (silica gel, hexanes:EtOAc 1:1) to afford oxazoline $47 \mathbf{a}(305 \mathrm{mg}, 79 \%)$ as a colorless oil. 47a: $R_{\mathrm{f}}=0.42$ (silica gel, hexanes:EtOAc 3:2); $[\alpha]_{\mathrm{D}}{ }^{32}=-$ $33.2\left(c=0.36, \mathrm{CHCl}_{3}\right)$; IR (neat) $v_{\max } 3329,2933,2849,1732,1660,1637,1508,1452,1235,1111$, 1085, 738, $702 \mathrm{~cm}^{-1} ;{ }^{1} \mathrm{H}$ NMR $\left(600 \mathrm{MHz}, \mathrm{CDCl}_{3}\right.$, ca 2:1 ratio of rotamers, only signals for the major isomer are noted) $\delta=7.64(\mathrm{~m}, 4 \mathrm{H}), 7.27-7.45(\mathrm{~m}, 11 \mathrm{H}), 5.44(\mathrm{~d}, J=10.5 \mathrm{~Hz}, 1 \mathrm{H}), 5.11(\mathrm{~m}, 2 \mathrm{H})$, $4.85(\mathrm{~d}, J=10.7,1 \mathrm{H}), 4.44(\mathrm{~m}, 1 \mathrm{H}), 4.12(\mathrm{~d}, J=9.1 \mathrm{~Hz}, 1 \mathrm{H}), 3.60-3.77(\mathrm{~m}, 2 \mathrm{H}), 3.71(\mathrm{~s}, 3 \mathrm{H}), 3.39$ (br s, 3 H), 2.37 (m, $1 \mathrm{H}), 1.55-1.79(\mathrm{~m}, 2 \mathrm{H}), 1.47$ (s, $3 \mathrm{H}), 1.36$ (d, $J=6.9 \mathrm{~Hz}, 3 \mathrm{H}), 1.09-1.23$ (m, 1 $\mathrm{H}), 1.04(\mathrm{~s}, 9 \mathrm{H}), 0.89(\mathrm{~d}, J=6.7 \mathrm{~Hz}, 3 \mathrm{H}) \mathrm{pm} ;{ }^{13} \mathrm{C} \mathrm{NMR}\left(150 \mathrm{MHz}, \mathrm{CDCl}_{3}\right.$, ca 2:1 ratio of rotamers, only signals for the major isomer are noted) $\delta=174.2,173.2,172.2,171.5,164.5,155.5,136.2,135.5$, $133.6,133.4,129.8,129.6,128.5,128.4,128.3,128.2,128.1,128.0,127.7,79.6,78.5,75.4,66.9,64.4$, 60.9, 51.8, 45.5, 36.1, 34.9, 32.3, 30.8, 28.0, 27.4, 26.8, 25.2, 19.7, 16.3 ppm; HRMS (ESI-TOF): calcd for $\mathrm{C}_{39} \mathrm{H}_{51} \mathrm{~N}_{3} \mathrm{O}_{7} \mathrm{Si}[\mathrm{M}+\mathrm{Na}]^{+}:$724.3388, found: 724.3387 . 


\section{Oxazoline 47d (Scheme 4):}

To a stirred solution of azido ester $44 \mathrm{~d}(112.7 \mathrm{mg}, 0.229 \mathrm{mmol})$ in toluene $(10 \mathrm{~mL})$ was added at room temperature $\mathrm{PMe}_{3}(1 \mathrm{M}$ in toluene, $0.294 \mathrm{~mL}, 0.294 \mathrm{mmol})$. The reaction mixture was stirred at ambient

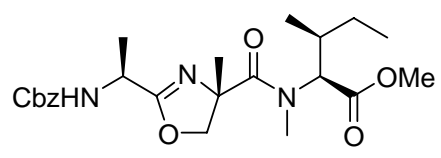
temperature for $2 \mathrm{~h}$ and then the solvents were evaporated. The resulting residue was purified by flash column chromatography (silica gel, hexanes:EtOAc 7:3) to yield oxazoline $\mathbf{4 7 d}(86.2 \mathrm{mg}, 83 \%)$ as a colorless oil. 47d: $R_{\mathrm{f}}=0.25$ (silica gel, hexanes:EtOAc 7:3); $[\alpha]_{\mathrm{D}}{ }^{32}=-54.2\left(c=1.06, \mathrm{CHCl}_{3}\right)$; IR (neat) $v_{\max }$ $3330,2965,2877,1730,1632,1518,1454,1401,1313,1246,1084,1052,983,740,698 \mathrm{~cm}^{-1} ;{ }^{1} \mathrm{H}$ NMR $\left(600 \mathrm{MHz}, \mathrm{CDCl}_{3}\right.$, ca 2:1 ratio of rotamers, only signals for the major isomer are noted) $\delta=7.31-7.36$ (m, $5 \mathrm{H}), 5.44(\mathrm{bd}, J=10.8 \mathrm{~Hz}, 1 \mathrm{H}), 5.07-5.16(\mathrm{~m}, 3 \mathrm{H}), 4.84$ (d, $J=10.8 \mathrm{~Hz}, 1 \mathrm{H}), 4.41-4.45(\mathrm{~m}, 1$ H), 4.00 (d, J = 9.0 Hz, 1 H), 3.69 (s, 3 H), 3.32 (s, 3 H), 1.93-2.04 (m, 1 H), 1.48 (s, 3 H), 1.34 (d, J = $6.6 \mathrm{~Hz}, 3 \mathrm{H}), 1.28-1.40(\mathrm{~m}, 1 \mathrm{H}), 1.00-1.10(\mathrm{~m}, 1 \mathrm{H}), 0.94-0.98$ (m, $3 \mathrm{H}), 0.84$ (t, J = 7.2 Hz, $3 \mathrm{H}) \mathrm{ppm}$; ${ }^{13} \mathrm{C}$ NMR (150 MHz, $\mathrm{CDCl}_{3}$, ca 2:1 ratio of rotamers, only signals for the major isomer are noted): $\delta=$ $174.3,173.0,172.3,167.5,155.5,136.5,128.5,128.4,128.3,128.2,128.0,128.0,79.6,75.4,66.9,64.5$, 61.6, 51.7, 45.4, 35.7, 32.6, 30.8, 27.4, 26.3, 25.1, 19.6, 15.9, 15.2, 14.1, 11.9 ppm; HRMS (ESI-TOF): calcd for $\mathrm{C}_{23} \mathrm{H}_{33} \mathrm{~N}_{3} \mathrm{O}_{6}[\mathrm{M}+\mathrm{H}]^{+}: 448.2442$, found: 448.2440 .

\section{Thioamide 9a (Scheme 4):}

To a thoroughly argon-purged stirred solution of oxazoline $47 \mathbf{a}(148.9 \mathrm{mg}, 0.212 \mathrm{mmol})$ in EtOH (5 $\mathrm{mL}$ ) was added $20 \% \mathrm{Pd}(\mathrm{OH})_{2} / \mathrm{C}(45 \mathrm{mg}, 30 \% \mathrm{w} / \mathrm{w})$ at ambient temperature. The reaction mixture was

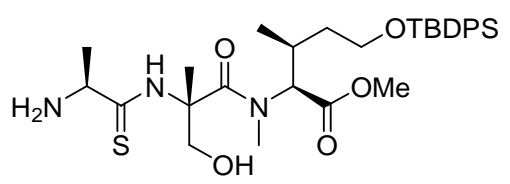
further purged with argon and the flask refilled with hydrogen $(1 \mathrm{~atm}$, balloon). The reaction mixture was stirred for $3 \mathrm{~h}$ and then the solution was filtered through a pad of celite, the pad was thoroughly washed with $\mathrm{MeOH}$ and the filtrate was concentrated to afford the desired crude amino oxazoline (106 mg, $88 \%$ ) as a pale yellow oil which was used without further purification; $R_{\mathrm{f}}=0.1$ (silica gel, hexanes:EtOAc 3:7); ${ }^{1} \mathrm{H}$ NMR (600 MHz, $\mathrm{CDCl}_{3}$, ca 2:1 ratio of rotamers, only signals for the major isomer are noted) $\delta=7.63(\mathrm{~m}, 4 \mathrm{H}), 7.31-7.42(\mathrm{~m}, 6 \mathrm{H}), 5.50(\mathrm{~d}, J=10.4 \mathrm{~Hz}, 1 \mathrm{H}), 5.00(\mathrm{dd}, J=8.9$, $20.3 \mathrm{~Hz}, 1 \mathrm{H}), 4.84$ (d, $J=10.4 \mathrm{~Hz}, 1 \mathrm{H}), 4.06$ (dd, $J=8.9,45.4 \mathrm{~Hz}, 1 \mathrm{H}), 3.60-3.79$ (m, $2 \mathrm{H}), 3.69$ (s, 
$3 \mathrm{H}), 3.40(\mathrm{~s}, 3 \mathrm{H}), 2.36(\mathrm{~m}, 1 \mathrm{H}), 1.56-1.78(\mathrm{~m}, 1 \mathrm{H}), 1.32-1.55(\mathrm{~m}, 6 \mathrm{H}), 1.09-1.25(\mathrm{~m}, 1 \mathrm{H}), 1.03$ (s, $9 \mathrm{H}), 0.89(\mathrm{dd}, J=6.3,14.9 \mathrm{~Hz}, 3 \mathrm{H}) \mathrm{ppm} ;{ }^{13} \mathrm{C} \mathrm{NMR}\left(150 \mathrm{MHz}, \mathrm{CDCl}_{3}\right.$, ca 2:1 ratio of rotamers, only signals for the major isomer are noted) $\delta=174.3,172.2,169.7,135.4,133.5,133.4,129.6,127.6,79.6$, $75.5,64.6,61.8,61.0,60.8,58.1,51.9,45.3,35.9,35.0,32.2,30.8,29.8,28.0,26.8,25.2,20.3,19.1$, 18.3, 16.3 ppm; HRMS (ESI-TOF): calcd for $\mathrm{C}_{31} \mathrm{H}_{45} \mathrm{~N}_{3} \mathrm{O}_{5} \mathrm{Si}[\mathrm{M}+\mathrm{Na}]^{+}:$590.3021, found: 590.3030 .

Through a solution of the above amino oxazoline $(44.1 \mathrm{mg}, 0.141 \mathrm{mmol})$ in $\mathrm{MeOH}: \mathrm{Et} 3 \mathrm{~N}(2: 1,4.5 \mathrm{~mL})$ was bubbled $\mathrm{H}_{2} \mathrm{~S}$ (g) for $1 \mathrm{~h}$ at ambient temperature. The $\mathrm{H}_{2} \mathrm{~S}$ (g) stream was stopped, and the septa closing the reaction flask was sealed. The reaction mixture was stirred at room temperature for $72 \mathrm{~h}$ and then concentrated. The crude thioamide 9a was dried under vacuo and was used without further purification.

\section{Thioamide 9d (Scheme 4):}

A solution of oxazoline $47 \mathrm{~d}(114.6 \mathrm{mg}, 0.256 \mathrm{mmol})$ in EtOH $(10 \mathrm{~mL})$ was thoroughly degassed by bubbling argon through it and then treated with $10 \% \mathrm{Pd}(\mathrm{OH})_{2} / \mathrm{C}(114 \mathrm{mg}, 100 \% \mathrm{w} / \mathrm{w})$ at ambient

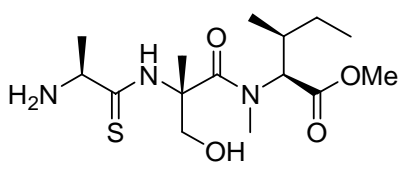
temperature. The reaction mixture was degassed once again by bubbling argon and then filled with $\mathrm{H}_{2}(1 \mathrm{~atm}$, balloon) and stirred at room temperature for $2 \mathrm{~h}$. The mixture was filtered through a short pad of celite and concentrated to obtain the desired amino oxazoline $(79.4 \mathrm{mg}, 100 \%)$ as a colorless oil which was used in the next step without further purification. $R_{\mathrm{f}}=0.24$ (silica gel, MeOH:EtOAc 1:9); $[\alpha]_{\mathrm{D}}{ }^{32}=-33.2(c$ $=0.84, \mathrm{CHCl}_{3}$ ); IR (neat) $v_{\max } 3413,2966,1737,1631,1402,1249,1196,1002,950 \mathrm{~cm}^{-1} ;{ }^{1} \mathrm{H}$ NMR $\left(500 \mathrm{MHz}, \mathrm{CDCl}_{3}\right.$, ca 2:1 ratio of rotamers, only signals for the major isomer are noted) $\delta=8.90$ (bs, 2 H), $5.03(\mathrm{~d}, J=9.0 \mathrm{~Hz}, 1 \mathrm{H}), 4.82(\mathrm{~d}, J=11.0 \mathrm{~Hz}, 1 \mathrm{H}), 4.09-4.29(\mathrm{~m}, 2 \mathrm{H}), 3.73(\mathrm{~s}, 3 \mathrm{H}), 2.93(\mathrm{~s}, 3 \mathrm{H})$, 1.85-2.06 (m, $1 \mathrm{H}), 1.66(\mathrm{~d}, J=7.0 \mathrm{~Hz}, 3 \mathrm{H}), 1.52(\mathrm{~s}, 3 \mathrm{H}), 1.32-1.48(\mathrm{~m}, 1 \mathrm{H}), 0.88-1.40(\mathrm{~m}, 4 \mathrm{H})$,

0.92-0.88 (m, $3 \mathrm{H}) \mathrm{ppm} ;{ }^{13} \mathrm{C} \mathrm{NMR}\left(125 \mathrm{MHz}, \mathrm{CDCl}_{3}\right.$, ca 2:1 ratio of rotamers, only signals for the major isomer are noted) $\delta=174.1,172.8,171.3,80.1,78.4,75.7,75.5,64.9,61.6,52.2,51.6,44.9$, 44.8, 35.0, 32.6, 32.4, 30.6, 27.0, 25.8, 25.1, 24.8, 16.6, 15.8, 15.6, 12.1, 11.6, 10.8 ppm; HRMS (ESITOF): calcd for $\mathrm{C}_{15} \mathrm{H}_{27} \mathrm{~N}_{3} \mathrm{O}_{4}[\mathrm{M}+\mathrm{H}]^{+}:$314.2074, found: 314.2068 . 
Thioamide 9d was prepared from the above amino oxazoline by a similar procedure as that described for the preparation of thioamide 9a and was used crude in the next step.

\section{Azido ester carboxylic acid 12 (Scheme 5):}

A solution of $\mathrm{N}_{3}$-Ala-OH $16(813.0 \mathrm{mg}, 7.070 \mathrm{mmol})$ in $\mathrm{DMF}(7 \mathrm{~mL})$ was cooled to $0{ }^{\circ} \mathrm{C}$ and $(\mathrm{COCl})_{2}$ $(0.55 \mathrm{~mL}, 6.305 \mathrm{mmol})$ was very carefully (violent evolution of gas!) added with stirring. Once the

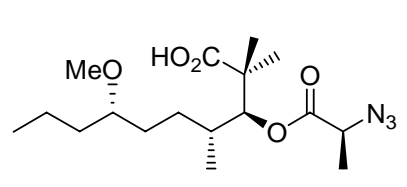
addition was complete, the reaction mixture was warmed to room temperature. In a second flask containing decanoic acid $15(228.8 \mathrm{mg}, 0.879 \mathrm{mmol})$ in DMF (5 mL) was added 4-DMAP (54 mg, $0.442 \mathrm{mmol})$ and $\mathrm{Et}_{3} \mathrm{~N}$ (1.84 mL, $13.201 \mathrm{mmol}$ ), and the mixture was cooled to $0{ }^{\circ} \mathrm{C}$. The in situ formed acid chloride was then carefully added to the hydroxy decanoic acid mixture at $0{ }^{\circ} \mathrm{C}$ with stirring. The reaction mixture was heated to 50 ${ }^{\circ} \mathrm{C}$ and stirred at that temperature for $24 \mathrm{~h}$. The resulting mixture was cooled to room temperature and then quenched with aq $\mathrm{HCl}(1 \mathrm{~N}, 10 \mathrm{~mL})$ and extracted with $\mathrm{Et}_{2} \mathrm{O}(3 \times 25 \mathrm{~mL})$. The combined organic layers were washed with brine $(25 \mathrm{~mL})$, dried with $\mathrm{MgSO}_{4}$, filtered and concentrated. The resulting residue was purified by flash column chromatography (silica gel, hexanes:EtOAc:AcOH 8:2:0.1) to yield azido ester carboxylic acid $12(288.4 \mathrm{mg}, 94 \%)$ as a colorless oil. 12: $R_{\mathrm{f}}=0.33$ (silica gel,

hexanes:EtOAc:AcOH 8:2:0.1); $[\alpha]_{\mathrm{D}}{ }^{32}=+20.2\left(c=1.01, \mathrm{CHCl}_{3}\right)$; IR (neat) $v_{\max } 2922,2106,1742$, 1457, 1381, 1256, 1193, 1086, $948 \mathrm{~cm}^{-1} ;{ }^{1} \mathrm{H}$ NMR (500 MHz, $\left.\mathrm{CDCl}_{3}\right) \delta=9.93(\mathrm{bs}, 1 \mathrm{H}), 5.18(\mathrm{~d}, J=$ $3.5 \mathrm{~Hz}, 1 \mathrm{H}), 3.92(\mathrm{q}, J=7.0 \mathrm{~Hz}, 1 \mathrm{H}), 3.27$ (s, $3 \mathrm{H}), 3.08-3.10(\mathrm{~m}, 1 \mathrm{H}), 1.77-1.79(\mathrm{~m}, 1 \mathrm{H}), 1.46$ (d, $J$ $=7.5 \mathrm{~Hz}, 3 \mathrm{H}), 1.22-1.51(\mathrm{~m}, 8 \mathrm{H}), 1.21(\mathrm{~s}, 3 \mathrm{H}), 1.19(\mathrm{~s}, 3 \mathrm{H}), 0.87-0.88(\mathrm{~m}, 6 \mathrm{H}) \mathrm{ppm} ;{ }^{13} \mathrm{C}$ NMR $(125$ $\left.\mathrm{MHz}, \mathrm{CDCl}_{3}\right): \delta=181.3,170.6,80.7,80.6,57.5,56.3,46.6,35.6,34.3,31.4,30.9,22.4,20.9,18.4$, 16.8, 15.2, 14.2 ppm; HRMS (ESI-TOF): calcd for $\mathrm{C}_{17} \mathrm{H}_{31} \mathrm{~N}_{3} \mathrm{O}_{5}[\mathrm{M}+\mathrm{Na}]^{+}:$380.2156, found: 380.2151 .

\section{Azido methyl ester 8d (Scheme 5):}

To a stirring solution of the crude thioamide 9d (prepared as described above) in DMF (15 mL) were sequentially added azido ester carboxylic acid 12 (110.0 mg, 0.308 mmol), PyAOP (321.0 mg, 0.616 $\mathrm{mmol})$, and $\operatorname{Pr}_{2} \mathrm{NEt}(0.107 \mathrm{~mL}, 0.614 \mathrm{mmol})$ at ambient temperature. The reaction mixture was stirred at room temperature for $18 \mathrm{~h}$ then quenched with sat aq $\mathrm{NH}_{4} \mathrm{Cl}$ solution $(10 \mathrm{~mL})$. The resulting mixture 
was extracted with EtOAc $(3 \times 50 \mathrm{~mL})$ and the combined layers were washed with brine $(50 \mathrm{~mL})$, dried with $\mathrm{MgSO}_{4}$, filtered and concentrated. The resulting residue was purified by flash column

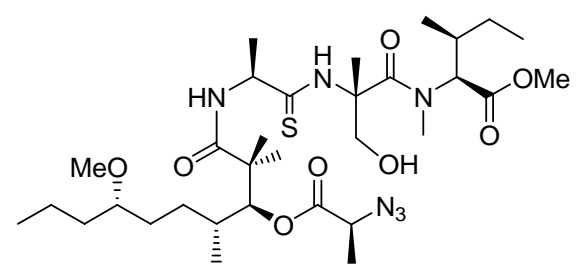
chromatography (silica gel, hexanes:EtOAc 1:2) to yield azido methyl ester 8d (134.2 mg, 63\% based on azido ester carboxylic acid 12) as a yellow oil. 8d: $R_{\mathrm{f}}=0.14$ (silica gel, hexanes:EtOAc $1: 2) ;[\alpha]_{\mathrm{D}}^{32}=+8.6\left(c=2.07, \mathrm{CHCl}_{3}\right) ;$ IR (film) $v_{\max } 3246,2965$, 2995, 2874, 2100, 1739, 1638, 1502, 1457, 1372, 1261, 1201, 1095, 1040, 940, $583 \mathrm{~cm}^{-1}$; ${ }^{1} \mathrm{H}$ NMR (500 $\mathrm{MHz}, \mathrm{CDCl}_{3}$, ca 2:1 ratio of rotamers, only signals for the major isomer are noted) $\delta=8.94(\mathrm{~s}, 1 \mathrm{H})$, $6.98(\mathrm{bs}, 1 \mathrm{H}), 5.13(\mathrm{~d}, J=3.3 \mathrm{~Hz}, 1 \mathrm{H}), 4.92(\mathrm{bd}, J=7.0 \mathrm{~Hz}, 1 \mathrm{H}), 4.68-4.73(\mathrm{~m}, 1 \mathrm{H}), 4.18(\mathrm{bm}, 1 \mathrm{H})$, 4.04-4.09 (m, 1 H), $4.00(\mathrm{dd}, J=7.1,14.1 \mathrm{~Hz}, 1 \mathrm{H}), 3.67$ (s, $3 \mathrm{H}), 3.67$ (bm, $1 \mathrm{H}), 3.26$ (s, $3 \mathrm{H}), 3.05-$ $3.10(\mathrm{~m}, 1 \mathrm{H}), 3.01(\mathrm{bs}, 3 \mathrm{H}), 1.91-1.96(\mathrm{~m}, 1 \mathrm{H}), 1.75-1.81(\mathrm{~m}, 1 \mathrm{H}), 1.66(\mathrm{~s}, 3 \mathrm{H}), 1.51(\mathrm{~d}, J=7.0 \mathrm{~Hz}$ $3 \mathrm{H}), 1.40(\mathrm{~d}, J=6.6 \mathrm{~Hz}, 3 \mathrm{H}), 1.19(\mathrm{bs}, 6 \mathrm{H}), 1.17-1.66(\mathrm{~m}, 9 \mathrm{H}), 1.03-1.11(\mathrm{~m}, 1 \mathrm{H}), 0.93(\mathrm{~d}, J=6.6$ $\mathrm{Hz}, 3 \mathrm{H}), 0.84-0.88(\mathrm{~m}, 9 \mathrm{H}) \mathrm{ppm} ;{ }^{13} \mathrm{C} \mathrm{NMR}\left(150 \mathrm{MHz}, \mathrm{CDCl}_{3}\right.$, ca 2:1 ratio of rotamers, only signals for the major isomer are noted) $\delta=203.3,175.8,171.9,170.3,81.5,80.4,63.8,57.8,56.3,55.2,51.7$, $46.5,46.4,35.5,34.1,33.2,31.3,31.2,30.8,30.3,25.9,22.7,22.4,21.5,20.2,18.4,15.9,15.1,15.0$, 14.2 ppm; HRMS (ESI-TOF): calcd for $\mathrm{C}_{32} \mathrm{H}_{58} \mathrm{~N}_{6} \mathrm{O}_{8} \mathrm{~S}[\mathrm{M}+\mathrm{H}]^{+}: 687.4109$, found: 687.4113.

\section{Azido ester thioamide peptide 49d (Scheme 5):}

A solution of azido methyl ester $8 d(15 \mathrm{mg}, 0.022 \mathrm{mmol})$ in $\mathrm{CH}_{2} \mathrm{Cl}_{2}(2 \mathrm{~mL})$ was cooled to $0{ }^{\circ} \mathrm{C}$ and $2,6-$ lutidine $(3.8 \mu \mathrm{L}, 0.033 \mathrm{mmol})$ and $\operatorname{TBSOTf}(7.5 \mu \mathrm{L}, 0.026 \mathrm{mmol})$ were sequentially added with stirring.

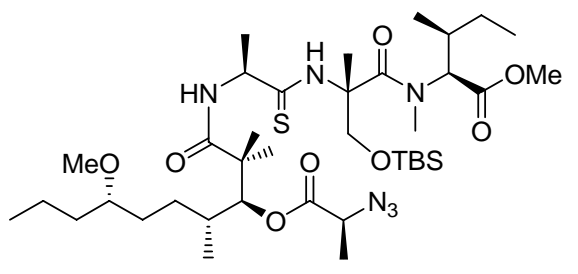

The reaction mixture was stirred for $2 \mathrm{~h}$ at $0{ }^{\circ} \mathrm{C}$ and then quenched with $\mathrm{MeOH}(3 \mathrm{~mL})$. The solvents were removed under vacuo and the product was purified by flash column chromatography (silica gel, hexanes:EtOAc 3:1) to afford azido ester thioamide peptide 49d $(17 \mathrm{mg}, 99 \%)$ as a colorless oil. 49d: $R_{\mathrm{f}}=0.44$ (silica gel, hexanes:EtOAc $\left.2: 1\right) ;[\alpha]_{\mathrm{D}}^{32}=-75.1(c=0.80$, $\mathrm{CHCl}_{3}$ ); IR (film) $v_{\max } 3271,2942,2861,2096,1736,1637,1507,1454,1384,1255,1190,1090,1063$, 1002, $837 \mathrm{~cm}^{-1} ;{ }^{1} \mathrm{H} \mathrm{NMR}\left(500 \mathrm{MHz}, \mathrm{CDCl}_{3}\right.$, ca 5:1 ratio of rotamers, only signals for the major isomer are noted) $\delta=8.25(\mathrm{~s}, 1 \mathrm{H}), 7.15(\mathrm{~d}, J=2.0 \mathrm{~Hz}, 1 \mathrm{H}), 5.07(\mathrm{~d}, J=3.5 \mathrm{~Hz}, 1 \mathrm{H}), 4.93-4.96(\mathrm{~m}, 1 \mathrm{H})$, 
4.66-4.71 (m, $1 \mathrm{H}), 4.54(\mathrm{~d}, J=10.0 \mathrm{~Hz}, 1 \mathrm{H}), 4.28(\mathrm{t}, J=6.5 \mathrm{~Hz}, 1 \mathrm{H}), 4.14(\mathrm{q}, J=7.0 \mathrm{~Hz}, 1 \mathrm{H}), 3.95$ $(\mathrm{d}, J=10.0 \mathrm{~Hz}, 1 \mathrm{H}), 3.67(\mathrm{~s}, 3 \mathrm{H}), 3.26(\mathrm{~s}, 3 \mathrm{H}), 3.05-3.07(\mathrm{~m}, 1 \mathrm{H}), 2.98(\mathrm{~s}, 3 \mathrm{H}), 1.89-1.91(\mathrm{~m}, 1 \mathrm{H})$, 1.81-1.84 (m, $1 \mathrm{H}), 1.69$ (s, $3 \mathrm{H}), 1.54$ (d, $J=7.0 \mathrm{~Hz}, 3 \mathrm{H}), 1.45$ (d, J = 6.5 Hz, $3 \mathrm{H}), 1.23-1.50$ (m, 9 H), 1.19 (s, 3 H), $1.16(\mathrm{~s}, 3 \mathrm{H}), 1.04-1.07$ (m, $1 \mathrm{H}), 0.93$ (d, J=6.5 Hz, $3 \mathrm{H}), 0.85$ (s, $9 \mathrm{H}), 0.83-0.89$

$(\mathrm{m}, 9 \mathrm{H}), 0.03(\mathrm{~s}, 3 \mathrm{H}), 0.02(\mathrm{~s}, 3 \mathrm{H}) \mathrm{ppm} ;{ }^{13} \mathrm{C} \mathrm{NMR}\left(125 \mathrm{MHz}, \mathrm{CDCl}_{3}\right.$, ca 5:1 ratio of rotamers, only signals for the major isomer are noted) $\delta=202.5,174.5,171.8,171.1,170.3,82.2,80.5,64.4,62.9$, $61.5,57.8,57.5,56.4,54.7,51.7,45.8,35.6,34.3,33.1,31.1,30.9,25.8,25.6,23.9,23.0,21.7,20.4$, 18.5, 18.4, 18.2, 17.1, 16.9, 15.9, 14.5, 14.3, 10.6, -5.5, -5.6 ppm; HRMS (ESI-TOF): calcd for $\mathrm{C}_{38} \mathrm{H}_{72} \mathrm{~N}_{6} \mathrm{O}_{8} \mathrm{SSi}[\mathrm{M}+\mathrm{Na}]^{+}: 823.4794$, found: 823.4790 .

\section{Thioamide cyclic peptide 51d (Scheme 5):}

To a solution of azido ester thioamide peptide $49 \mathrm{~d}(47 \mathrm{mg}, 0.058 \mathrm{mmol})$ in 1,2 dichloroethane $(2 \mathrm{~mL})$ was added $\mathrm{Me}_{3} \mathrm{SnOH}\left(632 \mathrm{mg}, 3.492 \mathrm{mmol}\right.$ ) and the reaction mixture was heated at $75^{\circ} \mathrm{C}$ and stirred at

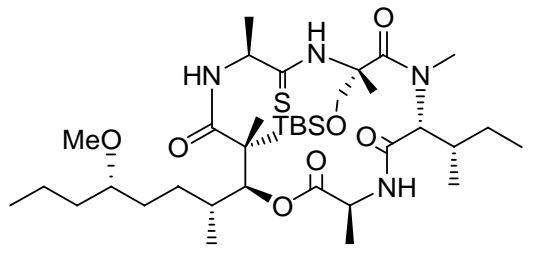
that temperature for $48 \mathrm{~h}$. The reaction mixture was cooled to room temperature and then concentrated under reduced pressure. The resulting residue was filtered through a short pad of silica gel and the filtrate concentrated. The crude carboxylic acid 50d was taken up in THF: $\mathrm{H}_{2} \mathrm{O}(10: 1,4 \mathrm{~mL})$ and cooled to $0{ }^{\circ} \mathrm{C}$. To this mixture was added $\mathrm{PMe}_{3}(1 \mathrm{M}$ in toluene, $0.174 \mathrm{~mL}$, $0.174 \mathrm{mmol}$ ) the resulting mixture was stirred at the same temperature for $2 \mathrm{~h}$ before it was concentrated and dried under vacuo. To a solution of the crude hydroxy amine in $\mathrm{CH}_{2} \mathrm{Cl}_{2}(40 \mathrm{~mL})$ was added HATU (44.1 mg, $0.116 \mathrm{mmol})$, HOAt $(15.8 \mathrm{mg}, 0.116 \mathrm{mmol})$, and $i \operatorname{Pr}_{2} \mathrm{NEt}(25 \mu \mathrm{L}, 0.116 \mathrm{mmol})$. The reaction mixture was stirred at room temperature for $13 \mathrm{~h}$ and then concentrated under vacuo. The resulting product was purified by flash column chromatography (silica gel, hexanes:EtOAc 1:1) to yield thioamide cyclic peptide 51d (16 mg, 38\%), as a colorless oil. 51d: $R_{\mathrm{f}}=0.33$ (silica gel, hexanes:EtOAc $1: 1) ;[\alpha]_{\mathrm{D}}^{32}=-55\left(c=0.21, \mathrm{CHCl}_{3}\right)$; IR (film) $v_{\max } 3318,3236,2954,2848,1731,1684,1642,1510$, 1460, 1378, 1250, 1196, 1096, 1061, $837 \mathrm{~cm}^{-1} ;{ }^{1} \mathrm{H}$ NMR $\left(500 \mathrm{MHz}, \mathrm{CDCl}_{3}\right) \delta=8.28(\mathrm{~s}, 1 \mathrm{H}), 7.20(\mathrm{~d}$, $J=9.5 \mathrm{~Hz}, 1 \mathrm{H}), 6.88(\mathrm{~d}, J=9.5 \mathrm{~Hz}, 1 \mathrm{H}), 5.22(\mathrm{~d}, J=10.0 \mathrm{~Hz}, 1 \mathrm{H}), 5.12(\mathrm{~d}, J=2.0 \mathrm{~Hz}, 1 \mathrm{H}), 5.04(\mathrm{~d}$, $J=10.0 \mathrm{~Hz}, 1 \mathrm{H}), 4.75-4.81(\mathrm{~m}, 1 \mathrm{H}), 3.74(\mathrm{~d}, J=10.5 \mathrm{~Hz}, 1 \mathrm{H}), 3.24(\mathrm{~s}, 3 \mathrm{H}), 3.23-3.29(\mathrm{~m}, 1 \mathrm{H})$, 
2.97-2.99 (m, $1 \mathrm{H}), 2.80$ (s, $3 \mathrm{H}), 2.13-2.15$ (m, $1 \mathrm{H}), 1.79-1.81(\mathrm{~m}, 1 \mathrm{H}), 1.78(\mathrm{~s}, 3 \mathrm{H}), 1.66-1.74$ (m, $1 \mathrm{H}), 1.42(\mathrm{~d}, J=7.0 \mathrm{~Hz}, 3 \mathrm{H}), 1.31(\mathrm{~d}, J=6.5 \mathrm{~Hz}, 3 \mathrm{H}), 1.21-1.50(\mathrm{~m}, 9 \mathrm{H}), 1.21(\mathrm{~s}, 3 \mathrm{H}), 1.19$ (s, 3 H), 1.04-1.07 (m, 1 H), 0.97 (d, J = 6.5 Hz, $3 \mathrm{H}), 0.85$ (s, 9 H), 0.83-0.89 (m, $8 \mathrm{H}), 0.03$ (s, $3 \mathrm{H}),-0.01$ (s, $3 \mathrm{H}) \mathrm{ppm} ;{ }^{13} \mathrm{C}$ NMR $\left(125 \mathrm{MHz}, \mathrm{CDCl}_{3}\right) \delta=203.9,175.8,171.3,170.7,169.5,80.5,80.1,63.8,62.0$, 60.3, 56.6, 54.6, 53.1, 46.9, 46.8, 35.6, 34.1, 32.1, 31.9, 31.7, 31.5, 29.7, 27.7, 27.6, 26.0, 24.3, 23.5, 21.2, 18.7, 18.5, 16.9, 14.7, 14.4, 14.2, 14.1, -5.3, -5.5 ppm; HRMS (ESI-TOF): calcd for $\mathrm{C}_{37} \mathrm{H}_{70} \mathrm{~N}_{4} \mathrm{O}_{7} \mathrm{SSi}[\mathrm{M}+\mathrm{H}]^{+}:$743.4807, found: 743.4803 .

\section{Hydroxy thioamide cyclic peptide 52d (Scheme 5):}

To a stirred solution of thioamide cyclic peptide 51d (1.9 mg, $0.0025 \mathrm{mmol})$ in $\mathrm{MeCN}(1 \mathrm{~mL})$ was added an $\mathrm{HF}$ aq solution in $\mathrm{MeCN}(0.25 \mathrm{~mL}$, made from dilution of $0.1 \mathrm{~mL} 50 \%$ aq $\mathrm{HF}$ in $10 \mathrm{~mL}$

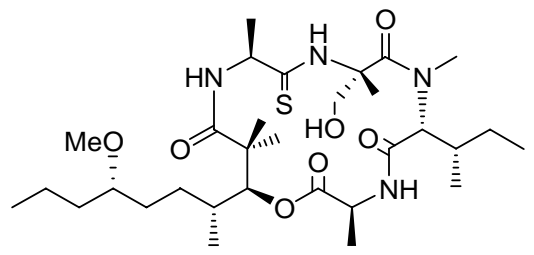
$\mathrm{MeCN}$ ) at $0{ }^{\circ} \mathrm{C}$. After allowing to warm up to room temperature, the reaction mixture was stirred for $18 \mathrm{~h}$, and then diluted with EtOAc (20 $\mathrm{mL}$ ) and quenched by the slow addition of sat aq $\mathrm{NaHCO}_{3}$ solution $(20 \mathrm{~mL})$. The resulting mixture was extracted with EtOAc $(3 \times 15 \mathrm{~mL})$ and the combined layers were washed with brine $(15 \mathrm{~mL})$, dried with $\mathrm{MgSO}_{4}$, filtered and concentrated under vacuo. The resulting residue was purified by flash column chromatography (silica gel, EtOAc) to yield pure hydroxy thioamide cyclic peptide 52d $(1.57 \mathrm{mg}, 100 \%)$ as a colorless oil. $\mathbf{5 2 d}: \quad R_{\mathrm{f}}=0.31$ (silica gel, EtOAc); $[\alpha]_{\mathrm{D}}{ }^{32}=-42\left(c=0.61, \mathrm{CHCl}_{3}\right)$; IR (film) $v_{\max } 3319,3238,2952,2840,1730,1687$, 1643, 1511, 1464, 1376, 1253, 1198, 1091, 1060, $831 \mathrm{~cm}^{-1} ;{ }^{1} \mathrm{H}$ NMR $\left(500 \mathrm{MHz}, \mathrm{CDCl}_{3}\right) \delta=9.51(\mathrm{~s}, 1$ H), $7.10(\mathrm{~d}, J=8.5 \mathrm{~Hz}, 1 \mathrm{H}), 6.88(\mathrm{~d}, J=10.0 \mathrm{~Hz}, 1 \mathrm{H}), 5.11(\mathrm{~d}, J=2.5 \mathrm{~Hz}, 1 \mathrm{H}), 5.05(\mathrm{~d}, J=10.0 \mathrm{~Hz}$, $1 \mathrm{H}), 4.77-4.82(\mathrm{~m}, 1 \mathrm{H}), 3.75-3.80(\mathrm{~m}, 1 \mathrm{H}), 3.25(\mathrm{~s}, 3 \mathrm{H}), 3.16-3.19(\mathrm{~m}, 1 \mathrm{H}), 3.01-3.04(\mathrm{~m}, 1 \mathrm{H})$, $2.81(\mathrm{~s}, 3 \mathrm{H}), 2.11-2.14(\mathrm{~m}, 1 \mathrm{H}), 1.81(\mathrm{~s}, 3 \mathrm{H}), 1.67-1.72(\mathrm{~m}, 1 \mathrm{H}), 1.44(\mathrm{~d}, J=7.5 \mathrm{~Hz}, 3 \mathrm{H}), 1.32(\mathrm{~d}, J$ $=7.0 \mathrm{~Hz}, 3 \mathrm{H}), 1.23(\mathrm{~s}, 3 \mathrm{H}), 1.20-1.48(\mathrm{~m}, 9 \mathrm{H}), 1.19(\mathrm{~s}, 3 \mathrm{H}), 0.97(\mathrm{~d}, J=7.0 \mathrm{~Hz}, 3 \mathrm{H}), 0.83-0.89(\mathrm{~m}$, $9 \mathrm{H}) \mathrm{ppm} ;{ }^{13} \mathrm{C} \mathrm{NMR}\left(125 \mathrm{MHz}, \mathrm{CDCl}_{3}\right) \delta=205.5,176.0,172.3,170.7,169.4,80.5,78.1,63.1,60.6$, $60.4,56.5,53.1,51.6,50.8,46.8,35.4,33.8,31.8,31.2,27.6,24.1,23.5,20.8,20.9,18.5,18.4,16.9$, 16.7, 14.3, 14.2, 11.2 ppm; HRMS (ESI-TOF): calcd for $\mathrm{C}_{31} \mathrm{H}_{56} \mathrm{~N}_{4} \mathrm{O}_{7} \mathrm{~S}[\mathrm{M}+\mathrm{H}]^{+}: 628.3870$, found: 628.3874. 


\section{Halipeptin analogue 4d (Scheme 5):}

To a stirred solution of hydroxy thioamide cyclic peptide 52d $(33.4 \mathrm{mg}, 0.049 \mathrm{mmol})$ in $\mathrm{CH}_{2} \mathrm{Cl}_{2}(10$ $\mathrm{mL})$ cooled to $-78^{\circ} \mathrm{C}$ was added DAST $(98 \mu \mathrm{L}, 0.098 \mathrm{mmol})$. The reaction mixture was stirred at -78

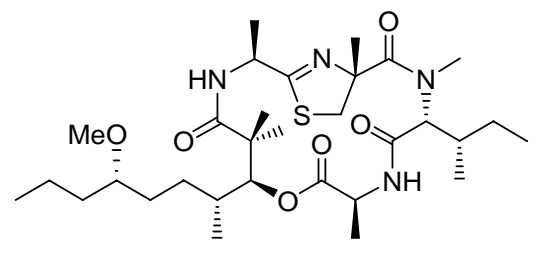

${ }^{\circ} \mathrm{C}$ for $1 \mathrm{~h}$ and then quenched with sat aq $\mathrm{NaHCO}_{3}$ solution $(2 \mathrm{~mL})$. The resulting mixture was warmed to room temperature and then extracted with $\mathrm{CH}_{2} \mathrm{Cl}_{2}(3 \times 5 \mathrm{~mL})$. The combined organic layers were washed with brine $(5 \mathrm{~mL})$, dried with $\mathrm{MgSO}_{4}$, filtered and concentrated under vacuo. The product was purified by flash column chromatography (silica gel, hexanes:EtOAc $1: 2)$ to yield halipeptin analogue $\mathbf{4 d}(23.9 \mathrm{mg}, 80 \%)$ as a colorless oil. $\mathbf{4 d}: R_{\mathrm{f}}=0.55$ (silica gel, hexanes:EtOAc 1:2); $[\alpha]_{\mathrm{D}}^{32}=+6.0\left(c=0.15, \mathrm{CHCl}_{3}\right)$; IR (film) $v_{\max } 3413,3342,2966,2932$, 2861, 1743, 1667, 1637, 1514, 1455, 1373, 1261, 1096, 1032, 961, 797, 750, $585 \mathrm{~cm}^{-1} ;{ }^{1} \mathrm{H}$ NMR $(500$ $\mathrm{MHz}, \mathrm{CDCl}_{3}$, ca 3:1 ratio of rotamers, only signals for the major isomer are noted) $\delta=7.17$ (d, $J=5.3$ $\mathrm{Hz}, 1 \mathrm{H}), 7.11(\mathrm{~d}, J=7.0 \mathrm{~Hz}, 1 \mathrm{H}), 5.02(\mathrm{~d}, J=1.7 \mathrm{~Hz}, 1 \mathrm{H}), 4.70-4.74(\mathrm{~m}, 1 \mathrm{H}), 4.56-4.62(\mathrm{~m}, 1 \mathrm{H})$, $4.48(\mathrm{~d}, J=10.9 \mathrm{~Hz}, 1 \mathrm{H}), 3.50$ (d, $J=11.6 \mathrm{~Hz}, 1 \mathrm{H}), 3.49$ (d, $J=11.6 \mathrm{~Hz}, 1 \mathrm{H}), 3.27$ (s, $3 \mathrm{H}), 3.04-$ 3.07 (m, 1 H), 2.98 (s, 3 H), 2.14-2.19 (m, 1 H), 1.84-1.99 (m, 1 H), 1.60 (d, J = 7.0 Hz, 3 H), 1.50 (d, $J$ $=7.0 \mathrm{~Hz}, 3 \mathrm{H}), 1.45(\mathrm{~s}, 3 \mathrm{H}), 1.22(\mathrm{~s}, 3 \mathrm{H}), 1.20-1.48(\mathrm{~m}, 8 \mathrm{H}), 1.13(\mathrm{~s}, 3 \mathrm{H}), 0.86-0.90(\mathrm{~m}, 10 \mathrm{H})$, $0.79-0.81(\mathrm{~m}, 3 \mathrm{H}) \mathrm{ppm} ;{ }^{13} \mathrm{C}$ NMR $\left(150 \mathrm{MHz}, \mathrm{CDCl}_{3}\right.$, ca $3: 1$ ratio of rotamers, only signals for the major isomer are noted) $\delta=174.7,174.3,172.4,169.6,169.6,84.8,82.8,80.6,63.6,56.5,51.6,47.9$, $45.4,44.5,35.6,34.4,33.9,31.5,31.2,30.8,26.9,26.4,25.7,22.3,20.3,19.5,18.4,15.5,14.4,14.3$, 11.6 ppm; HRMS (ESI-TOF): calcd for $\mathrm{C}_{31} \mathrm{H}_{54} \mathrm{~N}_{4} \mathrm{O}_{6} \mathrm{~S}$ [M+ H] $]^{+}: 611.3837$, found: 611.3844 .

\section{Thiazoline azido ester 53d (Scheme 6):}

A stirred solution of azido methyl ester $8 \mathbf{d}(76.2 \mathrm{mg}, 0.111 \mathrm{mmol})$ in $\mathrm{CH}_{2} \mathrm{Cl}_{2}(17.2 \mathrm{~mL})$ was cooled to $-78^{\circ} \mathrm{C}$ and DAST $(73.0 \mu \mathrm{L}, 0.553 \mathrm{mmol})$ was added. The reaction mixture was stirred at $-78^{\circ} \mathrm{C}$ for $1 \mathrm{~h}$

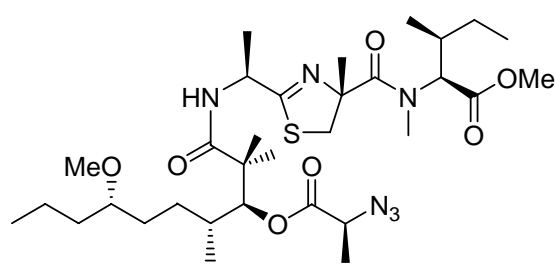
and then quenched with sat aq $\mathrm{NaHCO}_{3}$ solution $(10 \mathrm{~mL})$. The resulting mixture was warmed to room temperature and then extracted with $\mathrm{CH}_{2} \mathrm{Cl}_{2}(3 \times 20 \mathrm{~mL})$. The combined organic layers 
were washed with brine $(20 \mathrm{~mL})$, dried with $\mathrm{MgSO}_{4}$, filtered and concentrated under vacuo. The resulting product was purified by flash column chromatography (silica gel, hexanes:EtOAc 1:1) to yield thiazoline azido ester 53d (53.4 mg, 72\%) as a yellow oil. 53d: $R_{\mathrm{f}}=0.63$ (silica gel, hexanes:EtOAc $1: 1) ;[\alpha]_{\mathrm{D}}{ }^{32}=-11.5\left(c=2.31, \mathrm{CHCl}_{3}\right)$; IR (film) $v_{\max } 3377,2965,2935,2874,2100,1739,1633,1507$, 1457, 1377, 1261, 1196, 1090, 1005, $940 \mathrm{~cm}^{-1} ;{ }^{1} \mathrm{H} \mathrm{NMR}\left(600 \mathrm{MHz}, \mathrm{CDCl}_{3}\right.$, ca 3:1 ratio of rotamers, only signals for the major isomer are noted) $\delta=6.67(\mathrm{~d}, J=6.6 \mathrm{~Hz}, 1 \mathrm{H}), 5.14(\mathrm{~d}, J=1.7 \mathrm{~Hz}, 1 \mathrm{H}), 4.84$ $(\mathrm{d}, J=10.9 \mathrm{~Hz}, 1 \mathrm{H}), 4.74-4.79(\mathrm{~m}, 1 \mathrm{H}), 4.09$ (d, $J=11.4 \mathrm{~Hz}, 1 \mathrm{H}), 3.94-3.97$ (m, $1 \mathrm{H}), 3.68$ (s, $3 \mathrm{H})$, $3.26(\mathrm{~s}, 3 \mathrm{H}), 3.25(\mathrm{~s}, 3 \mathrm{H}), 3.17$ (d, $J=11.4 \mathrm{~Hz}, 1 \mathrm{H}), 3.04-3.06(\mathrm{~m}, 1 \mathrm{H}), 1.99-2.01$ (m, $1 \mathrm{H}), 1.76-$ $1.79(\mathrm{~m}, 1 \mathrm{H}), 1.47-1.50(\mathrm{~m}, 6 \mathrm{H}), 1.37(\mathrm{~d}, J=6.6 \mathrm{~Hz}, 3 \mathrm{H}), 1.28-1.44(\mathrm{~m}, 9 \mathrm{H}), 1.18(\mathrm{~s}, 3 \mathrm{H}), 1.17(\mathrm{~s}, 3$ $\mathrm{H}), 0.92-0.99(\mathrm{~m}, 4 \mathrm{H}), 0.85-0.88(\mathrm{~m}, 6 \mathrm{H}), 0.82(\mathrm{t}, J=7.5 \mathrm{~Hz}, 3 \mathrm{H}) \mathrm{ppm} ;{ }^{13} \mathrm{C} \mathrm{NMR}\left(150 \mathrm{MHz}, \mathrm{CDCl}_{3}\right.$, ca 3:1 ratio of rotamers, only signals for the major isomer are noted) $\delta=174.2,172.8,172.8,171.7$, $170.3,85.2,81.6,80.6,62.0,57.8,56.4,51.8,48.5,46.6,43.7,35.6,34.3,32.9,32.8,31.7,31.3,24.9$, 23.3, 23.1, 21.8, 20.1, 18.4, 17.0, 15.9, 15.2, 14.2, 10.7 ppm; HRMS (ESI-TOF): calcd for $\mathrm{C}_{32} \mathrm{H}_{56} \mathrm{~N}_{6} \mathrm{O}_{7} \mathrm{~S}$ $[\mathrm{M}+\mathrm{H}]^{+}: 669.4004$, found: 669.4010 .

\section{Halipeptin D 1d, halipeptin D analogue 3d and halipeptin D analogue 4d (Scheme 6):}

To a solution of thiazoline azido ester $53 \mathbf{d}(81.7 \mathrm{mg}, 0.0780 \mathrm{mmol})$ in 1,2 dichloroethane $(20 \mathrm{~mL})$ was added $\mathrm{Me}_{3} \mathrm{SnOH}(1.32 \mathrm{~g}, 7.305 \mathrm{mmol})$ and the resulting mixture was heated at $90{ }^{\circ} \mathrm{C}$ and stirred at that

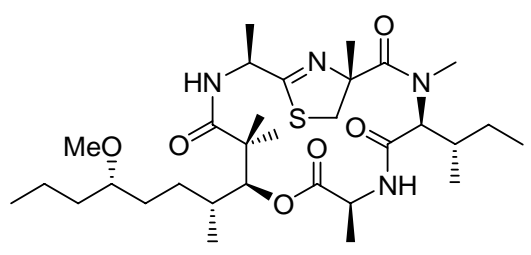
temperature for $48 \mathrm{~h}$. The reaction mixture was cooled to room temperature and then concentrated under vacuo. The crude product was filtered through a short pad of silica and the filtrate was concentrated to dryness. The resulting residue was taken up in

THF: $\mathrm{H}_{2} \mathrm{O}(10: 1,5.5 \mathrm{~mL})$ and cooled to $0{ }^{\circ} \mathrm{C}$. To this stirring solution was added $\mathrm{PMe}_{3}(1 \mathrm{M}$ in toluene, $0.480 \mathrm{~mL}, 0.480 \mathrm{mmol}$ ) at $0{ }^{\circ} \mathrm{C}$ and the reaction mixture was stirred at that temperature for $2 \mathrm{~h}$, then was concentrated and dried under high vacuum to afford crude amine 54d. To a solution of this crude amine (54a) in $\mathrm{CH}_{2} \mathrm{Cl}_{2}(41 \mathrm{~mL})$ was added HATU (145.0 mg, $\left.0.381 \mathrm{mmol}\right)$, HOAt (52.0 mg, 0.382 $\mathrm{mmol})$ and $\mathrm{K}_{2} \mathrm{CO}_{3}(65 \mathrm{mg}, 0.471 \mathrm{mmol})$ and the so obtained reaction mixture was stirred at room temperature for $13 \mathrm{~h}$ and then concentrated. The resulting residue was purified by flash column 
chromatography (silica gel, hexanes:EtOAc 1:1) to yield halipeptin D (1d) (18 mg, 25\%), halipeptin D analogue 3d (3.6 mg, 5\%), and halipeptin D analogue 4d (13.5 mg, 18\%) as colorless oils. halipeptin D 1d: $R_{\mathrm{f}}=0.36$ (silica gel, hexanes:EtOAc $\left.1: 1\right) ;[\alpha]_{\mathrm{D}}{ }^{32}=-19.1\left(c=0.46, \mathrm{CHCl}_{3}\right)$; IR (film) $v_{\max } 3435$, $3331,2966,2931,2782,1749,1671,1637,1514,1455,1401,1373,1261,1155,1091,1038,973,808$, $756,585 \mathrm{~cm}^{-1} ;{ }^{1} \mathrm{H}$ NMR $\left(500 \mathrm{MHz}, \mathrm{CDCl}_{3}\right) \delta=7.20(\mathrm{~d}, J=7.7 \mathrm{~Hz}, 1 \mathrm{H}), 7.01(\mathrm{~d}, J=8.5 \mathrm{~Hz}, 1 \mathrm{H}), 4.98$ (d, $J=10.3 \mathrm{~Hz}, 1 \mathrm{H}), 4.74-4.84$ (m, $2 \mathrm{H}), 4.68$ (d, $J=3.0 \mathrm{~Hz}, 1 \mathrm{H}), 4.13$ (d, $J=12.1 \mathrm{~Hz}, 1 \mathrm{H}), 3.28$ (s, 3 H), $3.27(\mathrm{~d}, J=12.1 \mathrm{~Hz}, 1 \mathrm{H}), 3.05-3.09(\mathrm{~m}, 1 \mathrm{H}), 2.78$ (s, $3 \mathrm{H}), 2.16-2.22(\mathrm{~m}, 1 \mathrm{H}), 1.88-1.92(\mathrm{~m}, 1$ H), 1.49 (d, $J=7.4 \mathrm{~Hz}, 3 \mathrm{H}), 1.44$ (s, $3 \mathrm{H}), 1.39$ (d, $J=7.4 \mathrm{~Hz}, 3 \mathrm{H}), 1.27-1.49$ (m, $9 \mathrm{H}), 1.18$ (s, $3 \mathrm{H})$, 1.12 (s, $3 \mathrm{H}), 0.99-1.04(\mathrm{~m}, 1 \mathrm{H}), 0.88-0.96(\mathrm{~m}, 9 \mathrm{H}), 0.79$ (d, $J=7.0 \mathrm{~Hz}, 3 \mathrm{H}) \mathrm{ppm} ;{ }^{13} \mathrm{C}$ NMR $(150$ $\left.\mathrm{MHz}, \mathrm{CDCl}_{3}\right) \delta=177.2,173.6,172.5,169.6,169.3,83.9,82.5,80.6,65.0,56.5,49.5,48.5,45.8,44.3$, $35.7,34.2,33.5,31.9,31.2,30.7,26.2,25.0,23.1,22.3,22.0,18.5,18.0,17.7,14.4,14.3,12.5$ ppm; HRMS (ESI-TOF): calcd for $\mathrm{C}_{31} \mathrm{H}_{54} \mathrm{~N}_{4} \mathrm{O}_{6} \mathrm{~S}[\mathrm{M}+\mathrm{H}]^{+}:$: 611.3837, found: 611.3836 .

halipeptin D analogue 3d: $R_{\mathrm{f}}=0.36$ (silica gel, hexanes:EtOAc 1:1); $[\alpha]_{\mathrm{D}}{ }^{32}=-13.8\left(c=0.45, \mathrm{CHCl}_{3}\right)$; IR (film) $v_{\max } 2965,2924,2874,1749,1673,1638,1613,1507,1452,1397,1371,1261,1095,1035$,

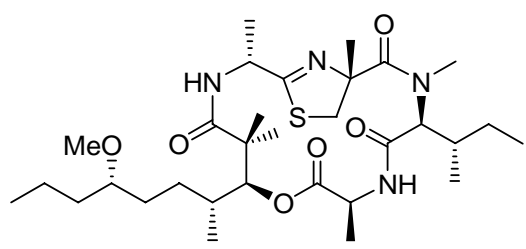
$970,804,668 \mathrm{~cm}^{-1} ;{ }^{1} \mathrm{H}$ NMR $\left(500 \mathrm{MHz}, \mathrm{CDCl}_{3}\right) \delta=6.79(\mathrm{~d}, J=5.5$ $\mathrm{Hz}, 1 \mathrm{H}), 6.58(\mathrm{~d}, J=9.2 \mathrm{~Hz}, 1 \mathrm{H}), 5.28(\mathrm{~d}, J=10.3 \mathrm{~Hz}, 1 \mathrm{H}), 4.81-$ 4.87 (m, $1 \mathrm{H}), 4.72-4.77(\mathrm{~m}, 1 \mathrm{H}), 4.71(\mathrm{~d}, J=1.9 \mathrm{~Hz}, 1 \mathrm{H}), 4.01$ (d, $J$ $=12.2 \mathrm{~Hz}, 1 \mathrm{H}), 3.32(\mathrm{~d}, J=12.2 \mathrm{~Hz}, 1 \mathrm{H}), 3.27(\mathrm{~s}, 3 \mathrm{H}), 3.05-3.09$ (m, $1 \mathrm{H}), 2.78$ (s, $3 \mathrm{H}), 2.18-2.24$ (m, $1 \mathrm{H}), 2.02-2.10$ (m, $1 \mathrm{H}), 1.45$ (d, J = 6.6 Hz, $3 \mathrm{H}), 1.43$ (s, $3 \mathrm{H})$, 1.32 (d, $J=7.0$ Hz, 3 H), 1.22 (s, 3 H), 1.15-1.51 (m, 9 H), 1.10 (s, 3 H), 1.02-1.06 (m, 1 H), 0.96-1.02 $(\mathrm{m}, 6 \mathrm{H}), 0.88(\mathrm{t}, J=7.1 \mathrm{~Hz}, 3 \mathrm{H}), 0.66(\mathrm{~d}, J=6.6 \mathrm{~Hz}, 3 \mathrm{H}) \mathrm{ppm} ;{ }^{13} \mathrm{C} \mathrm{NMR}\left(150 \mathrm{MHz}, \mathrm{CDCl}_{3}\right) \delta=$ $176.9,173.6,172.7,170.4,169.3,87.8,82.1,80.5,64.8,56.4,49.1,49.0,45.1,43.4,35.7,33.4,32.9$, 32.3, 31.1, 30.6, 25.5, 24.3, 23.3, 22.8, 21.5, 19.5, 18.4, 17.5, 14.3, 14.1, 12.5 ppm; HRMS (ESI-TOF): calcd for $\mathrm{C}_{31} \mathrm{H}_{54} \mathrm{~N}_{4} \mathrm{O}_{6} \mathrm{~S}[\mathrm{M}+\mathrm{H}]^{+}: 611.3837$, found: 611.3833 .

\section{Azido methyl ester 8a (Scheme 6):}

To a stirred solution of azido ester carboxylic acid $12(73.5 \mathrm{mg}, 0.206 \mathrm{mmol})$ in DMF $(8 \mathrm{~mL})$ at ambient

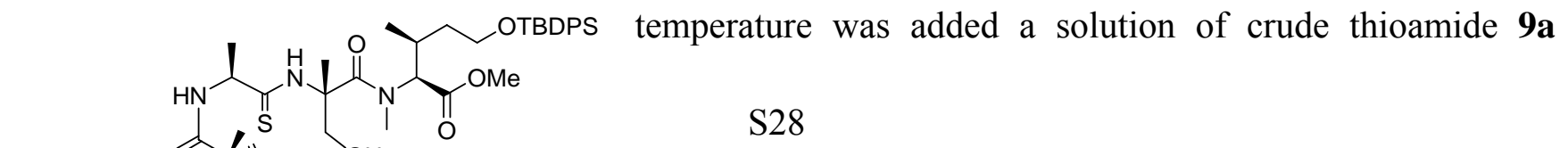


$(0.187 \mathrm{mmol})$ in DMF (2 mL), followed by $i \operatorname{Pr}_{2} \mathrm{EtN}(54 \mathrm{~mL}, 0.308 \mathrm{mmol})$ and PyAOP (161 mg, 1.65 mmol). After stirring the reaction mixture for $18 \mathrm{~h}$ at ambient temperature, the reaction mixture was quenched with sat aq $\mathrm{NH}_{4} \mathrm{Cl}$ solution $(50 \mathrm{~mL})$ and extracted with $\mathrm{Et}_{2} \mathrm{O}(3 \times 50 \mathrm{~mL})$. The combined organic phase was washed with brine $(50 \mathrm{~mL})$, dried over $\mathrm{MgSO}_{4}$, filtered concentrated and purified by flash column chromatography (silica gel, hexanes:EtOAc 1:3) to afford azido methyl ester 8a (87.1 mg, $71 \%$ ) as a yellow oil. 8a: $R_{\mathrm{f}}=0.30$ (silica gel, hexanes:EtOAc 1:4); $[\alpha]^{32}{ }_{\mathrm{D}}=-48.8\left(\mathrm{c}=0.530, \mathrm{CHCl}_{3}\right)$; IR (film) $v_{\max } 3260,3037,2954,2860,2108,1737,1637,1508,1425,1261,1196,1108,1090,738,703$ $\mathrm{cm}^{-1} ;{ }^{1} \mathrm{H} \mathrm{NMR}\left(600 \mathrm{MHz}, \mathrm{CDCl}_{3}\right.$, ca 4:1 ratio of rotamers, only signals for the major isomer are noted) $\delta=8.84$ (br s, $1 \mathrm{H}), 7.64(\mathrm{~m}, 4 \mathrm{H}), 7.35-7.45$ (m, $6 \mathrm{H}), 7.03$ (br s, $1 \mathrm{H}), 5.07$ (d, J = 2.5 Hz, $1 \mathrm{H}), 4.95$

$(\mathrm{m}, 1 \mathrm{H}), 4.64(\mathrm{~m}, 1 \mathrm{H}), 4.30(\mathrm{~m}, 1 \mathrm{H}), 3.98(\mathrm{~m}, 1 \mathrm{H}), 3.62-3.75(\mathrm{~m}, 2 \mathrm{H}), 3.70(\mathrm{~s}, 3 \mathrm{H}), 3.40(\mathrm{~m}, 1 \mathrm{H})$, $3.28(\mathrm{~s}, 3 \mathrm{H}), 3.21(\mathrm{~m}, 1 \mathrm{H}), 3.08(\mathrm{~m}, 1 \mathrm{H}), 3.04$ (s, $3 \mathrm{H}), 2.34(\mathrm{~m}, 1 \mathrm{H}), 1.86(\mathrm{~m}, 1 \mathrm{H}), 1.10-1.80$ (m, 10 H), $1.74(\mathrm{~s}, 3 \mathrm{H}), 1.54(\mathrm{~d}, J=7.1 \mathrm{~Hz}, 3 \mathrm{H}), 1.43$ (s, $3 \mathrm{H}), 1.19(\mathrm{~s}, 3 \mathrm{H}), 1.16(\mathrm{~s}, 3 \mathrm{H}), 1.02(\mathrm{~s}, 9 \mathrm{H}), 0.90$ $(\mathrm{m}, 6 \mathrm{H}), 0.86(\mathrm{~d}, J=6.8 \mathrm{~Hz}, 3 \mathrm{H}) \mathrm{ppm} ;{ }^{13} \mathrm{C} \mathrm{NMR}\left(150 \mathrm{MHz}, \mathrm{CDCl}_{3}, c a\right.$ 4:1 ratio of rotamers, only signals for the major isomer are noted) $\delta=175.9,172.5,171.3,169.9,135.5,135.5,133.6,133.5,129.7$, $129.6,127.7,127.7,127.6,125.5,82.1,80.6,80.6,80.5,64.2,64.0,61.0,58.1,56.4,51.9,45.8,35.6$, $35.5,34.2,31.4,31.1,31.0,30.3,26.8,24.1,22.8,20.9,19.2,18.4,18.4,17.1,16.9,16.3,14.4,14.3$ ppm; HRMS (ESI-TOF): calcd for $\mathrm{C}_{48} \mathrm{H}_{76} \mathrm{~N}_{6} \mathrm{O}_{9} \mathrm{SSi}[\mathrm{M}+\mathrm{Na}]^{+}: 963.5056$, found: 963.5036 .

\section{Thiazoline azido ester 53a (Scheme 6):}

To a cold $\left(-78{ }^{\circ} \mathrm{C}\right)$ stirred solution of azido methyl ester $8 \mathbf{a}(87.1 \mathrm{mg}, 0.092 \mathrm{mmol})$ in $\mathrm{CH}_{2} \mathrm{Cl}_{2}(8 \mathrm{~mL})$ was slowly added DAST $(61.1 \mu \mathrm{L}, 0.46 \mathrm{mmol})$ and the reaction mixture was stirred at that temperature

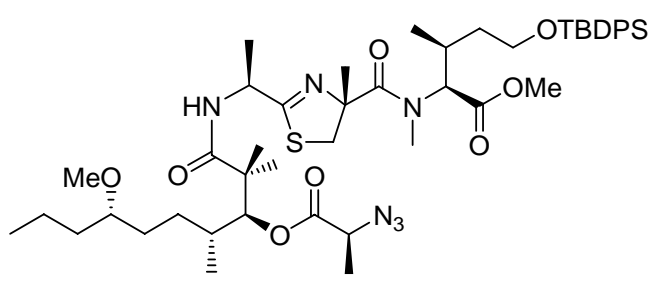
for $2 \mathrm{~h}$ before quenching with sat aq $\mathrm{NaHCO}_{3}$ solution $(10 \mathrm{~mL})$ and allowed to warm to room temperature. The layers were separated and the aqueous layer further extracted with $\mathrm{CH}_{2} \mathrm{Cl}_{2}$ $(2 \times 5 \mathrm{~mL})$, the combined organic extracts were washed with water $(10 \mathrm{~mL})$, dried over $\mathrm{MgSO}_{4}$, filtered and concentrated. The resulting residue was purified by flash column chromatography (silica gel, hexanes:EtOAc 1:3) to afford thiazoline azido ester 53a (67.4 mg, $78.8 \%$ ) as a pale yellow oil. 53a: $R_{\mathrm{f}}=0.59$ (silica gel, hexanes:EtOAc $\left.1: 1\right) ;[\alpha]^{32}{ }_{\mathrm{D}}=-36.9(c=0.065$, 
$\mathrm{CHCl}_{3}$ ); IR (neat) $v_{\max } 3378,2954,2931,2860,2097,1737,1631,1508,1461,1255,1190,1090,1008$, $697 \mathrm{~cm}^{-1}$; ${ }^{1} \mathrm{H} \mathrm{NMR}\left(600 \mathrm{MHz}, \mathrm{CDCl}_{3}\right.$, ca 4:1 ratio of rotamers, only signals for the major isomer are noted) $\delta=7.64(\mathrm{~m}, 4 \mathrm{H}), 7.34-7.45(\mathrm{~m}, 6 \mathrm{H}), 6.78(\mathrm{~d}, J=7.0 \mathrm{~Hz}, 1 \mathrm{H}), 5.09(\mathrm{~s}, 1 \mathrm{H}), 4.88(\mathrm{~d}, J=10.6$ Hz, $1 \mathrm{H}), 4.83$ (m, $1 \mathrm{H}), 4.04(\mathrm{~m}, 2 \mathrm{H}), 3.65-3.75$ (m, $2 \mathrm{H}), 3.71(\mathrm{~s}, 3 \mathrm{H}), 3.29$ (s, $3 \mathrm{H}), 3.28$ (s, $3 \mathrm{H})$, $3.17(\mathrm{~d}, J=12.0 \mathrm{~Hz}, 1 \mathrm{H}), 3.08(\mathrm{~m}, 1 \mathrm{H}), 2.37(\mathrm{~m}, 1 \mathrm{H}), 1.84(\mathrm{~m}, 1 \mathrm{H}), 1.78(\mathrm{~m}, 1 \mathrm{H}), 1.62(\mathrm{~m}, 1 \mathrm{H})$, 1.20-1.55 (m, $20 \mathrm{H}), 1.18(\mathrm{~s}, 3 \mathrm{H}), 1.03(\mathrm{~s}, 9 \mathrm{H}), 0.87(\mathrm{~m}, 9 \mathrm{H}) \mathrm{ppm} ;{ }^{13} \mathrm{C} \mathrm{NMR}\left(150 \mathrm{MHz}, \mathrm{CDCl}_{3}, c a\right.$ 4:1 ratio of rotamers, only signals for the major isomer are noted) $\delta=174.3,172.9,171.6,170.1,135.5$, $133.5,133.3,129.7,127.6,85.7,82.2,81.9,80.5,65.4,62.3,61.0,58.1,57.8,56.4,52.0,48.0,46.3$, $44.2,35.8,35.0,34.2,32.8,31.6,31.1,29.7,28.2,26.8,25.2,23.7,22.7,22.6,22.2,20.2,19.6,19.1$, 18.4, 17.0, 16.9, 16.3, 15.0, 14.2 ppm; HRMS (ESI-TOF): calcd for $\mathrm{C}_{48} \mathrm{H}_{74} \mathrm{~N}_{6} \mathrm{O}_{8} \mathrm{SSi}[\mathrm{M}+\mathrm{Na}]^{+}$: 945.4950, found: 945.4947 .

\section{TBDPS-protected halipeptin A 55, TBDPS-protected halipeptin A analogue 56 and TBDPS- protected halipeptin A analogue 57 (Scheme 6):}

To a solution of thiazoline azido ester 53a $(29.3 \mathrm{mg}, 0.0280 \mathrm{mmol})$ in 1,2 dichloroethane $(8 \mathrm{~mL})$ was added $\mathrm{Me}_{3} \mathrm{SnOH}\left(474 \mathrm{mg}, 2.622 \mathrm{mmol}\right.$ ) and the resulting mixture was heated at $90{ }^{\circ} \mathrm{C}$ and stirred at that

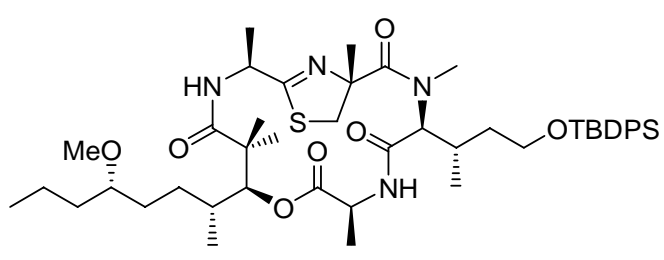
temperature for $48 \mathrm{~h}$. The reaction mixture was cooled to room temperature and then concentrated under vacuo. The crude product was filtered through as short pad of silica and the filtrate was concentrated to dryness. The resulting residue was taken up in THF: $\mathrm{H}_{2} \mathrm{O}(10: 1,5.5 \mathrm{~mL})$ and cooled to $0{ }^{\circ} \mathrm{C}$. To this stirring solution was added $\mathrm{PMe}_{3}$ ( $1 \mathrm{M}$ in toluene, $0.16 \mathrm{~mL}, 0.160 \mathrm{mmol}$ ) at $0{ }^{\circ} \mathrm{C}$ and the reaction mixture was stirred at that temperature for $2 \mathrm{~h}$, then was concentrated and dried under high vacuum to afford crude amine 54a. To a stirred solution of this crude amine (54a) $(15 \mathrm{mg}, 0.017 \mathrm{mmol})$ in $\mathrm{CH}_{2} \mathrm{Cl}_{2}(10 \mathrm{~mL})$ were sequentially added HOAt (4.6 mg, $0.034 \mathrm{mmol}), \mathrm{K}_{2} \mathrm{CO}_{3}(23.3 \mathrm{mg}, 0.17 \mathrm{mmol})$ and HATU (12.8 $\left.\mathrm{mg}, 0.034 \mathrm{mmol}\right)$ at ambient temperature. After stirring the reaction mixture at that temperature for $24 \mathrm{~h}$, the reaction was quenched with water $(10 \mathrm{~mL})$ and the layers were separated. The aqueous layer was extracted with $\mathrm{CH}_{2} \mathrm{Cl}_{2}(10 \mathrm{~mL})$ and the combine organic extracts were washed with brine $(10 \mathrm{~mL})$, dried over $\mathrm{MgSO}_{4}$, 
filtered and concentrated. The resulting residue was purified by preparative TLC (silica gel, hexanes:EtOAc 2:1) to afford TBDPS-protected halipeptin A 55 (4.6 mg, 31\%), TBDPS-protected halipeptin A analogue 56 (1.5 mg, 10\%) and TBDPS-protected halipeptin A analogue 57 (2.0 mg, 14\%) as colorless oils. TBDPS-protected halipeptin A (55): $R_{\mathrm{f}}=0.35$ (silica gel, hexanes:EtOAc $\left.1: 1\right) ;[\alpha]^{32}$ $\mathrm{D}=-18.5\left(c=0.2, \mathrm{CHCl}_{3}\right) ; \mathrm{IR}($ film $) v_{\max } 3418,3326,2956,2918,2863,1737,1672,1640,1510,1459$, $1376,1246,1112,1099,820,705 \mathrm{~cm}^{-1} ;{ }^{1} \mathrm{H} \mathrm{NMR}\left(600 \mathrm{MHz}, \mathrm{CDCl}_{3}\right.$, ca 8:1 ratio of rotamers, only signals for the major isomer are noted) $\delta=7.81(\mathrm{~m}, 4 \mathrm{H}), 7.26(\mathrm{~m}, 6 \mathrm{H}), 7.20(\mathrm{~d}, J=7.5 \mathrm{~Hz}, 1 \mathrm{H}), 6.89$ $(\mathrm{d}, J=8.2 \mathrm{~Hz}, 1 \mathrm{H}), 5.11(\mathrm{~d}, J=10.5 \mathrm{~Hz}, 1 \mathrm{H}), 4.82-4.95(\mathrm{~m}, 2 \mathrm{H}), 4.75(\mathrm{~d}, J=2.7 \mathrm{~Hz}, 1 \mathrm{H}), 4.13(\mathrm{~d}, J$ $=12.1 \mathrm{~Hz}, 1 \mathrm{H}), 3.73(\mathrm{~m}, 1 \mathrm{H}), 3.64(\mathrm{~m}, 1 \mathrm{H}), 3.19(\mathrm{~s}, 3 \mathrm{H}), 3.05(\mathrm{~m}, 1 \mathrm{H}), 2.93(\mathrm{~s}, 3 \mathrm{H}), 2.88(\mathrm{~d}, J=$ $12.0 \mathrm{~Hz}, 1 \mathrm{H}), 2.84(\mathrm{~m}, 1 \mathrm{H}), 1.99(\mathrm{~m}, 1 \mathrm{H}), 1.24-1.75(\mathrm{~m}, 1 \mathrm{H}), 1.43$ (d, J=6.9 Hz, $3 \mathrm{H}), 1.19$ (s, $9 \mathrm{H})$, $1.18(\mathrm{~s}, 3 \mathrm{H}), 1.11(\mathrm{~s}, 3 \mathrm{H}), 0.98(\mathrm{~d}, J=6.3 \mathrm{~Hz}, 3 \mathrm{H}), 0.98(\mathrm{~s}, 3 \mathrm{H}), 0.91(\mathrm{t}, J=7.0 \mathrm{~Hz}, 3 \mathrm{H}), 0.85(\mathrm{t}, J=$ 7.0 Hz, $6 \mathrm{H}) \mathrm{ppm} ;{ }^{13} \mathrm{C} \mathrm{NMR}\left(150 \mathrm{MHz}, \mathrm{CDCl}_{3}\right.$, ca 8:1 ratio of rotamers, only signals for the major isomer are noted) $\delta=177.4,173.1,172.1,169.9,169.1,136.1,136.0,134.1,133.9,130.2,130.1,84.0$, $82.4,80.6,65.0,64.2,62.0,56.3,49.8,49.3,49.1,46.0,44.6,44.2,36.1,35.6,34.5,32.4,31.6,30.6$, 28.2, 27.9, 27.1, 26.0, 22.9, 22.6, 22.1, 19.4, 18.8, 18.6, 17.5, 14.8, 14.6 ppm; HRMS (ESI-TOF): calcd for $\mathrm{C}_{47} \mathrm{H}_{72} \mathrm{~N}_{4} \mathrm{O}_{7} \mathrm{SSi}[\mathrm{M}+\mathrm{H}]^{+}$: 865.4963, found: 865.4971 .

TBDPS-protected halipeptin A analogue 56: $R_{\mathrm{f}}=0.34$ (silica gel, hexanes:EtOAc $1: 1$ ); $[\alpha]_{\mathrm{D}}^{32}=-6.0$ $\left(c=0.1, \mathrm{CHCl}_{3}\right)$; IR (film) $v_{\max } 3411,3315,2922,2858,1737,1673,1636,1508,1450,1428,1380$,

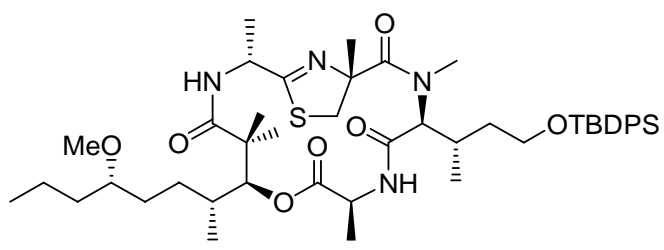
1242, 1109, 1088, 822, 742, $699 \mathrm{~cm}^{-1} ;{ }^{1} \mathrm{H}$ NMR (500 MHz, $\left.\mathrm{CDCl}_{3}\right) \delta=7.80(\mathrm{~m}, 4 \mathrm{H}), 7.25(\mathrm{~m}, 6 \mathrm{H}), 6.87(\mathrm{~d}, J=5.4 \mathrm{~Hz}$, $1 \mathrm{H}), 6.58(\mathrm{~d}, J=9.0 \mathrm{~Hz}, 1 \mathrm{H}), 5.36(\mathrm{~d}, J=10.3 \mathrm{~Hz}, 1 \mathrm{H})$, $4.98(\mathrm{qd}, J=7.2,14.3 \mathrm{~Hz}, 1 \mathrm{H}), 4.87$ (d, $J=1.8 \mathrm{~Hz}, 1 \mathrm{H}), 4.72$ $(\mathrm{d}, J=6.7 \mathrm{~Hz}, 1 \mathrm{H}), 4.05(\mathrm{~d}, J=12.2 \mathrm{~Hz}, 1 \mathrm{H}), 3.75(\mathrm{~m}, 1 \mathrm{H}), 3.65(\mathrm{~m}, 1 \mathrm{H}), 3.18(\mathrm{~s}, 3 \mathrm{H}), 3.04(\mathrm{~m}, 1$ H), $2.91(\mathrm{~s}, 3 \mathrm{H}), 2.78(\mathrm{~m}, 1 \mathrm{H}), 2.23(\mathrm{~m}, 1 \mathrm{H}), 1.74(\mathrm{~m}, 1 \mathrm{H}), 1.36(\mathrm{~d}, J=6.7 \mathrm{~Hz}, 3 \mathrm{H}), 1.21(\mathrm{~s}, 3 \mathrm{H})$, $1.19(\mathrm{~s}, 9 \mathrm{H}), 1.00(\mathrm{~d}, J=7.2 \mathrm{~Hz}, 3 \mathrm{H}), 1.14(\mathrm{~s}, 3 \mathrm{H}), 0.91(\mathrm{dd}, J=7.0,14.9 \mathrm{~Hz}, 3 \mathrm{H}), 0.82(\mathrm{~d}, J=6.8$ $\mathrm{Hz}, 3 \mathrm{H}) \mathrm{ppm} ;{ }^{13} \mathrm{C} \mathrm{NMR}\left(125 \mathrm{MHz}, \mathrm{CDCl}_{3}\right) \delta=177.2,173.6,172.5,170.6,169.4,136.3,136.2,134.2$, $130.3,127.7,85.1,82.2,80.8,65.0,62.3,56.4,49.8,49.7,45.6,43.8,36.2,33.6,32.8,31.7,30.8,30.4$, 
28.4, 27.3, 24.5, 23.4, 23.3, 21.8, 19.3, 19.0, 18.4, 14.7 ppm; HRMS (ESI-TOF): calcd for $\mathrm{C}_{47} \mathrm{H}_{72} \mathrm{~N}_{4} \mathrm{O}_{7} \mathrm{SSi}[\mathrm{M}+\mathrm{H}]^{+}:$865.4963, found: 865.4973.

TBDPS-protected halipeptin A analogue 57: $R_{\mathrm{f}}=0.46$ (silica gel, hexanes:EtOAc $1: 1$ ); $[\alpha]^{32}=$ $+6.0\left(c=0.2, \mathrm{CHCl}_{3}\right)$; IR (film) $v_{\max } 3412,3322,2970,2924,2856,1736,1674,1634,1498,1452$, 1378, 1242, 1112, 1089, 817, 737, 703, 612, $505 \mathrm{~cm}^{-1} ;{ }^{1} \mathrm{H}$ NMR $\left(600 \mathrm{MHz}, \mathrm{C}_{6} \mathrm{D}_{6}\right.$, ca 5:1 ratio of

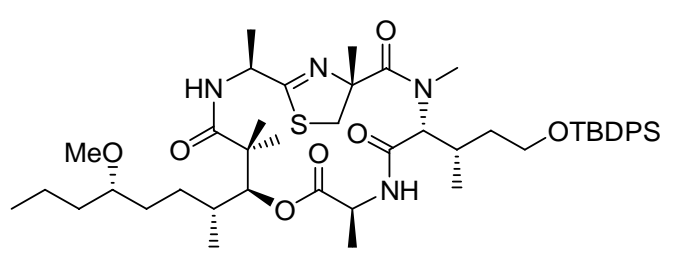
rotamers, only signals for the major isomer are noted) $\delta=7.85$ $(\mathrm{d}, J=7.0 \mathrm{~Hz}, 2 \mathrm{H}), 7.77(\mathrm{~d}, J=5.7 \mathrm{~Hz}, 2 \mathrm{H}), 7.25(\mathrm{~m}, 6 \mathrm{H})$, $7.18(\mathrm{~d}, J=5.5 \mathrm{~Hz}, 1 \mathrm{H}), 6.20(\mathrm{dd}, J=5.3,24.7 \mathrm{~Hz}, 1 \mathrm{H}), 5.04$ (s, $1 \mathrm{H}), 4.73(\mathrm{~m}, 1 \mathrm{H}), 4.52(\mathrm{~d}, J=10.6 \mathrm{~Hz}, 1 \mathrm{H}), 3.88(\mathrm{~m}, 1$ H), $3.70(\mathrm{~m}, 1 \mathrm{H}), 2.96-3.24(\mathrm{~m}, 1 \mathrm{H}), 3.15(\mathrm{~s}, 3 \mathrm{H}), 3.03(\mathrm{~s}, 3 \mathrm{H}), 2.61(\mathrm{~d}, J=11.0 \mathrm{~Hz}, 1 \mathrm{H}), 2.34$ (br d, $J=8.8 \mathrm{~Hz}, 1 \mathrm{H}), 2.05(\mathrm{~m}, 1 \mathrm{H}), 1.94(\mathrm{~m}, 1 \mathrm{H}), 1.20(\mathrm{~s}, 9 \mathrm{H}), 0.80-1.70(\mathrm{~m}, 35 \mathrm{H}) \mathrm{ppm} ;{ }^{13} \mathrm{C}$ NMR $(150$ $\mathrm{MHz}, \mathrm{C}_{6} \mathrm{D}_{6}$, ca 5:1 ratio of rotamers, only signals for the major isomer are noted) $\delta=174.7,172.1$, $170.9,169.9,136.1,134.4,134.2,134.1,130.1,128.4,85.1,82.8,81.8,80.6,64.1,62.6,56.3,51.7$, $50.7,48.9,45.7,44.6,36.0,34.9,32.7,31.9,31.5,30.9,30.2,28.3,27.2,26.7,25.9,25.3,23.4,22.7$, 20.4, 19.8, 19.4, 19.0, 18.8, 18.0, 16.3, 15.4, 14.5 ppm; HRMS (ESI-TOF): calcd for $\mathrm{C}_{47} \mathrm{H}_{72} \mathrm{~N}_{4} \mathrm{O}_{7} \mathrm{SSi}[\mathrm{M}$ $+\mathrm{H}]^{+}:$865.4963, found: 865.4966.

\section{Halipeptin A 1a, halipeptin A analogue 3a and halipeptin A analogue 4a (Scheme 6):}

To a cooled $\left(0^{\circ} \mathrm{C}\right)$ stirred solution of TBDPS-protected halipeptin A 55 (4 mg, $\left.0.0046 \mathrm{mmol}\right)$ in DMF $(1 \mathrm{~mL})$ was added TAS-F $(6.3 \mathrm{mg}, 0.023 \mathrm{mmol})$, and the solution was stirred for $16 \mathrm{~h}$ before it was

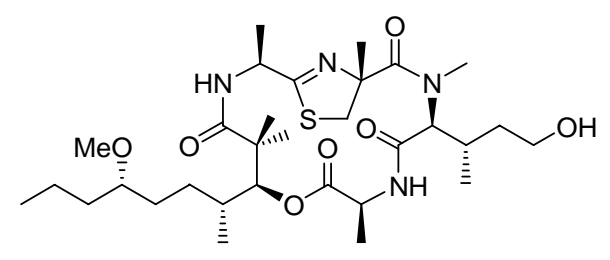

EtOAc) to afford halipeptin A 1a $(2.4 \mathrm{mg}, 85 \%)$ as a colorless oil. TBDPS-protected halipeptin A analogues 56 and 57 were deprotected following the same experimental procedure as for TBDPSprotected halipeptin A 55, to afford halipeptin A analogues: 3a (81\%) and 4a (85\%). 
Halipeptin A 1a: $R_{\mathrm{f}}=0.17$ (silica gel, EtOAc); $[\alpha]_{\mathrm{D}}^{32}=-15.2\left(c=0.25, \mathrm{CHCl}_{3}\right)$; IR (film) $v_{\max } 3402$, 2952, 2913, 2845, 1733, 1723, 1640, 1455, 1372, 1254, 1093, 1040, $795 \mathrm{~cm}^{-1} ;{ }^{1} \mathrm{H}$ NMR (400 MHz, $\left.\mathrm{C}_{6} \mathrm{D}_{6}\right) \delta=7.21(\mathrm{~d}, J=7.4 \mathrm{~Hz}, 1 \mathrm{H}), 6.92(\mathrm{~d}, J=8.2 \mathrm{~Hz}, 1 \mathrm{H}), 5.11(\mathrm{~d}, J=10.4 \mathrm{~Hz}, 1 \mathrm{H}), 4.86(\mathrm{~m}, 2 \mathrm{H})$, $4.76(\mathrm{~d}, J=2.7 \mathrm{~Hz}, 1 \mathrm{H}), 4.12(\mathrm{~d}, J=12.1 \mathrm{~Hz}, 1 \mathrm{H}), 3.41(\mathrm{~m}, 1 \mathrm{H}), 3.30(\mathrm{~m}, 1 \mathrm{H}), 3.19(\mathrm{~s}, 3 \mathrm{H}), 3.04(\mathrm{~m}$, $1 \mathrm{H}), 2.89(\mathrm{~s}, 3 \mathrm{H}), 2.89$ (d, $J=12.0 \mathrm{~Hz}, 1 \mathrm{H}), 2.68(\mathrm{~m}, 1 \mathrm{H}), 1.99$ (m, $1 \mathrm{H}), 1.26-1.60(\mathrm{~m}, 10 \mathrm{H}), 1.43$ $(\mathrm{d}, J=6.9 \mathrm{~Hz}, 3 \mathrm{H}), 1.20(\mathrm{~s}, 3 \mathrm{H}), 1.14(\mathrm{~s}, 3 \mathrm{H}), 0.98-1.10(\mathrm{~m}, 1 \mathrm{H}), 1.04(\mathrm{~d}, J=6.3 \mathrm{~Hz}, 3 \mathrm{H}), 1.01(\mathrm{~s}, 3$ H), $0.91(\mathrm{t}, J=7.1 \mathrm{~Hz}, 3 \mathrm{H}), 0.87(\mathrm{~d}, J=7.3 \mathrm{~Hz}, 3 \mathrm{H}), 0.84(\mathrm{~d}, J=6.9 \mathrm{~Hz}, 3 \mathrm{H}) \mathrm{ppm} ;{ }^{13} \mathrm{C}$ NMR $(100$ $\left.\mathrm{MHz}, \mathrm{C}_{6} \mathrm{D}_{6}\right) \delta=177.4,173.1,172.2,169.9,169.3,110.1,84.1,82.4,80.6,65.0,60.4,56.3,49.8,49.1$, $46.0,44.6,36.1,35.7,34.5,32.4,31.6,30.6,28.4,26.0,22.9,22.6,22.1,18.8,18.7,17.5,14.8,14.6$ ppm; HRMS (ESI-TOF) calcd for $\mathrm{C}_{31} \mathrm{H}_{54} \mathrm{~N}_{4} \mathrm{O}_{7} \mathrm{~S}[\mathrm{M}+\mathrm{H}]^{+}:$627.3786, found: 627.3790 .

Halipeptin A analogue 3a: colorless oil; $R_{\mathrm{f}}=0.18$ (silica gel, EtOAc); $[\alpha]_{\mathrm{D}}^{32}=-12.1\left(c=0.3, \mathrm{CHCl}_{3}\right)$; IR (neat) $v_{\max } 3430,2961,2917,2855,1733,1710,1662,1644,1507,1485,1374,1255,1095 \mathrm{~cm}^{-1} ;{ }^{1} \mathrm{H}$

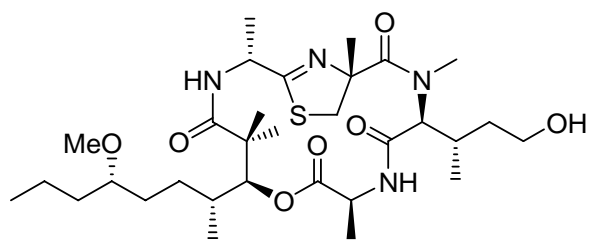
$\operatorname{NMR}\left(500 \mathrm{MHz}, \mathrm{CDCl}_{3}\right) \delta=6.79(\mathrm{~d}, J=5.5 \mathrm{~Hz}, 1 \mathrm{H}), 6.58(\mathrm{~d}, J=$ $8.5 \mathrm{~Hz}, 1 \mathrm{H}), 5.39$ (d, $J=10.0 \mathrm{~Hz}, 1 \mathrm{H}), 4.84-4.87$ (m, $1 \mathrm{H}), 4.75$ $4.78(\mathrm{~m}, 1 \mathrm{H}), 4.74(\mathrm{~d}, J=1.9 \mathrm{~Hz}, 1 \mathrm{H}), 4.03(\mathrm{~d}, J=12.0 \mathrm{~Hz}, 1 \mathrm{H})$, 3.79-3.82 (m, 1H), 3.67-3.72 (m, $1 \mathrm{H}), 3.33(\mathrm{~d}, J=12.0 \mathrm{~Hz}, 1 \mathrm{H})$, $3.27(\mathrm{~s}, 3 \mathrm{H}), 3.07-3.09(\mathrm{~m}, 1 \mathrm{H}), 2.78(\mathrm{~s}, 3 \mathrm{H}), 2.51-2.55(\mathrm{~m}, 1 \mathrm{H}), 2.08-2.17(\mathrm{~m}, 1 \mathrm{H}), 1.43(\mathrm{~d}, J=6.4$ Hz, $3 \mathrm{H}), 1.41(\mathrm{~s}, 3 \mathrm{H}), 1.31$ (d, J= 7.1 Hz, $3 \mathrm{H}), 1.22$ (s, $3 \mathrm{H}), 1.14-1.52(\mathrm{~m}, 10 \mathrm{H}), 1.09$ (s, $3 \mathrm{H}), 1.02-$ $1.08(\mathrm{~m}, 1 \mathrm{H}), 0.96-1.02(\mathrm{~m}, 6 \mathrm{H}), 0.68 \mathrm{ppm}(\mathrm{d}, J=6.5 \mathrm{~Hz}, 3 \mathrm{H}) ;{ }^{13} \mathrm{C} \mathrm{NMR}\left(125 \mathrm{MHz}, \mathrm{CDCl}_{3}\right) \delta=$ $176.9,173.6,172.8,170.3,169.2,84.7,82.2,80.5,64.4,60.9,56.4,49.2,49.1,45.1,43.3,35.7,32.9$, 32.3, 31.1, 30.7, 29.7, 28.3, 24.3, 23.2, 22.9, 21.5, 19.5, 18.4, 18.2, 14.3, 14.2 ppm; HRMS (ESI-TOF) calcd for $\mathrm{C}_{31} \mathrm{H}_{54} \mathrm{~N}_{4} \mathrm{O}_{7} \mathrm{~S}\left[\mathrm{M}+\mathrm{H}^{+}\right]$: 627.3786, found: 627.3790 .

Halipeptin A analogue 4a: colorless oil; $R_{\mathrm{f}}=0.35$ (silica gel, EtOAc); $[\alpha]_{\mathrm{D}}^{32}=+7.2\left(c=0.3, \mathrm{CHCl}_{3}\right)$; IR (neat) $v_{\max } 3415,2958,2919,2862,1735,1663,1644,1511,1453,1372,1253,1091,728 \mathrm{~cm}^{-1} ;{ }^{1} \mathrm{H}$

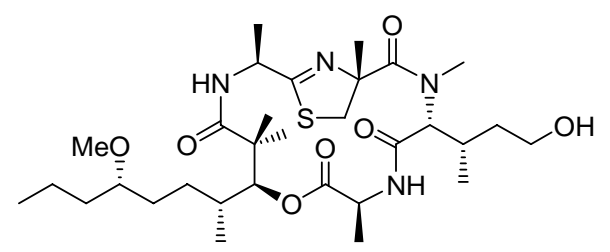

NMR (600 MHz, $\mathrm{CDCl}_{3}$, ca 3:1 ratio of rotamers, only signals for the major isomer are noted) $\delta=7.56(\mathrm{~d}, J=5.0 \mathrm{~Hz}, 1 \mathrm{H}), 6.16(\mathrm{~m}$, $1 \mathrm{H}), 4.91$ (br s, $1 \mathrm{H}), 4.64(\mathrm{td}, J=7.1,13.9 \mathrm{~Hz}, 1 \mathrm{H}), 4.57$ (d, $J=$ $10.9 \mathrm{~Hz}, 1 \mathrm{H}), 4.56$ (br s, $1 \mathrm{H}), 3.59$ (m, $3 \mathrm{H}), 3.41$ (q, $J=11.7$ 
$\mathrm{Hz}, 1 \mathrm{H}), 3.20(\mathrm{~s}, 3 \mathrm{H}), 2.97(\mathrm{~m}, 2 \mathrm{H}), 2.86(\mathrm{~s}, 3 \mathrm{H}), 0.80-2.20(\mathrm{~m}, 35 \mathrm{H}) \mathrm{ppm} ;{ }^{13} \mathrm{C} \mathrm{NMR}(150 \mathrm{MHz}$, $\mathrm{CDCl}_{3}$, ca $3: 1$ ratio of rotamers, only signals for the major isomer are noted) $\delta=174.6,172.6,170.7$, $170.1,169.8,85.4,83.1,81.5,63.5,61.9,56.7,51.3,48.8,45.5,44.4,37.9,36.3,34.6,33.3,31.4,29.3$, 27.4, 25.7, 23.5, 22.4, 20.2, 18.8, 16.6, 16.0, 14.8, 14.1 ppm; HRMS (ESI-TOF): calcd for $\mathrm{C}_{31} \mathrm{H}_{54} \mathrm{~N}_{4} \mathrm{O}_{7} \mathrm{~S}$ $[\mathrm{M}+\mathrm{H}]^{+}: 627.3786$, found: 627.3792 .

\section{Oxazoline 58 (Scheme 7):}

Azido dipeptide 11d was coupled with Cbz-D-Ala to give the corresponding tripeptide following the same procedure as that described for azido ester 44d. The product was purified by flash column

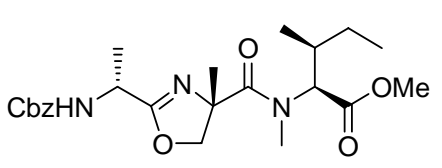
chromatography (silica gel, hexane/EtOAc 3:1) to yield the desired tripeptide (1.24 $\mathrm{g}, 69 \%$ ) as a colorless oil; $R_{\mathrm{f}}=0.40$ (silica gel, hexanes:EtOAc 2:1); $[\alpha]_{\mathrm{D}}{ }^{32}=-40.9\left(c=1.82, \mathrm{CHCl}_{3}\right)$; IR (film) $v_{\max } 3354$, 2966, 2884, 2108, 1731, 1713, 1643, 1531, 1455, 1396, 1331, 1255, 1202, 1173, 1073, 1002, 750, 697 $\mathrm{cm}^{-1} ;{ }^{1} \mathrm{H} \mathrm{NMR}\left(400 \mathrm{MHz}, \mathrm{CDCl}_{3}\right.$, ca 4:1 ratio of rotamers, only signals for the major isomer are noted) $\delta=7.26-7.36(\mathrm{~m}, 5 \mathrm{H}), 5.30(\mathrm{bd}, J=7.4 \mathrm{~Hz}, 1 \mathrm{H}), 5.05-5.12(\mathrm{~m}, 2 \mathrm{H}), 4.75(\mathrm{bd}, J=10.6 \mathrm{~Hz}, 2 \mathrm{H})$, 4.33-4.43 (m, 1 H), 4.25 (bd, $J=11.2 \mathrm{~Hz}, 1 \mathrm{H}), 3.69$ (bs, $3 \mathrm{H}), 3.26$ (bs, $3 \mathrm{H}), 2.02-2.04$ (bm, $1 \mathrm{H})$, $1.38-1.45(\mathrm{~m}, 7 \mathrm{H}), 1.02-1.11(\mathrm{~m}, 1 \mathrm{H}), 0.95(\mathrm{~d}, J=6.4 \mathrm{~Hz}, 3 \mathrm{H}), 0.86(\mathrm{bt}, J=6.5 \mathrm{~Hz}, 3 \mathrm{H}) \mathrm{ppm} ;{ }^{13} \mathrm{C}$ NMR (150 MHz, $\mathrm{CDCl}_{3}$, ca 4:1 ratio of rotamers, only signals for the major isomer are noted) $\delta=$ $172.2,171.6,169.7,155.5,136.2,128.5,128.1,128.1,69.9,66.9,65.9,62.1,51.9,49.5,32.7,32.0$, 25.2, 19.5, 18.5, 15.8, 10.4 ppm; HRMS (ESI-TOF): calcd for $\mathrm{C}_{23} \mathrm{H}_{33} \mathrm{~N}_{5} \mathrm{O}_{7}[\mathrm{M}+\mathrm{H}]^{+}:$492.2453, found: 492.2457 .

Oxazoline 58 was prepared from the above tripeptide by the same procedure used to prepare oxazoline 47d. The product was purified by flash column chromatography (silica gel, hexane/EtOAc 3:1) to yield the desired oxazoline $58\left(1.34 \mathrm{~g}, 80 \%\right.$ ) as a pale yellow oil; 58: $R_{\mathrm{f}}=0.30$ (silica gel, hexanes:EtOAc $2: 1) ;[\alpha]_{\mathrm{D}}^{32}=-37.9\left(c=3.19, \mathrm{CHCl}_{3}\right)$; IR (film) $v_{\max } 3331,2966,2931,1731,1631,1534,1455,1308$, 1237, 1061, 985, 738, $697 \mathrm{~cm}^{-1} ;{ }^{1} \mathrm{H} \mathrm{NMR}\left(500 \mathrm{MHz}, \mathrm{CDCl}_{3}\right.$, ca 4:1 ratio of rotamers, only signals for the major isomer are noted) $\delta=7.28-7.33(\mathrm{~m}, 5 \mathrm{H}), 5.33(\mathrm{~d}, J=5.9 \mathrm{~Hz}, 1 \mathrm{H}), 5.04-5.14(\mathrm{~m}, 3 \mathrm{H}), 4.81-$ $4.84(\mathrm{~m}, 1 \mathrm{H}), 4.29-4.46(\mathrm{~m}, 1 \mathrm{H}), 3.98(\mathrm{~d}, J=8.8 \mathrm{~Hz}, 1 \mathrm{H}), 3.67$ (s, $3 \mathrm{H}), 3.29$ (s, 3 H), 1.90-2.01 (m, 1 
H), $1.45(\mathrm{~s}, 3 \mathrm{H}), 1.33-1.41(\mathrm{~m}, 3 \mathrm{H}), 1.26-1.32(\mathrm{~m}, 1 \mathrm{H}), 1.01-1.07$ (m, $1 \mathrm{H}), 0.92-0.97$ (m, $3 \mathrm{H}), 0.82$ $(\mathrm{t}, J=7.4 \mathrm{~Hz}, 3 \mathrm{H}) \mathrm{ppm} ;{ }^{13} \mathrm{C} \mathrm{NMR}\left(150 \mathrm{MHz}, \mathrm{CDCl}_{3}\right.$, ca 4:1 ratio of rotamers, only signals for the major isomer are noted) $\delta=174.1,172.1,167.6,155.3,136.3,128.5,128.1,79.0,75.4,66.8,64.5,61.7$, 51.8, 45.5, 35.6, 32.7, 30.9, 27.6, 26.4, 25.3, 19.6, 15.9, 12.0 ppm; HRMS (ESI-TOF): calcd for $\mathrm{C}_{23} \mathrm{H}_{33} \mathrm{~N}_{3} \mathrm{O}_{6}[\mathrm{M}+\mathrm{Na}]^{+}: 470.2261$, found: 470.2266 .

\section{Azido methyl ester 60 (Scheme 7):}

Oxazoline 58 was converted to thioamide 59 by the same procedure as that used to convert oxazoline 47d to thioamide 9d. Thioamide 59 was then reacted with azido ester carboxylic acid 12 (110.0 mg,

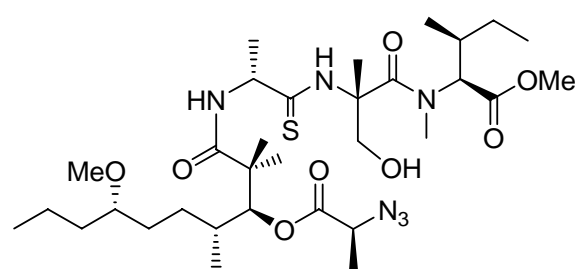
$0.308 \mathrm{mmol})$, PyAOP (321.0 mg, $0.616 \mathrm{mmol})$ and $i \mathrm{Pr}_{2} \mathrm{NEt}(0.107$ $\mathrm{mL}, 0.614 \mathrm{mmol})$ in $\mathrm{DMF}(15 \mathrm{~mL})$, following the same procedure used to prepare azido methyl ester $\mathbf{8 d}$, to give azido methyl ester $\mathbf{6 0}$ (134.2 $\mathrm{mg}, 63 \%$ based on azido ester carboxylic acid 12) as yellow oil. 60: $R_{\mathrm{f}}=0.14$ (silica gel, hexanes:EtOAc $\left.1: 2\right) ;[\alpha]_{\mathrm{D}}{ }^{32}=+8.6\left(c=2.07, \mathrm{CHCl}_{3}\right)$; IR (film) $v_{\max } 3246$, 2965, 2995, 2874, 2100, 1739, 1638, 1502, 1457, 1372, 1261, 1201, 1095, 1040, 940, $583 \mathrm{~cm}^{-1} ;{ }^{1} \mathrm{H}$ NMR (500 MHz, $\mathrm{CDCl}_{3}$, ca 3:1 ratio of rotamers, only signals for the major isomer are noted) $\delta=8.94$ (s, $1 \mathrm{H}), 6.98$ (bs, $1 \mathrm{H}), 5.13(\mathrm{~d}, J=3.3 \mathrm{~Hz}, 1 \mathrm{H}), 4.92(\mathrm{bd}, J=7.0 \mathrm{~Hz}, 1 \mathrm{H}), 4.68-4.73(\mathrm{~m}, 1 \mathrm{H}), 4.18$ (bm, $1 \mathrm{H}), 4.04-4.09$ (m, $1 \mathrm{H}), 4.00$ (dd, J=7.1, 14.1 Hz, 1 H), 3.67 (s, 3 H), 3.67 (bm, $1 \mathrm{H}), 3.26$ (s, 3 H), 3.05-3.10 (m, $1 \mathrm{H}), 3.01$ (bs, $3 \mathrm{H}), 1.91-1.96$ (m, $1 \mathrm{H}), 1.75-1.81$ (m, $1 \mathrm{H}), 1.66$ (s, $3 \mathrm{H}), 1.51$ (d, J $=7.0 \mathrm{~Hz}, 3 \mathrm{H}), 1.40(\mathrm{~d}, J=6.6 \mathrm{~Hz}, 3 \mathrm{H}), 1.19(\mathrm{bs}, 6 \mathrm{H}), 1.17-1.66(\mathrm{~m}, 9 \mathrm{H}), 1.03-1.11(\mathrm{~m}, 1 \mathrm{H}), 0.93$ $(\mathrm{d}, J=6.6 \mathrm{~Hz}, 3 \mathrm{H}), 0.84-0.88(\mathrm{~m}, 9 \mathrm{H}) \mathrm{ppm} ;{ }^{13} \mathrm{C} \mathrm{NMR}\left(150 \mathrm{MHz}, \mathrm{CDCl}_{3}, c a 3: 1\right.$ ratio of rotamers, only signals for the major isomer are noted) $\delta=203.3,175.8,171.9,170.3,81.5,80.4,63.8,57.8,56.3$, $55.2,51.7,46.5,46.4,35.5,34.1,33.2,31.3,31.2,30.8,30.3,25.9,22.7,22.4,21.5,20.2,18.4,15.9$, 15.1, 15.0, 14.2 ppm; HRMS (ESI-TOF): calcd for $\mathrm{C}_{32} \mathrm{H}_{58} \mathrm{~N}_{6} \mathrm{O}_{8} \mathrm{~S}[\mathrm{M}+\mathrm{H}]^{+}$: 687.4109, found: 687.4113 .

\section{Thiazoline azido ester 61 (Scheme 7):}

Azido methyl ester $\mathbf{6 0}$ was converted to thiazoline azido ester $\mathbf{6 1}$ by the same procedure as that used to convert azido methyl ester 8d to thiazoline azido ester 53d. The product was purified by flash column 
chromatography (silica gel, hexane/EtOAc 3:1) to yield the desired thiazoline azido ester 61 (53.4 mg, $72 \%$ ) as a yellow oil. 61: $R_{\mathrm{f}}=0.63$ (silica gel, hexane/EtOAc 1:1); $[\alpha]_{\mathrm{D}}{ }^{32}=-11.5\left(c=2.31, \mathrm{CHCl}_{3}\right)$; IR

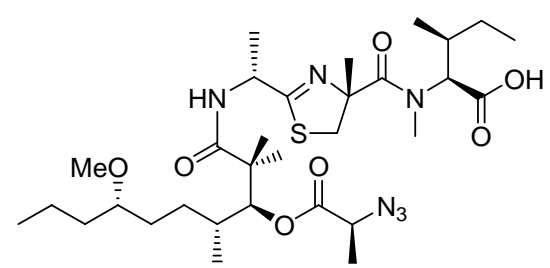

(film) $v_{\max } 3377,2965,2935,2874,2100,1739,1633,1507,1457$, 1377, 1261, 1196, 1090, 1005, $940 \mathrm{~cm}^{-1} ;{ }^{1} \mathrm{H}$ NMR (600 MHz, $\mathrm{CDCl}_{3}$, ca 3:1 ratio of rotamers, only signals for the major isomer are noted) $\delta=6.67(\mathrm{~d}, J=6.6 \mathrm{~Hz}, 1 \mathrm{H}), 5.14(\mathrm{~d}, J=1.7 \mathrm{~Hz}, 1 \mathrm{H}), 4.84$ (d, $J=10.9 \mathrm{~Hz}, 1 \mathrm{H}), 4.74-4.79(\mathrm{~m}, 1 \mathrm{H}), 4.09$ (d, $J=11.4 \mathrm{~Hz}, 1 \mathrm{H}), 3.94-3.97(\mathrm{~m}, 1 \mathrm{H}), 3.68$ (s, $3 \mathrm{H})$, $3.26(\mathrm{~s}, 3 \mathrm{H}), 3.25$ (s, $3 \mathrm{H}), 3.17$ (d, J=11.4 Hz, 1 H), 3.04-3.06 (m, $1 \mathrm{H}), 1.99-2.01$ (m, $1 \mathrm{H}), 1.76-$ $1.79(\mathrm{~m}, 1 \mathrm{H}), 1.47-1.50(\mathrm{~m}, 6 \mathrm{H}), 1.37(\mathrm{~d}, J=6.6 \mathrm{~Hz}, 3 \mathrm{H}), 1.28-1.44(\mathrm{~m}, 9 \mathrm{H}), 1.18(\mathrm{~s}, 3 \mathrm{H}), 1.17(\mathrm{~s}, 3$ $\mathrm{H}), 0.92-0.99$ (m, $4 \mathrm{H}), 0.85-0.88(\mathrm{~m}, 6 \mathrm{H}), 0.82$ (t, J=7.5 Hz, $3 \mathrm{H}) \mathrm{ppm} ;{ }^{13} \mathrm{C} \mathrm{NMR}\left(150 \mathrm{MHz}, \mathrm{CDCl}_{3}\right.$ ca 3:1 ratio of rotamers, only signals for the major isomer are noted) $\delta=174.2,172.8,172.8,171.7$, $170.3,85.2,81.6,80.6,62.0,57.8,56.4,51.8,48.5,46.6,43.7,35.6,34.3,32.9,32.8,31.7,31.3,24.9$, 23.3, 23.1, 21.8, 20.1, 18.4, 17.0, 15.9, 15.2, 14.2, 10.7 ppm; HRMS (ESI-TOF): calcd for $\mathrm{C}_{32} \mathrm{H}_{56} \mathrm{~N}_{6} \mathrm{O}_{7} \mathrm{~S}$ $[\mathrm{M}+\mathrm{H}]^{+}:$669.4004, found: 669.4010 .

\section{Halipeptin D analogue 3d (Scheme 7):}

Thiazoline azido ester $\mathbf{6 1}$ was reacted using the same described procedure that was used for thiazoline 53d to finally afford halipeptin D analogue 3d $(23.4 \mathrm{mg}, 59 \%$ from 62$)$ as a colorless oil. The physical

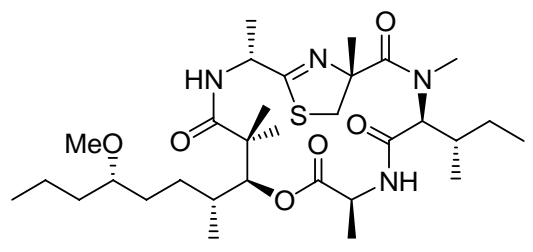
properties of the obtained compound were identical to those reported above for 3d.

\section{Materials and methods for anti-inflammatory studies}

Induction of edema in the mouse paw. Male Swiss mice weighing 28-30 g were divided in groups ( $n$ =7) and lightly anaesthetized with enflurane. Each group of animals received subplantar injection administration of $50 \mu \mathrm{l}$ of carrageenan $1 \% \mathrm{w} \mathrm{v}^{-1} \cdot{ }^{1,2}$ Paw volume was measured using a 
hydroplethismometer specially modified for small volume immediately before the subplantar injection and 2, 4, 6, 24, 48, 72 and $96 \mathrm{~h}$ thereafter. ${ }^{1}$ The increase in paw volume was evaluated as difference between the paw volume at each time-point and basal paw volume.

Drug treatment protocols. All compounds were administered i.p. with a dosage of $1 \mathrm{mg} \mathrm{kg}^{-1}$ at time 0 . The control group was treated with vehicle (PEG) at the same time-point. The volume injected was always $100 \mu 1$.

Drugs. Polyethylene glycol 400 (PEG) and carrageenan were purchased from Sigma Chemical Co. (Milan, Italy).

(1) Bucci, M.; Roviezzo, F.; Cicala, C.; Sessa, W. C.; Cirino, G. Br. J. Pharmacol. 2000, 131, 1316.

(2) Posadas, I.; Bucci, M.; Roviezzo, F.; Rossi, A.; Parente, L.; Sautebin, L.; Cirino, G. Br. J. Pharmacol. 2004, 142, 331-338.

Reference (4)(b) full citation from main text.

(4) (b) Data obtained by D. J. Faulkner and which appeared in a summary review, see: Fenical, W.; Jensen, P. R.; Kauffman, C.; Mayhead, S. L.; Faulkner, J. D.; Sincich, C.; Rao Manam, R.; Kantoroski, E. J.; West, L. M.; Strangman, W. K.; Shimizu, Y.; Li, B.; Thammana, S.; Drainville, K.; Davies-Coleman, M. T.; Kramer, R. A.; Fairchild, C. R.; Rose, W. C.; Wild, R. C.; Vite, G. D.; Peterson, R. W. Pharm. Biol. 2003, 41, 6-14. 